$$
\begin{gathered}
\text { José Vicente } \\
\text { García Santamaría } \\
\text { (Editor) }
\end{gathered}
$$

\title{
Transparencia informativa y buen gobierno corporativo
}

Cuadernos Artesanos de Latina / 131

Universitat d'Alacant Universidad de Alicante

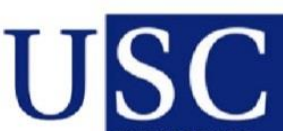

UNIVERSIDADE

DE SANTIAGO

DE COMPOSTELA

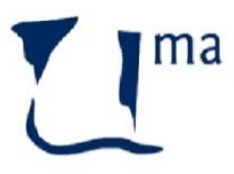

UNIVERSIDAD DE MALAGA

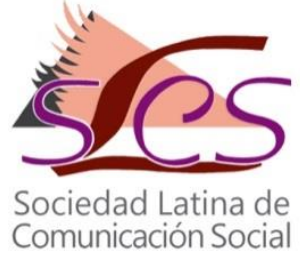




\section{Cuadernos Artesanos de Comunicación}

Coordinador editorial: José Manuel de Pablos - jpablos@ull.edu.es

\section{Comité Científico}

Presidencia: José Luis Piñuel Raigada (UCM)

Secretaría: Alberto Ardèvol (ULL)

- José Antonio Meyer (Benemérita Universidad Autónoma de Puebla, BUAP)

- Ramón Reig (Universidad de Sevilla, US)

- Miquel Rodrigo Alsina (Universidad Pompeu Fabra, UPF)

- Victoria Tur (Universidad de Alicante, UA)

- Miguel Vicente (Universidad de Valladolid, UVA)

- Ramón Zallo (Universidad del País Vasco, UPV-EHU)

- Núria Almiron (Universidad Pompeu Fabra, Barcelona, UPF)

- José Cisneros (Benemérita Universidad Autónoma de Puebla, BUAP)

- Bernardo Díaz Nosty (Universidad de Málaga, UMA)

- Carlos Elías (Universidad Nacional de Educación a Distancia, UNED)

- Paulina B. Emanuelli (Universidad Nacional de Córdoba, UNC)

- Marisa Humanes (Universidad Rey Juan Carlos, URJC)

- Juan José Igartua (Universidad de Salamanca, USAL)

- Maricela López-Ornelas (Universidad Autónoma de Baja California, AUBC)

- Javier Marzal (Universidad Jaume I, UJI)

* Queda expresamente autorizada la reproducción total o parcial de los textos publicados en este libro, en cualquier formato o soporte imaginables, salvo por explícita voluntad en contra del autor o autora o en caso de ediciones con ánimo de lucro. Las publicaciones donde se incluyan textos de esta publicación serán ediciones no comerciales y han de estar igualmente acogidas a Creative Commons. Harán constar esta licencia y el carácter no venal de la publicación.

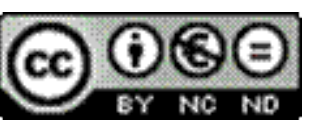

Este libro y cada uno de los capítulos que contiene (en su caso), así como las imágenes incluidas, si no se indica lo contrario, se encuentran bajo una Licencia Creative Commons Atribución-No Comercial-Sin Derivadas 3.0 Unported. Puede ver una copia de esta licencia en http://creativecommons.org/licenses/by-nc-nd/3.0/ Esto significa que Ud. es libre de reproducir y distribuir esta obra, siempre que cite la autoría, que no se use con fines comerciales o lucrativos y que no haga ninguna obra derivada. Si quiere hacer alguna de las cosas que aparecen como no permitidas, contacte con los coordinadores del libro o con el autor del capítulo correspondiente.

* La responsabilidad de cada texto es de su autor o autora. 


$$
\text { José Vicente García Santamaría (Editor) }
$$

\section{Transparencia informativa y buen gobierno corporativo}

Cuadernos Artesanos de Latina / 131

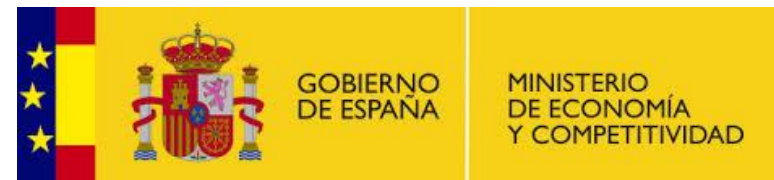

Este libro forma parte del proyecto de investigación CSO2014-52283-C2-1-P financiado por el Ministerio de Economía y Competitividad del Gobierno de España.

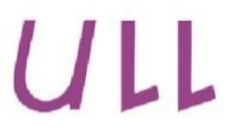

Universidad de La Laguna

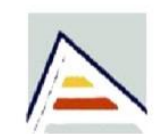

Universitat d'Alacant Universidad de Alicante

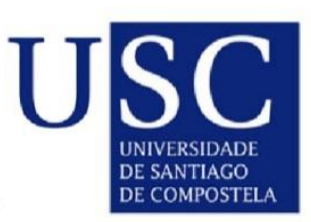

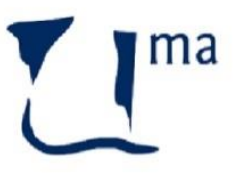

UNIVERSIDAD DE MÁAGA

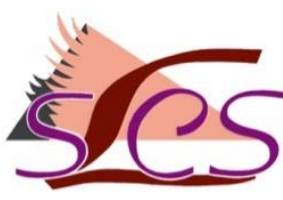

Sociedad Latina de Comunicación Social 
CAC 131 - Transparencia informativa y buen gobierno corporativo

José Vicente García Santamaría (Editor)

| Precio social: 7,10€| Precio en librería. 9,25€ |

Editores: Javier Herrero y Milena Trenta

Diseño: F. Drago

Imprime y distribuye: F. Drago. Andocopias S. L.

c/ La Hornera, 41. La Laguna. Tenerife.

Teléfono: 922250554 | fotocopiasdrago@,telefonica.net

Edita: Sociedad Latina de Comunicación Social - edición no venal - La Laguna (Tenerife), 2017 - Creative Commons

http://www.revistalatinacs.org/12SLCS/portada2014.html

Descargar en pdf:

http://www.cuadernosartesanos.org/\#131

Protocolo de envío de manuscritos:

http://www.cuadernosartesanos.org/protocolo.html

ISBN - 978-84-16458-89-9

DL: TF-1.182-2017

DOI: $10.4185 /$ ac131 


\title{
Transparencia informativa y buen gobierno corporativo
}

\begin{abstract}
Este nuevo Cuaderno de Latina, conformado por seis investigaciones desarrolladas por 14 profesores de diferentes universidades españolas, aborda la situación de la transparencia informativa y del Buen Gobierno Corporativo en las administraciones públicas, pero también en otras instituciones como los museos, las plataformas digitales que proporcionan soporte a la comunicación política, las empresas de comunicación o la diplomacia.

En total, son seis interesantes casos de estudio que, a buen seguro, contribuirán a la adquisición de una mayor cultura de la transparencia en España.
\end{abstract}

\section{Keywords}

Transparencia informativa, Buen Gobierno Corporativo, Portales de Transparencia, Cultura de la Transparencia.

José Vicente García Santamaría: Assistant Professor at University Carlos III (Madrid) and co-director of the Master of Corporate Communication and director of Research of the Institute for Journalistic Innovation (2IP).

He has worked as a marketing and communication consultant and worked for BBVA.

Visiting professor at the French Press Institute (Paris) and LUMSA (Rome) and research professor at the University of Sheffield (United Kingdom) and Perugia (Italy).

His most recent books are: "Multimedia groups in Spain" (2016), "The cinematographic exhibition in Spain" (2015) and "The business of the digital press" (2014).

\section{Forma de citar este libro}

José Vicente García Santamaría (Editor). (2017). Transparencia informativa y buen gobierno corporativo. Cuadernos Artesanos de Comunicación, cac131. La Laguna (Tenerife): Latina.

DOI: $10.4185 / \mathrm{cac} 131$ 


\section{Índice}

1 Buscando transparencia... Estrategias en el proceso de decisión de los grupos de medios presentes en la Bolsa española

M Rodríguez Pallares, MJ Pérez Serrano ............................................ 7

2 Metodologías de evaluación de la transparencia: procedimientos y problemas

P Molina Rodríguez-Navas, N Simelio Solà, M Corcoy Rius ....... 31

3 Transparencia y diplomacia: nuevas demandas sociales y rutinas profesionales

JL Manfredi Sánchez, JM Herranz de la Casa, LM Calvo Rubio . 51

4 La adaptación de los museos a la transparencia informativa a través de sus webs

D Cordón Benito, L Maestro Espínola

5 La transparencia municipal en España: análisis de los factores que más influyen en el grado de transparencia JV García Santamaría, J Martín Matallana

6 Transparencia y monitorización en el entorno digital. Hacia una tipología de las plataformas impulsadas por la ciudadanía

L Alonso-Muñoz, A Casero-Ripollés. 
Cómo citar: Rodríguez Pallares, M y Pérez Serrano MJ (2017): "Buscando transparencia... Estrategias en el proceso de decisión de los grupos de medios presentes en la Bolsa española”. Revista Latina de Comunicación Social, 72, pp. 719 a 736. http://www.revistalatinacs.org/072paper/1188/38es.html DOI: $10.4185 /$ RLCS-2017-1188

\title{
Buscando transparencia... Estrategias en el proceso de decisión de los grupos de medios presentes en la Bolsa española
}

Miriam Rodríguez Pallares, Universidad Internacional de la Rioja (UNIR) / MediaCom UCM - (UCM) miriam.rodriguez@,unir.net

María José Pérez Serrano, Universidad Complutense de Madrid (UCM) / MediaCom UCM - mariajoseperezserrano@pdi.ucm.es

\begin{abstract}
Introducción. La gestión estratégica exige tomar decisiones cuyo riesgo implícito se reduce con el acceso a la información y al conocimiento y contribuye a que, de cara al exterior, la empresa sea transparente. A partir de este razonamiento, el objetivo es analizar los canales de comunicación online dirigidos a accionistas e inversores transparencia externa- en las empresas de comunicación cotizadas españolas y reflexionar, después, sobre la existencia de modelos de gestión de contenidos y la vinculación entre transparencia, decisión y gestión estratégica. Metodología. Estudio de casos, análisis de contenido y observación no participante. Resultados y conclusiones. Las empresas analizadas son transparentes en términos económicofinancieros con sus stakeholders externos, lo que evidencia la buena
\end{abstract}


gestión de contenidos gerenciales y el asentamiento de condiciones favorables para la gestión estratégica. Asimismo, se constata que las empresas de comunicación estudiadas no tienen rasgos que se diferencien de otras sociedades cotizadas.

\section{Keywords}

Empresa de comunicación; transparencia; teoría de la decisión; gestión de la información; gestión de conocimiento.

\section{Contents}

1. Introducción. 2. Estado de la cuestión: la teoría de la decisión en la empresa de medios. 3. Material y método. 4. Análisis y resultados. 5. Discusión y conclusiones. 6. Referencias bibliográficas.

\section{Introducción}

T A ADAPTACIÓN a un nuevo paradigma socioeconómico, 1 donde los movimientos regulatorios y la concentración han marcado puntos de inflexión, ha supuesto que las empresas de medios de comunicación hayan pasado de operar en entornos locales a multiplicar su alcance y, por ende, su nivel de competitividad en el mercado. De este modo, los mass media se han visto obligados a buscar "mejoras sectoriales e individuales a través de la investigación para prever nuevas vías de negocio o mejores rendimientos a años vista" (Rodríguez-Pallares, 2012: 474) y encontrar, así, acomodo en el mercado. Esto es, se trata de aplicar estrategias o acciones ofensivas o defensivas por parte de la empresa con el objetivo de alcanzar una ventaja competitiva a largo plazo y posicionarse de un modo confortable en el mercado (Porter, 1999).

Este planteamiento contextualiza el objeto de estudio de esta investigación, que se centra en tres elementos estrechamente imbricados: la teoría de la toma de decisión (E1); la gestión de la información y del conocimiento (E2), y la transparencia organizativa (E3), nexo entre los dos primeros.

La aplicación de estrategias a largo plazo exige tomar decisiones (E1), y por decisión se entiende el proceso que implica un riesgo, que se 
reduce con el acceso a información, y es modificado por la variable de la personalidad del ejecutor (Pérez-Serrano, 2010), tradicionalmente identificado con un líder que, en términos pragmáticos, se relaciona con la persona en cuya responsabilidad recae la elección de una alternativa concreta de entre varias posibles para solventar un problema existente.

\section{Figura 1: Fórmula de la toma de decisiones}

Decisión = riesgo + (información + conocimiento $)+$ personalidad

Fuente: Elaboración propia

Si el acceso a la información, combinado con el conocimiento, se contempla como variable reductora de las probabilidades de error en la toma de decisiones, resulta, entonces, imprescindible la gestión sistematizada de estos elementos -información y conocimiento- a fin de custodiar, controlar y facilitar su recuperación para su posterior utilización estratégica (E2). Se trata, pues, de garantizar procesos de decisión fundamentados, sustentados en información, conocimiento y relaciones que van más allá de los recursos tradicionales y que pueden traducirse en una fuente de ventaja competitiva si se integran en la planificación y otras actividades de la empresa (Strandberg, 2010). Bajo este prisma, el valor de la información y el conocimiento se multiplica como variable condicionante del éxito en el contexto de la "cultura de lo intangible" (Carrillo y Nuño, 2010: 123), en tanto en cuanto, los stakeholders internos responsables de la toma de decisiones dependen de ellos.

Además, la proyección de la información y del conocimiento organizacional hacia los stakeholders externos e implicados directos en los procesos de gestión de las empresas, redunda también en la toma de decisiones, de tal forma que la transparencia (E3) de estos contenidos es resultado o espejo de la buena gestión de la información y el conocimiento y vehículo para una correcta toma de decisiones. Así, parece justificada la existencia de una relación bidireccional entre transparencia y estrategia, dado que la definición de esta última es el resultado de un conjunto de decisiones. 
Figura 2: Relación gráfica entre la gestión de la información y del conocimiento (E2), la teoría de la decisión (E1) y la transparencia (E3)

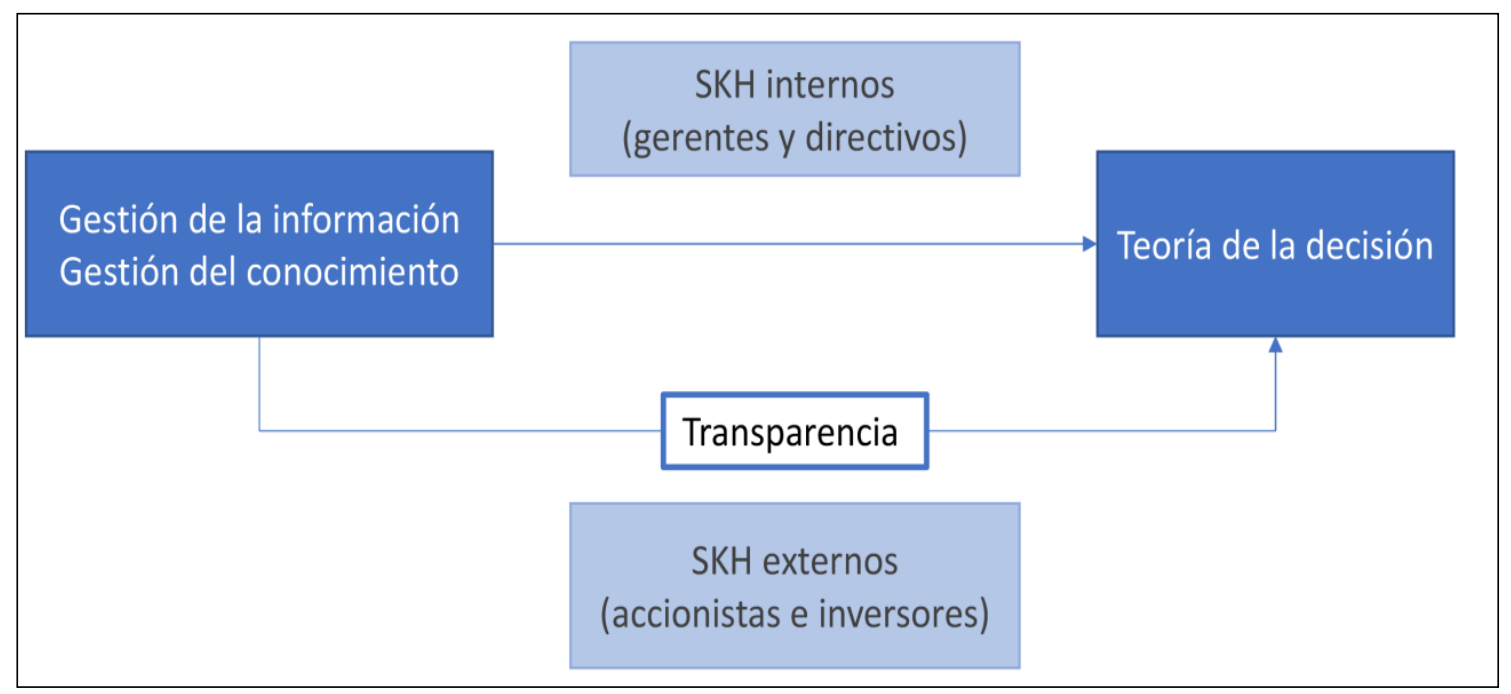

Fuente: Elaboración propia

\section{Estado de la cuestión: la teoría de la decisión en la empresa de medios}

El estudio de las empresas de comunicación ha dado lugar a la común aceptación de proposiciones que les otorgan cualidades distintivas y condicionantes en su forma de gestión desde una perspectiva intraempresarial, estructural y sistémica.

Una de estas particularidades es su propia producción, intangible en esencia y susceptible de ser explicitada y gestionada. En este sentido, el valor de los contenidos mediáticos o mediatizables se ha reforzado como fuente y prueba de su actividad, desde un enfoque funcional, y como resultado de su gestión como unidades de producción, desde un enfoque estratégico (Rodríguez-Pallares, 2016). De esta forma, se conjugan los dos fines tradicionalmente vinculados a este sector: el general, obtener beneficios económicos, y el particular, informar, formar y entretener con calidad (Nieto e Iglesias, 2000). Se entiende, en este contexto, por contenidos el concepto que engloba datos, información estructurada y no estructurada y conocimiento explicitado.

La gestión de estos contenidos tiene como objetivo primario el tratamiento y conservación de los fondos en el contexto digital 
organizativo; y, como objetivo secundario, su rentabilidad por reexplotación. En su proceso, confluyen "componentes tecnológicos, estrategia empresarial y prácticas profesionales" (Fernández, Rodríguez y Rodríguez, 2013: 393) con el fin de facilitar el uso y reutilización de contenidos en la ejecución de procesos de trabajo y la prestación de servicios a usuarios (Eíto, 2013).

Si bien el acceso a la información es condición para reducir el riesgo en la toma de decisiones, gestionar el conocimiento de una organización complementa su acción ${ }^{1}$, ya que el saber colectivo de una organización guarda estrecha relación con las diversas áreas funcionales de la misma (Nonaka y Takeuchi, 1999).

En este sentido, se entiende por conocimiento una "mezcla fluida de experiencia estructurada, valores, información contextual e internalización experta que proporciona un marco para la evaluación e incorporación de nuevas experiencias e información" (Davenport y Prusak, 2001: 6). Su gestión es un proceso estratégico integral y sistemático que vela por custodiar en el entorno empresarial el knowhow y el know-who de su actividad (Bueno, 1999; Nonaka y Takeuchi, 1999; Lai y Chu, 2002; Eíto-Brun, 2013, Davenport y Prusak, 2001; Núñez-Paula, 2004, Spender y Grant, 1996), o lo que es lo mismo, parte de su capital intelectual -compuesto por el capital humano, el capital estructural y el capital relacional-, un activo intangible que le confiere distinción y excelencia. Se trata, en definitiva, de gestionar lo que la empresa sabe, así como potenciar el aprendizaje colaborativo organizacional como recurso para alcanzar una ventaja competitiva y aplicar estrategias basadas en la experiencia, lo que redunda, de nuevo, en la reducción del riesgo en la toma de decisiones.

\footnotetext{
${ }^{1}$ Aunque es cierto que existe una lucha argumental en relación a quién depende de quién en lo que respecta a la gestión de contenidos y la gestión del conocimiento (Rodríguez-Pallares, 2016), desde el punto de vista de este proyecto, ambas disciplinas se entienden como complementarias (Nonaka y Takeuchi, 1999; Al-Hawamdeh, 2002; Newman, 1997; Pearson, 1999; Davenport y Prusak, 2001). La gestión de contenidos aborda el tratamiento de datos, información y conocimiento explícito o codificado y, a partir de ahí, pero sin obviarlo, la gestión del conocimiento se plantea un objetivo más complejo: gestionar el conocimiento tácito, lo que implica procesos de socialización (ya sean face to face, ya sean a través de las prestaciones tecnológicas al alcance) que permitan su democratización y su custodia en los límites organizacionales. Por esta razón, se desestima la relación excluyente a favor de la relación complementaria entre gestión de contenidos y gestión del conocimiento.
} 
El origen de la aplicación de la gestión del conocimiento en el contexto organizacional, o lo que es lo mismo, la economía basada en el conocimiento, se ha identificado, por un lado, con la Teoría de los Recursos y Capacidades y, por otro, con un más reciente enfoque evolutivo basado en el valor del capital intelectual y el conocimiento (Navas y Ortiz, 2002; Camelo Ordaz, 1996), cuyos pilares argumentales se vinculan a la teoría administrativa de la learning organization o la organización que aprende (Senge, 2005) como parte de la cultura de las organizaciones. Independientemente del origen dual de la base teórica que apoya este modelo de gestión, ambas rutas convergen en la idea de "dar valor al saber hacer de una organización y de salvaguardarlo, explicitándolo o democratizando el no explicitable, a través de buenas prácticas colaborativas" (Rodríguez-Pallares, 2014: 158). A modo de síntesis argumental, y recuperando la ecuación anterior (Figura 1), información y conocimiento son condicionantes reductores del riesgo en la toma de decisiones.

Según queda expuesto, la toma de decisiones ha estado tradicionalmente vinculada a la confianza, personalizada en la figura del líder, ahora también debe vincularse, y de facto se vincula, a la transparencia para con sus públicos objetivos. Ya se comentaba en el albor de este siglo que la transparencia comienza con la definición, claridad y comunicación de los principios que configuran a una unidad económica de producción (Nieto e Iglesias, 2000: 145), lo que entronca directamente con la ética organizacional o la rendición de cuentas que tienen que llevar a cabo personas e instituciones en el ámbito de sus funciones (Olalla, 2013).

Para Black (1994:195), la transparencia organizativa parte de la "declaración de objetivos que la empresa debería proporcionar para dar una orientación sobre qué tipo de comportamiento es obligatorio dentro de la organización”, precisando que debería “proceder de lo alto e irse reflejando hasta llegar a lo más bajo". Por tanto, se puede deducir que la transparencia recae sobre el poder decisor; es la confianza la que se atribuye al líder (empresarios y subordinados), y repercute en la imagen corporativa a través de las relaciones con sus grupos de interés. Con esta idea como sustrato teórico, la gestión de las actividades mercantiles está sujeta a la recomendación de ser transparentes, esto 
es, de establecer diálogo y hacer partícipes a la sociedad, en general, y a sus stakeholders, en particular, de sus acciones y decisiones con el fin de generar credibilidad y engagement, por un lado, y colaborar con la toma de decisiones, por otro, algo que ya se ponía de manifiesto en las directrices expuestas en la norma ISO 26000 (Guía de Responsabilidad Social Corporativa) donde, en su artículo 5.3.1, se instaba a establecer un diálogo fluido entre las organizaciones y sus stakeholders.

En esta misma línea, la Ley 19/2013, de 9 de diciembre, de Transparencia, Acceso a la Información Pública y Buen Gobierno, expone un marco normativo orientado a organizaciones e instituciones públicas; de forma literal, tan solo es aplicable a "las sociedades mercantiles en cuyo capital social la participación, directa o indirecta, de las entidades previstas en este artículo sea superior al 50 por 100", de acuerdo a lo expuesto en su capítulo I, artículo 2.1.g). A fin de cumplimentar este vacío en el caso de las sociedades mercantiles al margen del ámbito sujeto de aplicación de dicha ley, la Comisión Nacional del Mercado de Valores (CNMV) publicó, en 2015, el que denominó Código del buen gobierno de las sociedades cotizadas, una guía que puede considerarse una hoja de ruta de buenas prácticas, donde se especifican, en cinco de sus recomendaciones, directrices que manifiestan la petición de transparencia organizativa para todas las unidades de producción cotizadas en bolsa a través de sus web sites y, por lo tanto, afectan directamente al objeto de estudio aquí planteado:

\section{Figura 3: Resumen de las recomendaciones de la CNMV en relación a la transparencia online de las sociedades cotizadas}

\begin{tabular}{|c|c|c|}
\hline \multicolumn{3}{|c|}{ Consideraciones y recomendaciones de la CNMV } \\
\hline $\begin{array}{l}\text { Aspectos } \\
\text { sociales y } \\
\text { societarios }\end{array}$ & $\begin{array}{l}\text { III.1.4 } \\
\text { Reuniones y } \\
\text { contactos con } \\
\text { accionistas, } \\
\text { inversores } \\
\text { institucionales } \\
\text { y asesores de } \\
\text { voto }\end{array}$ & $\begin{array}{l}\text { Recomendación 4: Que la sociedad promueva una } \\
\text { política de comunicación y contactos con accionistas, } \\
\text { inversores institucionales y asesores de voto que sea } \\
\text { plenamente respetuosa con las normas contra el abuso } \\
\text { de mercado y dé un trato semejante a los accionistas que } \\
\text { se encuentren en la misma posición. } \\
\text { Y que la sociedad haga pública dicha política a través de } \\
\text { su página web, incluyendo información relativa a la } \\
\text { forma en que la misma se ha puesto en práctica e }\end{array}$ \\
\hline
\end{tabular}


identificando a los interlocutores o responsables de

llevarla a cabo

III.2.1

Aspectos económicofinancieros
Transparencia informativa $\mathrm{y}$ voto informado
Recomendación 6: Que las sociedades cotizadas que elaboren los informes que se citan a continuación, ya sea de forma preceptiva o voluntaria, los publiquen en su página web con antelación suficiente a la celebración de la junta general ordinaria, aunque su difusión no sea obligatoria:

a) Informe sobre la independencia del auditor.

b) Informes de funcionamiento de las comisiones de auditoría y de nombramientos y retribuciones.

c) Informe de la comisión de auditoría sobre operaciones vinculadas.

d) Informe sobre la política de responsabilidad social corporativa.

Recomendación 7: que la sociedad transmita en directo, a través de su página web, la celebración de las juntas generales de accionistas.
Aspectos vinculados a los RR.HH. $\mathrm{y}$ al gobierno corporativo.
III.3.2.2

Composición del consejo de administración
Recomendación 18: que las sociedades hagan pública a través de su página web, y mantengan actualizada, la siguiente información sobre sus consejeros:

a) Perfil profesional y biográfico

b) Otros consejos de administración a los que pertenezcan, se trate o no de sociedades cotizadas, así como sobre las demás actividades retribuidas que realice cualquiera que sea su naturaleza.

c) Indicación de la categoría de consejero a la que pertenezcan, señalándose, en el caso de consejeros dominicales, el accionista al que representen o con quien tengan vínculos.

d) Fecha de su primer nombramiento como consejero en la sociedad, así como de las posteriores reelecciones. Acciones de la compañía, y opciones sobre ellas, de las que sean titulares.

Fuente: CNMV (2015) 


\section{Metodología y límites}

De acuerdo con lo anteriormente expuesto, se plantea la siguiente hipótesis:

H1: La transparencia de contenidos y conocimiento redunda en la toma de decisiones y, por lo tanto, en la gestión estratégica.

Esta proposición inicial depende del cumplimiento de otras dos proposiciones conjeturales:

H1.1: La existencia de modelos de gestión de contenidos y del conocimiento es imprescindible para garantizar el acceso a la información por parte de los stakeholders internos responsables de la gestión de una empresa de comunicación (comunicación interna) y reducir el riesgo en su toma de decisiones.

H1.2: La existencia de canales de comunicación externa que faciliten el acceso a la información y al conocimiento explicitado por parte de los stakeholders externos interesados de forma directa en la gestión de las empresas de comunicación (accionistas e inversores, o lo que han venido a denominarse shareholders' ${ }^{2}$ ), evidencia la necesidad de modelos de gestión de estos activos intangibles y de transparencia organizativa.

El modelo aplicado para confirmar estas hipótesis se ha diseñado teniendo en cuenta las siguientes fases de estudio:

F0: Proceso de identificación y estudio de modelos de gestión de contenidos y del conocimiento en los casos analizados.

F1: Observación y estudio del proceso de comunicación de información y conocimiento explicitado por parte de una organización a sus públicos interesados, externos e internos.

F2: Análisis de la influencia que el acceso a contenidos y conocimiento tiene sobre la toma de decisiones de una organización.

\footnotetext{
${ }^{2}$ Los aún denominados shareholders -accionistas e inversores-, de forma conjunta a otros grupos de interés como los analistas financieros o los organismos reguladores (CNMV) y económicos (Bolsa de Valores), conforman el entorno, comunidad o grupo financiero, un público especialmente relevante en los procesos de gestión y comunicación organizacional, dado que condicionan, como partes implicadas, la actividad de la unidad de producción.
} 
Con este razonamiento, se trata de analizar F1 e inferir, a partir de una lógica inductiva, F0 y F2, y dar, así, respuesta a las hipótesis planteadas. Esto es, a partir del estudio del grado de transparencia, se trató de deducir la existencia de un modelo de gestión de contenidos y del conocimiento operativo e identificar un contexto favorable para reducir el riesgo en la toma de decisiones a largo plazo.

Figura 4: Relación gráfica de las hipótesis y los elementos de anclaje de este estudio

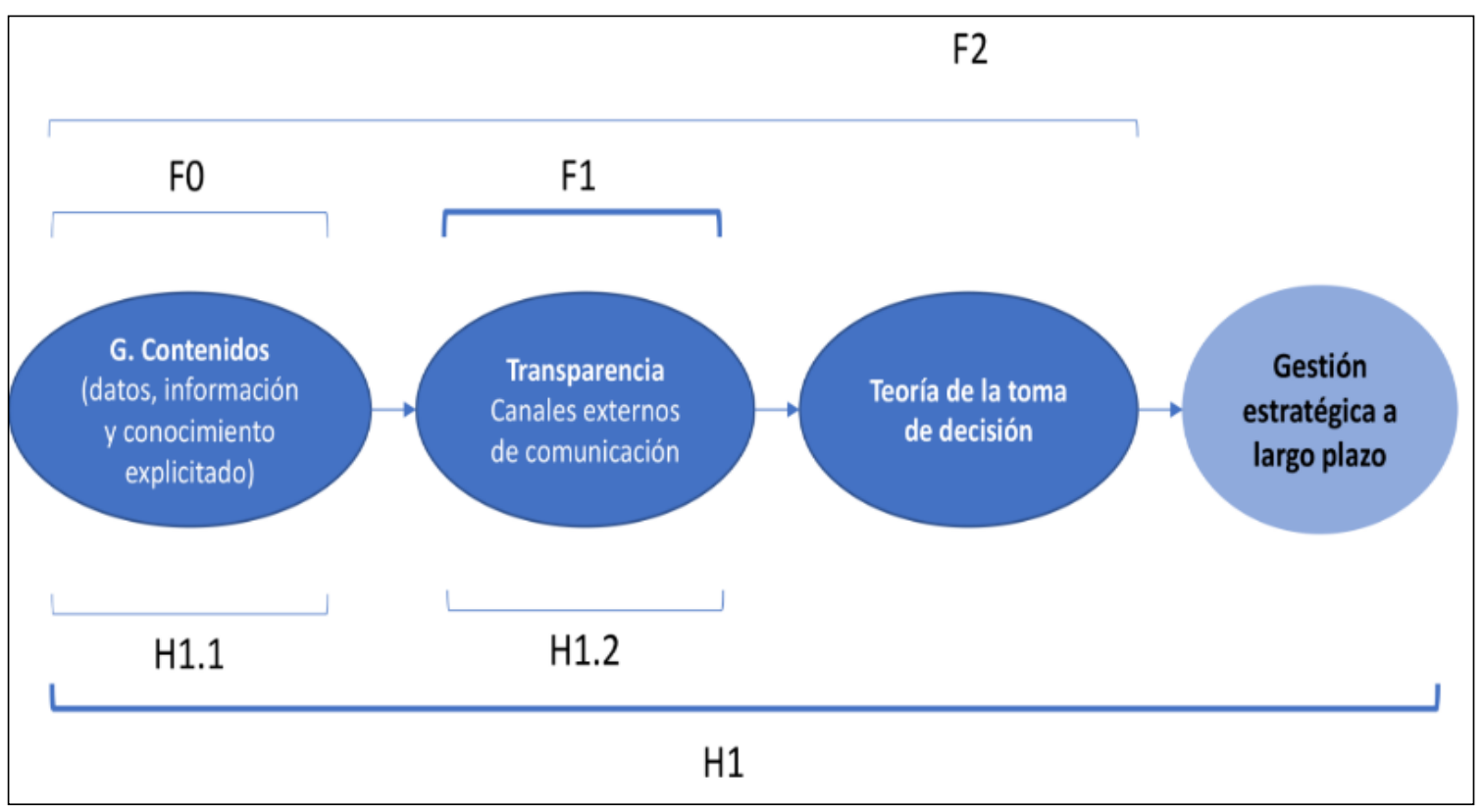

Fuente: Elaboración propia

A partir del método de estudio de casos múltiples, "existencial (no determinista) y constructivista" y que pone el énfasis en la interpretación (Stake, 2007), se acotó la muestra de análisis a los web sites de las cinco empresas de comunicación con sede social en España y cotizadas en el mercado de valores: Atresmedia, Mediaset España, PRISA, Vértice $360^{\circ}$ y Vocento (auque también cotiza en España, se excluye TV Azteca, S.A. de C.V. por tener su sede en México). 
Figura 5: Radiografía de la muestra

\begin{tabular}{|c|c|c|c|}
\hline \multirow{2}{*}{\multicolumn{2}{|c|}{$\begin{array}{l}\text { PRINCIPALES RASGOS } \\
\text { EMPRESARIALES }\end{array}$}} & \multicolumn{2}{|c|}{$\begin{array}{l}\text { SECTOR Y SUBSECTOR AL QUE PERTENECEN LAS } \\
\text { SOCIEDADES ANALIZADAS }\end{array}$} \\
\hline & & \multicolumn{2}{|c|}{ Servicios de Consumo - Medios de Comunicación y Publicidad } \\
\hline & Denominación social & $\begin{array}{l}\text { ATRESMEDIA CORP. DE } \\
\text { MEDIOS DE COM. }\end{array}$ & $\begin{array}{l}\text { MEDIASET ESPAÑA } \\
\text { COMUNICACION, } \\
\text { S.A. }\end{array}$ \\
\hline & $\begin{array}{l}\text { Marca o producto } \\
\text { destacado que } \\
\text { comercializa }\end{array}$ & Antena 3 TV & Telecinco \\
\hline 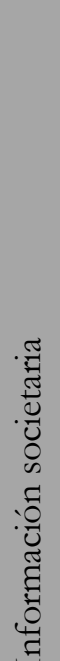 & $\begin{array}{l}\text { Detalles sobre su objeto } \\
\text { social }\end{array}$ & $\begin{array}{l}\text { "Atresmedia es uno de los grupos } \\
\text { líderes de comunicación en España, } \\
\text { especialmente desde que, en el año } \\
\text { 2012, se produjo la integración de La } \\
\text { Sexta en Atresmedia Televisión. } \\
\text { Atresmedia gestiona directamente siete } \\
\text { canales de televisión, tres emisoras de } \\
\text { radio, una productora cinematográfica } \\
\text { y está, además, a la vanguardia de los } \\
\text { nuevos soportes digitales". }\end{array}$ & $\begin{array}{l}\text { "Una de sus líneas } \\
\text { principales de actividad } \\
\text { es la explotación del } \\
\text { espacio publicitario de } \\
\text { las siete cadenas de } \\
\text { televisión que opera } \\
\text { (Telecinco, Cuatro, } \\
\text { LaSiete, Factoría de } \\
\text { Ficción, Boing, Divinity } \\
\text { y Energy) y de Internet, } \\
\text { que explota } \\
\text { comercialmente a través } \\
\text { de Publiespaña, } \\
\text { Publimedia Gestión y el } \\
\text { área Comercial". }\end{array}$ \\
\hline & Entrada en Bolsa & 29 de octubre de 2003 & 24 de junio de 2004 \\
\hline : & Mercado e índices & Mercado Continuo & $\begin{array}{l}\text { Mercado Continuo / } \\
\text { IBEX } 35\end{array}$ \\
\hline 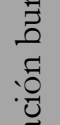 & $\begin{array}{l}\text { Capitalización } \\
\text { (miles de euros) }\end{array}$ & 2.566 .582 (hasta $17 / 05 / 2017$ ) & $\begin{array}{l}3.985 .051 \text { (hasta } \\
17 / 05 / 2017 \text { ) }\end{array}$ \\
\hline 节 & Cotización (euros) & 11,37 (cierre 17/05/2017) & $\begin{array}{l}11,835 \text { (cierre } \\
17 / 05 / 2017 \text { ) }\end{array}$ \\
\hline & Web & http://www.atresmedia.com/ & http://www.mediaset.es \\
\hline . & $\begin{array}{l}\text { Nombre del enlace para } \\
\text { el stakeholder estudiado }\end{array}$ & $\begin{array}{l}\text { Información corporativa, financiera y } \\
\text { responsabilidad corporativa - } \\
\text { Accionistas e inversores }\end{array}$ & Inversores \\
\hline 莺 & Ubicación & $\begin{array}{l}\text { Portada de } \\
\text { http://www.atresmediacorporacion.co } \\
\text { m/ (en menú del cintillo de cabecera) }\end{array}$ & $\begin{array}{l}\text { Portada (en menú del } \\
\text { cintillo de cabecera) }\end{array}$ \\
\hline : & $\begin{array}{l}\text { PROMOTORA DE } \\
\text { INFORMACIONES, } \\
\text { S.A. }\end{array}$ & $\begin{array}{l}\text { VERTICE TRESCIENTOS } \\
\text { SESENTA GRADOS, S.A. }\end{array}$ & VOCENTO, S.A. \\
\hline$\stackrel{\varrho}{\Xi}$ & El País & Telson & $A B C$ \\
\hline
\end{tabular}




\begin{tabular}{|c|c|c|c|}
\hline & $\begin{array}{l}\text { “PRISA está presente } \\
\text { en } 22 \text { países y llega a } \\
\text { más de } 60 \text { millones de } \\
\text { usuarios a través de sus } \\
\text { marcas globales. Es uno } \\
\text { de los grupos } \\
\text { mediáticos más grandes } \\
\text { del mundo hispano, y } \\
\text { cuenta con un abanico } \\
\text { extraordinario de } \\
\text { activos. Su presencia en } \\
\text { Brasil y Portugal, y en el } \\
\text { creciente mercado } \\
\text { hispano de Estados } \\
\text { Unidos, ha consolidado } \\
\text { una dimensión } \\
\text { iberoamericana con un } \\
\text { mercado global de más } \\
\text { de } 700 \text { millones de } \\
\text { personas". }\end{array}$ & $\begin{array}{l}\text { "Vértice } 360 \text { es un grupo audiovisual } \\
\text { especializado en la producción y } \\
\text { postproducción de contenidos para } \\
\text { cualquier pantalla (cine, TV y las } \\
\text { nuevas plataformas interactivas), la } \\
\text { prestación integral de servicios } \\
\text { técnicos y equipamiento para la } \\
\text { producción audiovisual y publicitaria, } \\
\text { la transmisión de canales y eventos en } \\
\text { directo, la generación de espectáculos } \\
\text { en vivo y el desarrollo de aplicaciones } \\
\text { y soluciones para la comunicación". }\end{array}$ & $\begin{array}{l}\text { "El posicionamiento } \\
\text { nacional, autonómico y } \\
\text { local de Vocento, } \\
\text { permite a la compañía } \\
\text { alcanzar, según el EGM, } \\
\text { una cobertura de más de } \\
30 \text { millones de personas } \\
\text { y sitúa a sus marcas en } \\
\text { un lugar privilegiado para } \\
\text { acceder a la información } \\
\text { y al entretenimiento } \\
\text { desde una perspectiva } \\
\text { multicanal y ajustada a } \\
\text { las nuevas tecnologías". }\end{array}$ \\
\hline \multirow{4}{*}{ 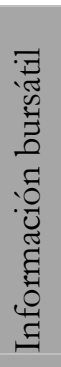 } & 28 de junio de 2000 & 19 de diciembre de 2007 & 8 de noviembre de 2006 \\
\hline & Mercado Continuo & Mercado Continuo & Mercado Continuo \\
\hline & $\begin{array}{l}256.472 \text { (hasta } \\
17 / 05 / 2017)\end{array}$ & 14.852 (hasta 17/05/2017) & $\begin{array}{l}195.579 \text { (hasta } \\
17 / 05 / 2017)\end{array}$ \\
\hline & $\begin{array}{l}3,274 \text { (cierre } \\
17 / 05 / 2017)\end{array}$ & 0,044 (cierre 14/04/2014) & $\begin{array}{l}1,565 \text { (cierre } \\
17 / 05 / 2017)\end{array}$ \\
\hline \multirow{3}{*}{ 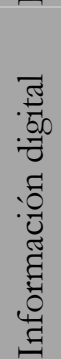 } & $\begin{array}{l}\text { http://www.prisa.com/ } \\
\text { es }\end{array}$ & http://www.vertice360.com/ & $\begin{array}{l}\text { http://www.vocento.co } \\
\mathrm{m} /\end{array}$ \\
\hline & Accionistas e inversores & Inversores & Accionistas e inversores \\
\hline & $\begin{array}{l}\text { Portada (en menú del } \\
\text { cintillo de cabecera) }\end{array}$ & $\begin{array}{l}\text { Portada (en menú del cintillo de } \\
\text { cabecera) }\end{array}$ & $\begin{array}{l}\text { Portada (en enlace } \\
\text { especial) }\end{array}$ \\
\hline
\end{tabular}

Fuente: Bolsa de Madrid / García-Santamaría, Pérez-Serrano y Alcolea, 2014 / Elaboración propia

Dada la lógica aplicada para la selección de la muestra, se acotó el campo de estudio al contexto gerencial y económico-financiero dirigido a accionistas e inversores, de tal forma que los objetivos específicos que vertebran esta investigación son los siguientes:

\section{O1: Identificar canales de comunicación externa específicos para accionistas e inversores.}

O2: Identificar contenidos vinculados a la estructura económicofinanciera y a la acción gerencial de las empresas a través de estos canales. 
Figura 6: Ficha técnica de la investigación

\begin{tabular}{|l|l|}
\hline Ámbito geográfico & España \\
\hline $\begin{array}{l}\text { Método de recogida de } \\
\text { información }\end{array}$ & $\begin{array}{l}\text { Observación externa o no participante (método } \\
\text { cualitativo) }\end{array}$ \\
\hline \multirow{4}{*}{ Indicadores } & $\begin{array}{l}\text { Información en el sitio web } \\
\text { Acceso a la información }\end{array}$ \\
\hline & $\begin{array}{l}\text { Usabilidad y sencillez a la hora de conocer la } \\
\text { información }\end{array}$ \\
\hline \multirow{2}{*}{ Tamaño muestral } & $\begin{array}{l}\text { Cinco empresas de Comunicación cotizadas en Bolsa } \\
\text { Sesenta Grados está actualmente suspendida desde el } 14 \\
\text { de Abril de 2014. Se valora para la investigación por } \\
\text { estar incluida dentro de las "Empresas Cotizadas" que } \\
\text { recoge Bolsa de Madrid }\end{array}$ \\
\hline Fechas del trabajo de campo & Primer trimestre de 2017 \\
\hline
\end{tabular}

Fuente: Elaboración propia

Una vez seleccionada la muestra se diseñó una matriz analítica (Figura 7) con el objetivo de establecer un patrón sistemático en el proceso de observación y cuantificación (Berelson, 1952; Bauer, 2000).

El análisis ha permitido, a través de la observación no participante (como usuario), graduar las respuestas de acuerdo al grado de accesibilidad de la información. Siguiendo los postulados del modelo Likert, se han considerado los siguientes códigos de identificación según la facilidad de acceso:

1. "Muy alta", cuando se ha encontrado dicha información pulsando hasta dos links, es decir, cuando la ruta no exige más de dos acciones por parte del usuario para acceder al contenido deseado.

2. "Alta", cuando se han necesitado hasta cuatro links para lograr el acceso a los contenidos solicitados.

3. "Buena", hasta seis links.

4. "Deficiente", hasta ocho links, y

5. "No se encuentra". 
Figura 7: Modelo analítico para el análisis de contenido ${ }^{3}$

\begin{tabular}{|c|c|c|c|c|c|c|c|}
\hline \multirow{2}{*}{\multicolumn{3}{|c|}{ CRITERIOS (generales y específicos) }} & \multicolumn{5}{|c|}{$\begin{array}{l}\text { ESCALA VALORATIVA - GRADO DE } \\
\text { ACCESIBILIDAD }\end{array}$} \\
\hline & & & & Alta & Bueng & Deficiente & No se \\
\hline \multirow{8}{*}{$\begin{array}{l}\text { I. Aspectos } \\
\text { sociales y } \\
\text { societarios }\end{array}$} & I.1. & $\begin{array}{l}\text { Forma societaria y } \\
\text { sede social }\end{array}$ & & & & & \\
\hline & I.2. & $\begin{array}{l}\text { Estructura de } \\
\text { capital (acciones) }\end{array}$ & & & & & \\
\hline & I.3. & Estatutos sociales & & & & & \\
\hline & I.4. & $\begin{array}{l}\text { Funcionamiento } \\
\text { interno (juntas) }\end{array}$ & & & & & \\
\hline & I.5. & Plan estratégico & & & & & \\
\hline & I.6. & $\begin{array}{l}\text { Misión, visión, } \\
\text { valores }\end{array}$ & & & & & \\
\hline & I.7. & $\begin{array}{l}\text { Oficina del } \\
\text { inversor y del } \\
\text { accionista }\end{array}$ & & & & & \\
\hline & I.8. & $\begin{array}{l}\text { Hechos relevantes } \\
\text { / CNMV }\end{array}$ & & & & & \\
\hline \multirow{6}{*}{$\begin{array}{l}\text { II. Aspectos } \\
\text { económico- } \\
\text { financieros }\end{array}$} & II.1. & Presupuestos & & & & & \\
\hline & II.2. & Cuentas anuales & & & & & \\
\hline & II.3. & Resultados & & & & & \\
\hline & II.4. & $\begin{array}{l}\text { Información } \\
\text { Pública Periódica }\end{array}$ & & & & & \\
\hline & II.5. & $\begin{array}{l}\text { Periodo medio de } \\
\text { pago a } \\
\text { proveedores }\end{array}$ & & & & & \\
\hline & II.6. & $\begin{array}{l}\text { Histórico de } \\
\text { cuentas anuales e } \\
\text { información } \\
\text { financiera }\end{array}$ & & & & & \\
\hline \multirow{2}{*}{$\begin{array}{l}\text { III. Aspectos } \\
\text { vinculados a los } \\
\text { RRHH y al }\end{array}$} & III.1. & $\begin{array}{l}\text { Organigrama } \\
\text { (esquema) }\end{array}$ & & & & & \\
\hline & III.2. & $\begin{array}{l}\text { Gobierno } \\
\text { corporativo }\end{array}$ & & & & & \\
\hline
\end{tabular}

Criterio I.7. (Oficina del inversor y el accionista): se entiende como tal al site concreto que aglutina resúmenes de información económico-financiera de la sociedad mercantil en cuestión destinada a los primeros sujetos de sus relaciones intraempresariales (inversores y accionistas). Dicha información también se puede recoger de forma más extendida y detallada en otros lugares de la web.

Criterio II.1. (Presupuestos): se entiende por tal a los datos significativos en torno a las bases presupuestarias del grupo de comunicación. A sabiendas de que el presupuesto no pertenece a la publicidad oficial de la sociedad mercantil, se considera que los datos en torno a los presupuestos supondrían un plus en la transparencia de la empresa en cuestión. 


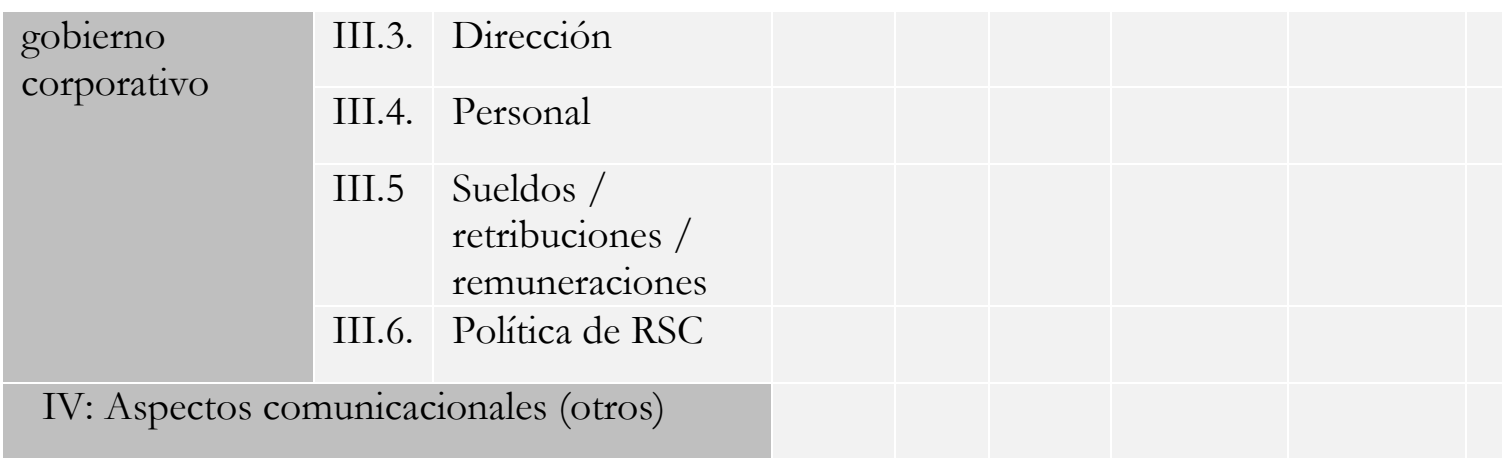

Fuente: Elaboración propia.

Asimismo, los criterios de análisis se han categorizado de acuerdo a cuatro aspectos concretos que ayudan, a posteriori, a comprender el grado de transparencia de las empresas sujetas a estudio. Aun cuando el criterio IV (aspectos comunicacionales) ${ }^{4}$ no tiene por qué ser de relevancia para el plano gerencial o económico-financiero de las empresas cotizadas, se incluye en el análisis ya que, dado el objeto social de la muestra del estudio, la visibilidad de estos contenidos supone un añadido destacable en su grado de transparencia y pone en valor la particularidad mercantil de las empresas de comunicación.

A la hora de cuantificar los resultados obtenidos, se han agrupado las categorías positivas (muy alta, alta y buena), por un lado, y negativas (deficiente y no se encuentra), por otro, de tal manera que a través de sus medias se pueda responder, afirmativa o negativamente, a la siguiente pregunta o research question (RQ): ¿Son las empresas de la muestra transparentes con sus accionistas e inversores? (I, II, III, IV) O más concretamente: ¿Son las empresas de la muestra transparentes desde la perspectiva económico-financiera con sus accionistas e inversores? (I, II, III).

\section{Resultados}

Como ya se ha apuntado, parece obvio que la toma de decisión es mucho más fácil y menos arriesgada cuanto mayor sea el volumen de información y conocimiento disponibles y que se planteen "modelos de decisión" dentro de las estructuras empresariales a fin de

\footnotetext{
${ }^{4}$ Se incluye aquí información relevante en torno a principios configuradores, difusión/audiencia, suscriptores, seguidores en redes sociales y publicidad (tarifas, formatos, tipos).
} 
proporcionar una exacta descripción y comprensión de la realidad. Así, a través de un mejor y preciso conocimiento, se puedan adoptar las decisiones más adecuadas y, en su caso, modificarlas en el sentido que más interese según la dinámica empresarial y las perspectivas del momento.

En función del tipo de modelo y del entorno en que la decisión va ser tomada, aparecen diferentes ambientes de decisión; y, en este momento, el nivel de información disponible determina el escenario en que la decisión ha de adoptarse, configurando así:

- Ambientes de certeza, cuando el decisor conoce con toda seguridad aquellos hechos de los que depende la decisión y sobre lo que el decisor tiene escaso o nulo grado de control (estados de naturaleza).

- Ambientes de riesgo, cuando el decisor ignora qué estados de la naturaleza van a presentarse, pero sí se conoce cuáles pueden aparecer y la probabilidad que tiene cada uno de ellos de hacerlo.

- Ambientes de incertidumbre estructurada, en los que son conocidos los diferentes estados de naturaleza, pero se desconoce la probabilidad asignada a cada uno de ellos, y

- Ambientes de incertidumbre no estructurada, donde el grado de información es mínimo, ya que ni siquiera se conocen los posibles estados de la naturaleza (Sevillano, 2001).

La diferencia fundamental entre los distintos ambientes radica en el nivel de información disponible y, consecuentemente, en el grado de transparencia que las empresas tengan al mostrar su información.

En esta línea, tras el análisis de contenido, se ha podido observar que los rasgos de transparencia positivos superan a los negativos en todas las empresas sujetas a estudio, a excepción de Vértice $360^{\circ}(44,79 \%$ resultados de transparencia positivos y 55,21\% resultados de transparencia negativos).

Mediaset cuenta con el mayor porcentaje de accesibilidad positiva a los contenidos asumidos como ítems de análisis, alcanzando un $65,42 \%$ de transparencia positiva, frente a un $34,68 \%$ de transparencia negativa. Muy cercano a estos porcentajes está Vocento, con un 63,54\% de 
accesibilidad positiva a los contenidos analizados y un $34,46 \%$ de negativos.

PRISA y Atresmedia alcanzan iguales resultados en esta comparativa, con un 56,25\% de contenidos cuya accesibilidad es catalogada como positiva y un $43,75 \%$ de contenidos que, bien no se encuentran, bien exigen más de seis clicks al usuario para recorrer la ruta necesaria para su acceso.

Al responder a la pregunta de cuál es la empresa de comunicación cotizada más transparente de acuerdo a las medias de los resultados obtenidos en la escala Likert (esto es, contabilizados de forma individual, sin agruparlos en positivos y negativos) los datos varían, siendo Vocento quien ostenta la condición de transparente más accesible, con $62,5 \%$, mientras el porcentaje de transparencia de Mediaset se reduce al 35,46\%.

Figura 8: Representación gráfica de la relación entre categorías positivas y negativas de transparencia en los web sites de las empresas analizadas y relación media de los resultados obtenidos en la escala Likert
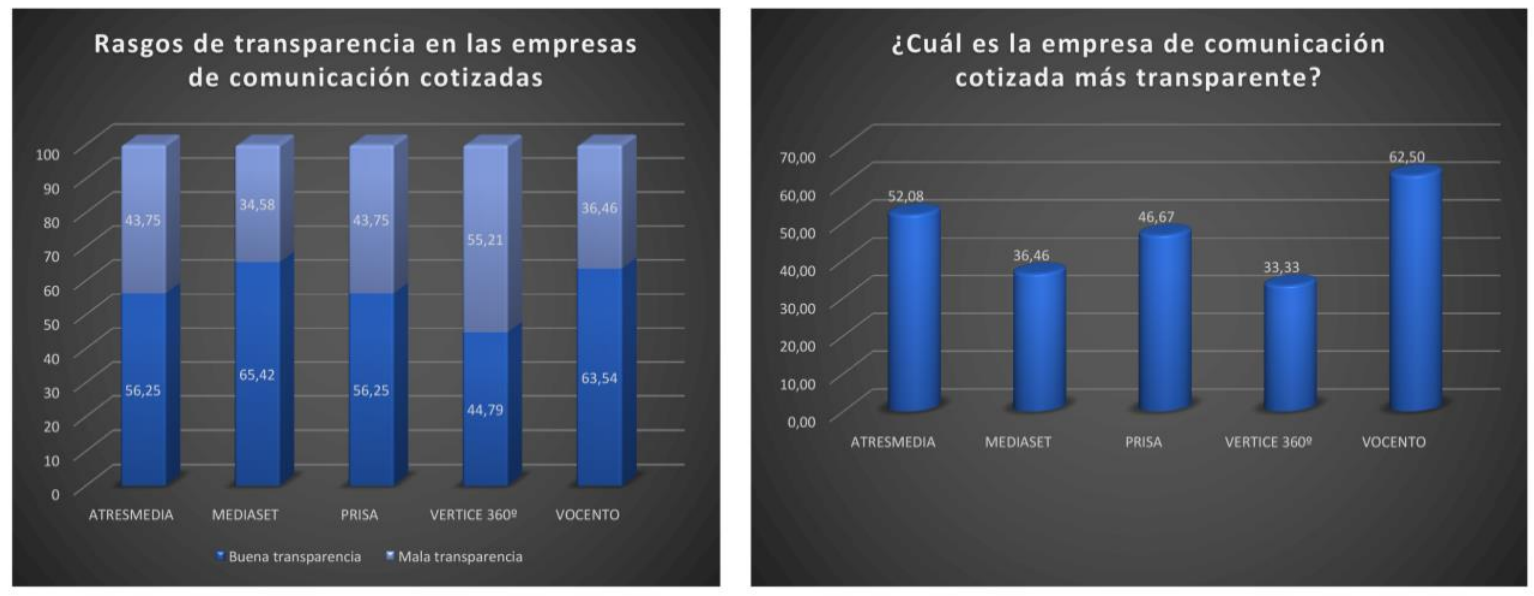

Fuente: Elaboración propia

Esta diferencia de cifras, en función el criterio de análisis, evidencia que en el caso de Vocento los contenidos informativos analizados en su generalidad son más accesibles, esto es, implican menos clicks por parte del usuario al navegar por su web site. Sirva este ejemplo para resaltar que, aunque las empresas analizadas ponen a disposición de accionistas e inversores de forma generalizada contenidos que les otorgan la condición de transparentes, no todas los ofrecen siguiendo los mismos 
criterios de accesibilidad, algo que afecta a la experiencia de usuario o user experience (UX).

Si se atiende a los diferentes criterios contemplados de forma individual (I, II, III, IV), los resultados vertidos revelan, de nuevo, leves discrepancias en lo relativo a la accesibilidad de los contenidos dirigidos a accionistas e inversores en los web sites sujetos a estudio.

En cuanto a los aspectos sociales y societarios, Atresmedia, Mediaset y PRISA están a la par en resultados: el web site de Vocento se yergue como el que facilita más la accesibilidad a los contenidos, con un $87,5 \%$ positiva, y el de Vértice $360^{\circ}$, el que menos, con solo un $62,5 \%$ de transparencia, aunque su acceso es muy alto, alto o bueno.

De modo semejante acontece en lo que a contenidos económicofinancieros se refiere: mientras Vértice $360^{\circ}$ encuentra equilibrio entre la buena y la mala accesibilidad a los contenidos de acuerdo a los ítems contemplados para esta variable, las empresas cotizadas más veteranas en el sector son más transparentes, esto es, simplifican la accesibilidad a los contenidos que presentan en sus web sites corporativos.

Sobre aspectos relacionados con el gobierno corporativo, Mediaset y Vocento no solo aportan más resultados, sino que, también, lo hacen de un modo más accesible. Mientras el acceso a la información referente a la composición del gobierno corporativo, dirección, personal y retribuciones salariales es positivo en todos los supuestos, conviene destacar -excepto en el caso de Vocento-, la inexistencia de un organigrama empresarial en unos casos y, en otros, la no inclusión de contenidos vinculados a la Responsabilidad Social Corporativa (RSC) en los espacios dedicados a accionistas e inversores de ninguno de los web sites analizados. Otra excepción la constituye Vértice $360^{\circ}$, aunque, aquí, la información se muestra de forma poco accesible.

Finalmente los resultados referentes al criterio IV $\mathrm{O}$ aspectos comunicacionales, revelan que, salvo Mediaset, que ofrece un datos sobre difusión y audiencia, no se contemplan como prioritarios para enriquecer la oferta informativa destinada a accionistas e inversores. Esto es, las empresas de comunicación, no ofrecen contenidos 
relativos a su actividad funcional a accionistas e inversores, limitando la comunicación con estos stakeholders a aspectos únicamente relacionados con la sociedad mercantil como unidad económica de producción, al margen de su objeto social.

Figura 9: Representación gráfica de la relación entre categorías positivas y negativas de transparencia de acuerdo a los criterios específicos
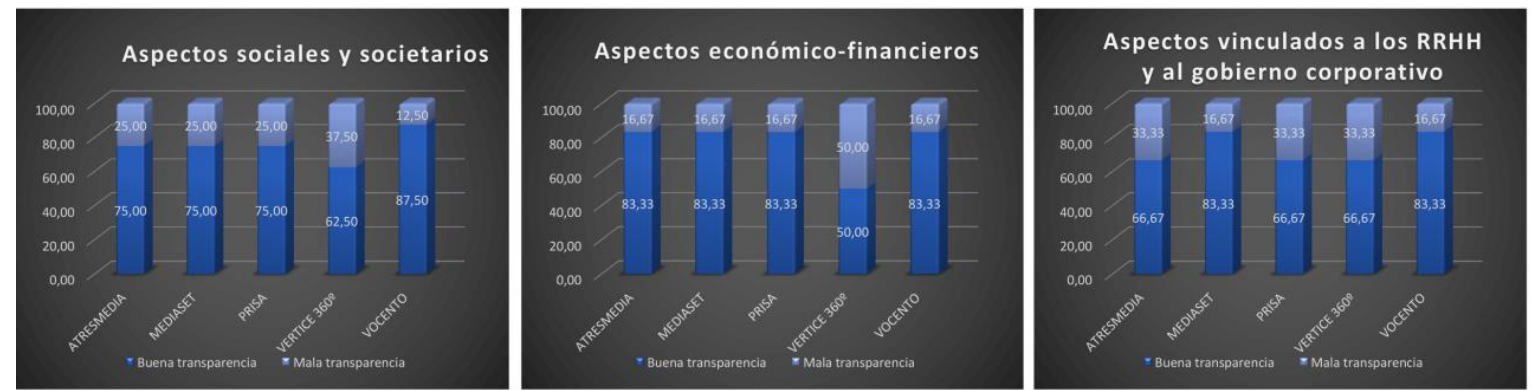

Fuente: Elaboración propia

\section{Discusión y conclusiones}

Tras el análisis de contenido y la cuantificación de los resultados obtenidos se confirma que, desde una perspectiva económicofinanciera y tomando como base las medias obtenidas en los criterios I, II, y III, la muestra analizada es transparente en un $75 \%$ de los contenidos online que responden a la categoría de positivos. Sin embargo, si a los aspectos societarios (I), económico-financieros (II) y corporativos (III) se les añaden los aspectos comunicacionales (IV), el porcentaje de transparencia en los web sites se reduce al 57,25\%.

Figura 10: Representación gráfica del porcentaje de transparencia de las empresas analizadas
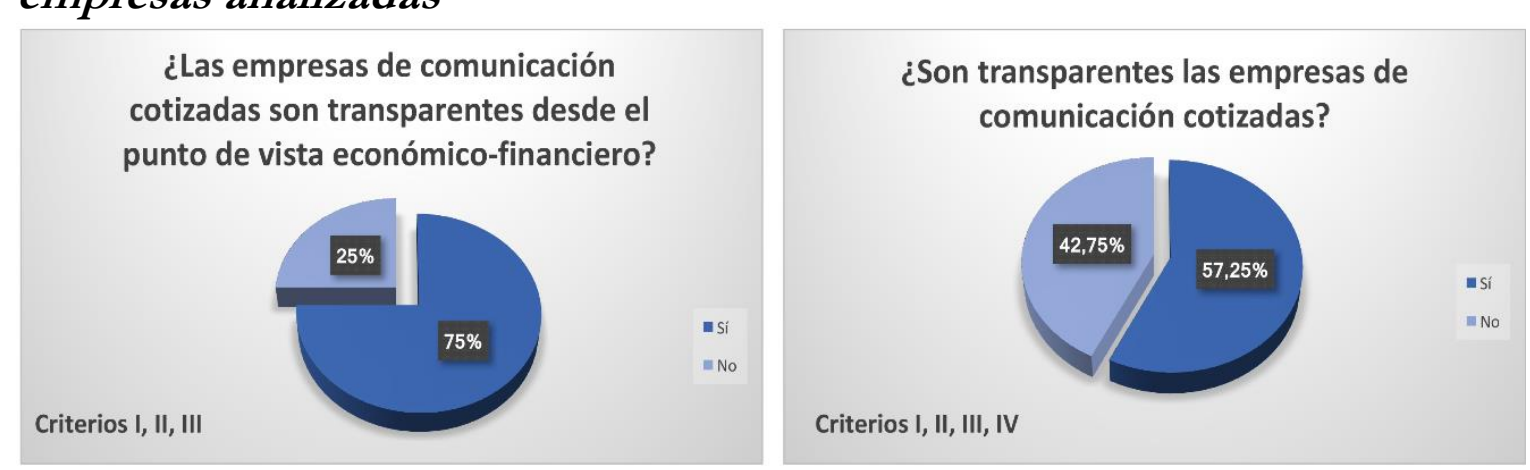

Fuente: Elaboración propia 
Esta diferencia de resultados evidencia que las empresas sujetas a estudio, pese a contar con las particularidades que su objeto social les otorga desde el punto de vista mercantil y administrativo, no se diferencian de aquellas cotizadas operantes en otros sectores en lo que se refiere a cuestiones de transparencia para con sus accionistas e inversores.

\subsection{Proyección deductiva}

Si realizamos el proceso de razonamiento en sentido contrario, esto es, aplicamos ahora una lógica deductiva, se puede decir que, dado que el grado de transparencia en los canales de comunicación online en términos gerenciales y económico-financieros es elevado $(75 \%)$, se presupone un modelo de gestión de contenidos y conocimiento explicitado (H1.2) que facilita el volcado de estos fondos informativos en los web sites analizados y, por lo tanto garantiza el acceso a la información por parte de los stakeholders externos. Si bien es imposible corroborar a partir del estudio realizado la centralización de todos los contenidos generados por la actividad empresarial en un mismo repositorio de datos (Rodríguez-Pallares, 2016), sí es viable razonar que la H1.2 se cumple en términos funcionales en el campo de estudio analizado.

Estos resultados, que confirman un alto grado de transparencia externa y que evidencian la existencia de modelos de gestión de contenidos y conocimiento explicitado en el campo gerencial y económicofinanciero, permiten deducir, asimismo, que el acceso a los mismos contenidos por parte de los stakeholders internos (responsables de la gestión empresarial) también existe (H1.1), hecho que redunda en el proceso de toma de decisiones y, por lo tanto, colabora con la gestión a largo plazo, confirmándose así la $\mathrm{H} 1$.

Finalmente, es necesario matizar el carácter específico del área de actividad organizacional sujeta a cuantificación y gradación de transparencia: la relativa a los procesos gerenciales y económicofinancieros. Esta particularidad implica la imposibilidad de extrapolar estos resultados a todas las áreas de una empresa de comunicación, 
aunque, atendiendo al fin lucrativo de las sociedades mercantiles, se muestra como ejemplo clarificador de la relación de dependencia entre la gestión de contenidos y conocimiento, la transparencia o acceso a la información y el proceso decisor en el contexto de la gestión estratégica.

Fechas:

- Inicio de la investigación: 1 de diciembre de 2016

- Término de la investigación: 20 de mayo de 2017

\section{Referencias bibliográficas}

S Al-Hawamdeh (2002): "Knowledge Management: re-thinking information management and facing the challenge of managing tacit knowledge". Information Research, 8 (1), pp. 1-39. Disponible en http://informationr.net/ir/8-1/paper143 [Última fecha de consulta: 11 de febrero de 2015].

M Bauer (2000): “Classical content analysis: A review”, en (Eds. M. Bauer \& G. Gaskell), Qualitative Researching with Text, Image and Sound, pp. 131-151. Thousand Oaks, CA: Sage.

B Berelson (1952): Content Analysis in Communication Researches. Glencoe III: Free Press.

S Black (1994): ABC de las Relaciones Públicas, Barcelona: Gestión 2000.

E Bueno (1999, 24 junio): La gestión del conocimiento: nuevos perfiles profesionales. Comunicación presentada en Cursos de Verano UCMEurforum. El Escorial, España. Disponible en http://www.sedic.es/bueno.pdf [Última fecha de consulta: 15 de febrero de 2015]

C Ordaz (1996): "El comportamiento de las empresas frente a la comercialización en sus innovaciones: algunas reflexiones teóricas". Investigaciones Europeas de Dirección y Economía de la Empresa, 2 (2), pp. 149-170

M Carrillo \& N Nuño (2010): "La documentación en la evaluación y gestión de la imagen corporativa”. El Profesional De La Información, 19 (2), pp.123-132. doi:10.3145/epi.2010.mar.02.

Comisión Nacional del Mercado de Valores (2015): Código del buen gobierno de las sociedades cotizadas. Disponible en https://www.cnmv.es/docportal/publicaciones/codigogov/codig 
o buen gobierno.pdf [Última fecha de consulta: 28 de diciembre de 2016]

R Eíto (2013): "Madurez de la gestión de contenidos, ¿sinónimo de desgaste o de oportunidades?”. El Profesional de la Información 22 (5), pp. 377-380 doi:10.3145/epi.2013.sep.01.

España. Ley 19/2013, de 9 de diciembre, de transparencia, acceso a la información pública y buen gobierno. Disponible en http://www.boe.es/boe/dias/2013/12/10/pdfs/BOE-A-201312887.pdf [Última fecha de consulta: 28 de diciembre de 2016]

M Fernández-Sande, MD Rodríguez-Barba \& M Rodríguez-Pallares (2013): "La gestión de contenidos como actividad estratégica en empresas de radiodifusión. Estudio de casos en la radio comercial española”. El Profesional de la Información 22 (5), pp. 392-398. doi: 0.3145/epi.2013.sep.03.

JV García-Santamaría, MJ Pérez-Serrano \& G Alcolea-Díaz (2014): "Las nuevas plataformas televisivas en España y su influencia en el mercado". Revista Latina de Comunicación Social 69, pp. 390-417. doi: 10.4185/RLCS-2014-1017.

L Hsiangchu \& C Tsai-Hsin (2002): "Knowledge management: A review of industrial cases". The Journal of Computer Information Systems, 42 (5), pp. 26. Disponible en http://connection.ebscohost.com/c/articles/7344671/knowledge -management-review-industrial-cases [Última fecha de consulta: 28 de diciembre de 2016]

ISO 26000 (2000). Guia de Responsabilidad Social. Disponible en https://www.iso.org/obp/ui\#\#iso:std:iso:26000:ed-1:v1:es [Última fecha de consulta: 15 de mayo de 2017$]$

JE Navas-López \& M Ortiz-de-Urbina-Criado (2002): “El capital intelectual en la empresa: Análisis de criterios y clasificación multidimensional". Economía Industrial, IV (346). Disponible en http://www.minetur.gob.es/Publicaciones/Publicacionesperiodic as/EconomiaIndustrial/RevistaEconomiaIndustrial/346/14\%20 EMILIO \%20NAVAS.pdf [Última fecha de consulta: 1 de mayo de 2017]

V Newman (1997): "Redefining knowledge management to deliver competitive advantage". Journal of Knowledge Management. 1 (2), pp. 123-132.

A Nieto \& F Iglesias (2000): La empresa informativa. Barcelona: Ariel 
I Nonaka \& H Takeuchi (1999): La organización creadora de conocimiento: Cómo las compañias japonesas crean la dinámica de la innovación. México D.F: Oxford University Press.

IA Núñez (2004): "La gestión de la información, el conocimiento, la inteligencia y el aprendizaje organizacional desde una perspectiva socio-psicológica". Acimed: Revista Cubana De Los Profesionales De La Información y La Comunicación En Salud.

J Olalla (2013): "La transparencia como un valor", en Newfield Network. Disponible en http://www.newfield.cl/newslettersantiguos/la-transparencia. [Última fecha de consulta: 1 de mayo de 2017]

TA Pearson (1999): "Measurements and the knowledge revolution". Quality Congress.ASQ's ... Annual Quality Congress Proceedings. Disponible en http://0search.proquest.com.cisne.sim.ucm.es/docview/214393563 [Última fecha de consulta: 1 de mayo de 2017]

MJ Pérez-Serrano (2010): "Análisis del valor de las empresas informativas". Palabra Clave, 13 (1), pp. 47-58.

M Porter (1999): Ser competitivo. Nuevas aportaciones y conclusiones. Bilbao: Deusto.

M Rodríguez-Pallares (2012): El capital intangible como clave estratégica en la empresa radiofónica española: El caso de la Cadena SER, en (Eds. M Fernández-Sande \& A Adami) Panorâmica de Comunicação e dos Meios no Brasil e Espanha / Panorámica de la Comunicación y los Medios en Brasil y España, pp. 473-495.

M Rodríguez-Pallares (2014): Análisis de los actuales modelos de gestión de contenidos y conocimiento en las grandes cadenas de radiodifusión españolas: SER, onda cero, COPE y RNE. Tesis doctoral: Universidad Complutense de Madrid.

M Rodríguez-Pallares (2016): "Propuesta conceptual de un modelo de gestión de contenidos y del conocimiento en la empresa radiofónica". Revista española de documentación científica, 39 (2) doi: 10.3989/redc.2016.2.1271.Disponible en http://redc.revistas.csic.es/index.php/redc/article/view/930 [Última fecha de consulta: 1 de mayo de 2017]

PM Senge (2005): La quinta disciplina: Cómo impulsar el aprendizaje en la organización inteligente. Buenos Aires: Granica. 
M Sevillano (2001): Teoría y práctica de la dirección de la Empresa Informativa (materiales docentes). Madrid: UCM.

JC Spender \& RM Grant (1996): "Knowledge and the firm:

Overview". Strategic Management Journal (1986-1998), 17, número especial invierno, (5). doi: 10.1002/smj.4250171103.

RE Stake (2007): Investigación con estudio de casos. Madrid: Morata.

L Strandberg (2010): "El compromiso con los grupos de interés". Cuadernos de la Cátedra "la Caixa" de la Responsabilidad Social de la Empresa y Gobierno Corporativo, 10. Navarra: IESE Business School. Disponible en http://www.iese.edu/es/files/Cuaderno $\% 20 \mathrm{No} \% 2010$ tcm561597.pdf [Última fecha de consulta: 15 de mayo de 2017]

Cómo citar: Rodríguez Pallares, M, et al (2017): "Buscando transparencia... Estrategias en el proceso de decisión de los grupos de medios presentes en la Bolsa española". Revista Latina de Comunicación Social, 72, pp. 719 a 736. http://www.revistalatinacs.org/072paper/1188/38es.html DOI: $\underline{10.4185 / R L C S-2017-1188}$ 
Cómo citar: Molina Rodríguez-Navas P, et al (2017): "Metodologías de evaluación de la transparencia: procedimientos y problemas". Revista Latina de Comunicación Social, 72, pp. 818 a 831.

http://www.revistalatinacs.org/072paper/1194/44es.html

DOI: $10.4185 /$ RLCS-2017-1194

Metodologías de evaluación de la transparencia: procedimientos y problemas

Pedro Molina Rodríguez-Navas - Departamento de Periodismo y de Ciencias de la Comunicación, Universidad Autónoma de Barcelona, España - pedro.molina@uab.cat

Núria Simelio Solà - Departamento de Periodismo y de Ciencias de la Comunicación, Universidad Autónoma de Barcelona, España nuria.simelio.sola@uab.cat

Marta Corcoy Rius - Universidad Autónoma de Barcelona, España - marta.corcoy@uab.es

\begin{abstract}
s
Introducción: La aprobación de la Ley de Transparencia en España en 2013, junto a la preocupación por la corrupción, el buen gobierno y la rendición de cuentas, ha provocado un importante aumento de los estudios sobre transparencia de las administraciones en los últimos años. Metodología: El objetivo de este artículo es exponer las diferentes complejidades metodológicas para analizar la transparencia de los contenidos publicados por las administraciones públicas en aspectos como la propia definición de transparencia, el objeto de estudio, los usuarios o los destinatarios. Resultados: Se presenta un modelo de análisis de la transparencia de las webs de los ayuntamientos: el proyecto Infoparticipa. La metodología que presentamos está basada en herramientas innovadoras que han
\end{abstract}


establecido un mapa de la transparencia local en España. Discusión y conclusiones: El Mapa Infoparticipa ha transcendido el ámbito académico mostrando su utilidad social al impulsar la mejora de la información publicada en las webs.

\section{Keywords}

transparencia; webs; comunicación pública; metodologías; rendición de cuentas.

\section{Contents}

1. Introducción 2. Definición de la metodología de evaluación 2.1. Identificación del objetivo de la evaluación y definición de transparencia 2.2. Legalidad versus derechos 2.3. Destinatarios 2.4. Metodología cuantitativa o cualitativa 2.5. Características del sujeto estudiado 2.6 Acreditaciones 3. Metodología Infoparticipa 3.1. Orígenes y perspectiva 3.2 Procedimiento 4. Conclusiones 5. Bibliografía

\section{Introducción}

— $\mathrm{N}$ los últimos años se han multiplicado los estudios sobre la interés es el resultado de diversos factores, como la proliferación de casos de corrupción y el seguimiento mediático que han conllevado, la aprobación de leyes de transparencia y buen gobierno, desde la estatal Ley 19/2013 del 9 de Diciembre de Transparencia, Acceso a la Información Pública y Buen Gobierno (España, 2013) hasta las diferentes leyes autonómicas o el interés de organismos internacionales que promueven la transparencia, relacionando su aplicación con beneficios en términos de democracia y desarrollo (United Nations, 2000: III; Comisión Europea, 2001; European Comission, 2010).

Estos estudios no solamente parten de iniciativas académicas. Diferentes organismos públicos, encargados de velar por el cumplimiento de las normas, encargan o realizan sus propias evaluaciones o desarrollan sistemas de autoevaluación. Así, por ejemplo, el Síndic de Greuges de Cataluña ha publicado en 2016 el Informe sobre transparencia, acceso a la información pública y buen gobierno 
(Síndic, 2016), elaborado por mandato del Parlamento de Cataluña bajo la función de evaluar el cumplimiento de la ley. El Consejo de Transparencia y Buen Gobierno de España, con la Agencia Estatal de Evaluación de las Políticas Públicas y la Calidad de los Servicios (AEVAL), ha desarrollado un procedimiento de autoevaluación, del cumplimiento de la Ley de Transparencia estatal, denominado MESTA (metodología de evaluación y seguimiento de la transparencia en la administración), que pone a disposición de las administraciones públicas de España. El propio Consejo ha presentado en 2017 un Informe de evaluación del cumplimiento de la Ley de Transparencia (Consejo de Transparencia, 2017) en que se ha evaluado a las principales instituciones políticas y jurídicas de España y a los organismos de relevancia constitucional recogidos en la propia Ley de Transparencia.

Igualmente, organizaciones civiles interesadas en el desarrollo de la democracia, la participación y el rendimiento de cuentas, crean sus propios sistemas de seguimiento. Algunas de estas son de ámbito internacional y otras se dirigen a entornos próximos como la política local. La más conocida es la actividad de Transparency Internacional, representada en España por la ONG Transparencia Internacional España (en http://transparencia.org.es) que evalúa periódicamente la transparencia de diferentes administraciones públicas y de otras organizaciones privadas como los clubs de fútbol.

Los procedimientos que se aplican en estos análisis tienen características diversas, relacionadas con grupos de cuestiones diferentes que determinan la metodología de evaluación, los procedimientos utilizados para el cálculo de resultados, la publicación de las investigaciones y otros problemas que abordamos en el siguiente apartado.

Por tanto, en este trabajo nos proponemos estudiar cuáles son las cuestiones que definen la metodología que finalmente se utiliza, así como el abanico de posibles soluciones para cada una de ellas. A continuación, exponemos las características del procedimiento Infoparticipa, una metodología con la que hemos dado respuesta compleja a los problemas derivados de abordar ese objeto de estudio desde una postura tanto académica como cívica. 


\section{Definición de la metodología de evaluación}

Para definir los indicadores de evaluación y el conjunto del procedimiento de medición de la transparencia de las administraciones públicas, hay que plantearse algunas cuestiones y determinar las respuestas que orientarán el diseño de la metodología. Las abordamos en los siguientes subapartados.

\subsection{Identificación del objetivo de la evaluación y definición de transparencia}

En primer lugar, el objetivo de la evaluación señalará las características del procedimiento. Si bien es cierto que, en principio, el objetivo general puede ser conocer si una administración pública es más o menos transparente, la idea que subyace en el concepto de transparencia acaba determinando las características del procedimiento. Aunque el término no es nuevo, actualmente está siendo relacionado con la expansión de Internet y las posibilidades de las nuevas tecnologías que facilitan a las administraciones promover la transparencia en el contexto de las experiencias de aplicación del gobierno electrónico, lo que incrementa la relevancia de la noción de transparencia en el campo académico y político. A pesar de esto, se alerta de que se está usando de forma muy genérica y sin que se hayan desarrollado criterios y metodologías para verificar si esas prácticas han tenido éxito (Bertot, Jaeger y Grims, 2010).

Algunos autores se centran en abordarla en relación al control de la corrupción, afirmando que una administración electrónica transparente facilita su reducción (Anderson, 2009). Si se concibe la transparencia, exclusiva o preferentemente, desde este punto de vista, es decir, como factor preventivo de la corrupción, los indicadores atenderán principalmente al control económico y se buscará comprobar si se publican informaciones tales como los presupuestos, el control de gasto, la adjudicación de contratos y el resto de informaciones que permiten saber de dónde proceden los recursos y cómo son utilizados. Un caso extremo lo encontramos en la evaluación que Transparencia Venezuela (en https://transparencia.org.ve/) hizo de una muestra de ayuntamientos entre 2004 y 2010, con indicadores divididos en 5 cinco grupos de índole económica: formulación y 
ejecución de presupuesto, adquisiciones de bienes y contrataciones de obras y servicios, tramitación de la Licencia de Actividad Económica, colocaciones Bancarias y tramitación del Permiso de Construcción. Sin duda se da este caso en relación a la gravedad del problema de la corrupción en el país, pero no podemos olvidar que en cualquiera de sus secciones nacionales, esta es la perspectiva de Transparency International, tal y como muestra su lema, "the global coalition against corruption", y la propia definición de la organización que ofrecen en su web (What is Transparency International? En https://www.transparency.org/about/):

From villages in rural India to the corridors of power in Brussels, Transparency International gives voice to the victims and witnesses of corruption. We work together with governments, businesses and citizens to stop the abuse of power, bribery and secret deals.

As a global movement with one vision, we want a world free of corruption. Through chapters in more than 100 countries and an international secretariat in Berlin, we are leading the fight against corruption to turn this vision into reality.

Por tanto, también aparece la misma idea en la explicación de TI España:

A través de sus capítulos en el mundo y su Secretariado Internacional, Transparencia Internacional aborda las diferentes facetas de la corrupción, tanto al interior de los países como en el plano de las relaciones económicas, comerciales y políticas internacionales. El propósito es comprender y enfrentar los dos rostros de la corrupción: quién corrompe y quién permite ser corrompido (en http://transparencia.org.es/que-es-ti).

Aunque en el apartado dedicado a la organización en España, introduce nuevos elementos:

Transparencia Internacional España asume que la transparencia es un importante objetivo de la sociedad actual, y que está inherentemente unida al derecho a saber de los ciudadanos, que exigen de forma creciente estar suficientemente informados y 
tener un mayor grado de participación en las decisiones que les afectan (en http://transparencia.org.es/acerca-de-ti-espana/).

De forma amplia, la transparencia se relaciona con el derecho esencial a la participación democrática e incluye, además de la prevención de la corrupción, la información sobre las actuaciones y decisiones políticas para que puedan ser conocidas y evaluadas, y la provisión de información veraz a la ciudadanía y a los medios de comunicación (Bertot, Jaeger y Grims, 2010) en beneficio del control democrático y de las posibilidades de diálogo, participación y rendición de cuentas. En este sentido, la transparencia estaría definida como un ideal democrático que obligaría a las administraciones públicas a hacer accesible para la ciudadanía toda información de interés general, considerando que es la propia ciudadanía la que financia los recursos utilizados por las administraciones y que por tanto, tiene el derecho a saber cómo se utilizan (Gandía, Marrahí y Huguet, 2016: 29).

Esta idea está presente en la legislación española, como podemos ver en la definición de transparencia que aparece en la Ley de Transparencia de Cataluña, orientada a propiciar la participación.

Transparencia: la acción proactiva de la Administración de dar a conocer la información relativa a sus ámbitos de actuación y sus obligaciones, con carácter permanente y actualizado, de la forma que resulte más comprensible para las personas y mediante los instrumentos de difusión que les permitan un amplio y fácil acceso a los datos y faciliten su participación en los asuntos públicos (Ley 19/2014, de 29 de diciembre, de transparencia, acceso a la información pública y buen gobierno, art. 2, a.; BOE núm. 18, de 21 de enero de 2015, referencia: BOE-A-2015-470, en https://www.boe.es/buscar/pdf/2015/BOE-A-2015-470consolidado.pdf).

Por tanto, si el foco de atención prioritario atañe a aspectos como el seguimiento de la acción de gobierno o si se entiende que la publicación de las informaciones ha de contribuir a incentivar la participación ciudadana en las políticas públicas, serán tan importantes como las económicas otras informaciones sobre la planificación y ejecución de los proyectos o sobre las propuestas y procesos de participación, entre otras. Así, la agenda de los responsables políticos o el plan de gobierno, 
son informaciones importantes para que los ciudadanos puedan evaluar la acción de los responsables políticos o los reglamentos de participación ciudadana y las informaciones sobre los plenos, en el caso de las corporaciones locales, lo son para determinar si se está informando puntualmente de la gestión y de la ejecución del plan de gobierno y/o si se están propiciando políticas abiertas a la participación de la ciudadanía en la definición de las políticas públicas. Una metodología que considere que la transparencia afecta a estos aspectos ha de contar con indicadores que midan la información que se ofrece sobre estos puntos.

Por otro lado, algunas investigaciones se han centrado concretamente en cómo las nuevas tecnologías han permitido facilitar este proceso de transparencia $y$ en como específicamente se ha mejorado la información con la utilización de nuevas plataformas unidereccionales, pero también con la incorporación de las redes sociales que han permitido favorecer el diálogo social. (Cameron, 2004; Simelio y Molina, 2014). En este línea, las TIC ofrecerían tres oportunidades básicas relacionadas con la transparencia: la promoción de la participación, la coproducción de contenidos entre administración y administrados y la colaboración abierta para buscar soluciones a los retos sociales (Bertot, Jaeger y Grimes, 2012: 86). Considerando estas vertientes, un procedimiento de evaluación así fundamentado debe incorporar indicadores que muestren cuáles son los resultados de esa voluntad de colaboración llevada a la práctica.

\subsection{Legalidad versus derechos}

Un segundo aspecto, derivado del anterior, es determinar la importancia que se otorga a las obligaciones legales en la definición de los indicadores. Es posible aplicar un procedimiento que considere exclusivamente las obligaciones legales para determinar su cumplimiento y, en ese caso, habrá que considerar el ámbito territorial estudiado y el de aplicación de la ley. Por ejemplo, en el caso español se puede considerar exclusivamente la ley nacional, pero se pueden tener en cuenta también las leyes autonómicas, donde las hay, ampliando así en algunos casos las obligaciones, o si se diseña un procedimiento para aplicar en diversos países se ha de tener en cuenta la legislación de cada país donde se aplica, así como las diferencias en 
las administraciones públicas estudiadas y sus competencias. En España, a partir de la aplicación de la Ley de Transparencia (España, 2013) se han desarrollado investigaciones para analizar su grado de cumplimiento en la administración, mostrando las dificultades que estas tienen para adaptarse a la nueva norma, de carácter académico (Beltrán-Orenes y Martínez-Pastor, 2006) o institucional, como el ya citado informe del Consejo de Transparencia y Buen Gobierno de España (Consejo de Transparencia, 2017).

Pero también se puede diseñar un procedimiento que tenga en cuenta la ley a la vez que considere otros elementos planteados desde la perspectiva de los derechos, ampliando las exigencias. Esto se proyecta cuando, por ejemplo, se considera la participación como objetivo fundamental de la transparencia. En cualquier caso, la definición del punto de vista implica considerar hasta qué punto la observación de las exigencias legales es suficiente o insuficiente, tanto en lo que respecta a la publicidad activa como a la pasiva, de forma que se proponga una relación de indicadores coherente con el objetivo.

\subsection{Destinatarios}

En tercer lugar, el interés que despierta la investigación en este campo merece considerar que será útil para diferentes colectivos de destinatarios, tales como responsables políticos, técnicos y profesionales de las administraciones públicas, organizaciones sociales o ciudadanía en general. Si los resultados de la evaluación se difunden exclusivamente en el campo académico o si se tiene la voluntad de trasladarlos a estos grupos interesados, afectará tanto a la metodología como a los procedimientos de difusión. Así, una evaluación que se proponga comunicar a la ciudadanía sus resultados, debe elaborar una metodología fácilmente comprensible y unos procedimientos de publicación adecuados, utilizando medios de comunicación, infografías, cartografías interactivas, etc.

En este punto, hay que plantearse, por tanto, la cantidad de información que se suministra. Una comunicación excesivamente breve, simplificando los procedimientos de evaluación y los resultados para poder llegar al máximo público posible, puede ser valorada como insuficiente por los colectivos profesionales o afectados. Por el 
contrario, la sobreinformación técnica puede provocar el efecto también indeseado de expulsar a las personas que requieren una información simplificada o breve, pero que desean igualmente ser informadas sobre el ejercicio de sus derechos.

En este sentido, es interesante tener en cuenta la investigación de Gértrudix, et. al. (2016) que muestra como existe una desconfianza de la ciudadanía hacía los datos abiertos que aportan las instituciones públicas españolas. Es necesario tener esto en cuenta para plantear como se debería gestionar la información y la comunicación entre administración y administrados para superar la poca credibilidad que la ciudadanía otorga a los responsables políticos. Además, esta desconfianza creada por las "malas prácticas" de los gobiernos ha llevado también a una reducción del interés de la ciudadanía por los asuntos públicos que provoca la necesidad de buscar metodologías que fomenten el compromiso ciudadano (Minguijón y Pac-Salas, 2012). Este es uno de los factores principales que impulsan la expansión de las organizaciones civiles, como los OCM (Observatorio Ciudadano Municipal, ver http://ocmunicipal.net) que recopilan los datos desde la proximidad y los ofrecen en un plano de igualdad de intereses que pretende, no sin dificultades para alcanzar el éxito, resultar creíble por su naturaleza.

\subsection{Metodología cuantitativa o cualitativa}

Por otra parte, la evaluación puede ser exclusivamente cuantitativa o puede incorporar elementos cualitativos. En este sentido, es posible hacer una valoración que considere exclusivamente la publicación de la información requerida o incluso la cantidad de informaciones y datos publicados. Pero es importante tener en cuenta que uno de los objetivos básicos de la transparencia es romper las barreras digitales para hacer posible que el cambio en las webs sea accesible para todos los colectivos (Fernández-Aquino, 2009). Así que también se pueden valorar aspectos cualitativos como la accesibilidad, la inteligibilidad de la información, la facilidad de acceso, la tipología de documentos en que se publican, etc. (Garrido, et al, 2014; Hong, et al., 2015).

También en este caso, el objetivo del análisis y los destinatarios han de concordar con la elección de la mejor metodología. Así, si el 
procedimiento se propone ser una guía para la práctica de la transparencia, cabe exigir el cumplimiento con criterios como por ejemplo, en qué apartado se deben publicar las informaciones o valorar si es suficiente con que la administración observada disponga de un portal de transparencia o si es necesario que la web corporativa sea transparente en su conjunto. El análisis cualitativo precisa de una mayor atención al delimitar la exigencia en los criterios de aplicación de cada indicador, ya que siempre es posible publicar algo más concreto o definido.

En cualquier caso, no parece útil diseñar una metodología exclusivamente cualitativa, ya que estos aspectos descansan sobre la previa disponibilidad de la información.

Otra cuestión relacionada, que diferencia unos procedimientos de otros, es la fórmula escogida para el cálculo del resultado de la evaluación. Mientras que en unos casos se ha optado por considerar todos los indicadores como igualmente valiosos, en otros, se ponderan de forma diferente, dependiendo, por ejemplo, de si las informaciones son de carácter económico o de otra índole. También se pueden considerar sistemas más complejos, incorporando una doble puntuación que valora por una parte los aspectos cuantitativos y, por otra, los cualitativos, u otros.

\subsection{Características del sujeto estudiado}

También cabe plantearse si en una misma tipología de análisis es posible o si es necesario establecer diferencias. Este problema se plantea, por ejemplo, cuando se analizan las webs de los ayuntamientos, ya que algunos son grandes ciudades, mientras que otros son pequeñas poblaciones. En España, aunque la legislación no establece ninguna diferencia, muchos ayuntamientos de pequeñas dimensiones argumentan que sus escasos recursos les impiden cumplir completamente con la ley, pero no hay que olvidar que el derecho de acceso a la información es igual para todos los ciudadanos, independientemente de que residan en uno u otro municipio.

Sn embargo, en un momento aún inicial de aplicación de la ley (aunque recordemos, ya vigente) es posible plantearse algunos márgenes diferenciales, dado que las administraciones mayores no están 
cumpliendo completamente. La cuestión es en qué aspectos se pueden hacer estas diferencias, considerando tanto la dificultad de obtener los documentos como las dificultades de publicación y también otros como la necesidad u otras prioridades que se establezcan.

Todos los factores abordados en los puntos anteriores, determinan el procedimiento y su concreción debiera eliminar cualquier subjetivismo de apreciación de los evaluadores. Sin embargo, en la práctica hay elementos que interfieren en la evaluación. Así, los espacios analizados, generalmente páginas web, pueden ser muy diferentes entre ellos, con menús muy diversos, epígrafes confusos y ordenados con criterios particulares. Igualmente, cada una de las informaciones están publicadas en documentos diferentes con grados de precisión diversos, con otras características a veces difícilmente contrastables y en evolución permanente. Por esto es necesario contar con guías de evaluación lo más precisas posibles, formar a los equipos de evaluadores para que conozcan los problemas con que se van a enfrentar y establecer un control de calidad que dé uniformidad a los resultados.

También en relación a las webs, se observa a menudo que las informaciones son recluidas en espacios específicos denominados de transparencia, mientras que en otros, las informaciones pueden encontrarse en diferentes apartados. Se busca así que el conjunto del espacio de publicación sea un espacio de transparencia. ¿Debe ser esto valorado? ¿Es mejor una opción sobre a otra y debe esto afectar a la valoración o se trata de un aspecto tangencial que no debe considerarse ya que debe dejarse que la administración correspondiente decida qué opción le parece mejor?

En este contexto, los estudios sobre el uso de la web 2.0 por parte de las administraciones muestran que existen limitaciones importantes para su desarrollo relacionados con la falta de presupuesto y las limitaciones tecnológicas (Ganapati y Reddick, 2012).

\subsection{Acreditaciones}

Por último, hay que considerar la incidencia en el proceso de estímulos como los sellos o certificaciones de transparencia, que pueden mejorar la calidad puntualmente en los aspectos considerados. 
Muchas de las organizaciones evaluadoras otorgan algún tipo de reconocimiento $\mathrm{o}$, al menos, establecen rankings en función de las puntuaciones con los que también se espera estimular a las organizaciones evaluadas, especialmente en los casos en que las puntuaciones han sido bajas, esperando que esta comparativa negativa provoque cambios de comportamiento.

\section{Metodología Infoparticipa}

La metodología Infoparticipa se plantea como una auditoría cívica de la transparencia de las administraciones públicas. Hasta ahora se ha aplicado preferentemente a la evaluación de las administraciones locales de España pero también se han evaluado las páginas de los Consejos Comarcales y Diputaciones de Cataluña y municipios de Ecuador. Actualmente, se está extendiendo a otros países como Colombia o Argentina. El proyecto cuenta con una herramienta fundamental que es el Mapa Infoparticipa (www.infoparticipa.com).

Una vez planteadas todas las cuestiones abordadas en la primera parte, vamos a explicar de forma razonada las soluciones que aporta el procedimiento infoparticipa y los logros obtenidos hasta ahora. Situamos este trabajo en un planteamiento complejo porque surge en el ámbito académico pero contando con profesionales con experiencia en la comunicación de las administraciones públicas, que además se propone sumar a la perspectiva científica la voluntad de incidencia en el ámbito profesional, político y cívico.

\subsection{Orígenes y perspectiva}

El proyecto Infoparticipa surge antes de la aprobación en España de la ley de Transparencia estatal y de las normas autonómicas. Se planteó tras constatar que los estudios anteriores desarrollados por el propio equipo concluían siempre verificando que la información aportada por las administraciones públicas a la ciudadanía era insuficiente y deficiente. Además, las propuestas derivadas de estos estudios no se llevaban a la práctica porque la inexistencia de legislación que obligase a las administraciones a ser transparentes y a informar de sus planes y de cómo eran ejecutados, impedía un avance en ese sentido. Reiteradamente, las publicaciones, primero en papel y después 
utilizando medios digitales, eran utilizadas como medio propagandístico del poder en cada momento. Por tanto, era necesario un método que hiciera una contribución para mejorar la información y la comunicación públicas, que provocara reacciones y que a la vez ofreciera soluciones.

La respuesta a estos problemas se planteó atendiendo a dos dimensiones. En primer lugar, considerando que la investigación en Ciencias Sociales desarrollada en una universidad pública debe proporcionar soluciones innovadoras a los nuevos problemas sociales. En segundo lugar, atendiendo a la importancia de definir criterios de calidad en la información y la comunicación de las administraciones públicas para que puedan comportarse como fuentes de información transparentes que fundamenten la participación ciudadana.

Esta perspectiva se plasmó en el Mapa de las Buenas de la Comunicación Pública Local en Cataluña, una plataforma web compuesta por un gestor de contenidos y unas herramientas de visualización de la información, para que cualquier persona pudiera obtener la información sobre las evaluaciones, y de participación, para que pudieran ponerse en contacto con los responsables del proyecto y comunicar discrepancias, cuando fuera necesario.

Esa primera plataforma está en el origen del actual Mapa Infoparticipa y permitió evaluar las carencias y fortalezas del proyecto para detectar las modificaciones necesarias y actuar en consecuencia. En el año siguiente se formuló la primera versión del Mapa Infoparticipa y un año después se desarrolló la segunda versión, actualmente activa, para poder incorporar nuevas funcionalidades que permiten extender el proyecto a otros ámbitos y con una arquitectura flexible capaz de adaptarse a esas nuevas circunstancias.

\subsection{Procedimiento}

El procedimiento de evaluación consta de una relación de indicadores que en principio fueron 41 y actualmente 52. La primera relación, a falta de una legislación específica, se construyó partiendo de la Ley de Bases de Régimen Local (España, 1985), del Texto Refundido de la Ley Municipal y de Régimen Local de Cataluña (Cataluña, 2003), y con otros documentos como el Decálogo de Buenas Prácticas de la 
Comunicación Local Pública (Labcompublica, 2016). La segunda se ha basado en la legislación de transparencia estatal (España, 2013) y en parte de la catalana (Cataluña, 2014), mucho más exigente y de la que no se han recogido todas las obligaciones, ya que en la fase de desarrollo e implantación actual del proyecto, esto no parece posible ni deseable.

Los 41 indicadores utilizados en las evaluaciones de 2013, 2014 y 2015, se dividieron en 4 grupos: ¿quiénes son los representantes políticos?, ¿cómo gestionan los recursos colectivos?, ¿cómo informan de la gestión de los recursos colectivos? y ¿qué herramientas ofrecen para la participación ciudadana en el control democrático?

En 2016 y 2017 se han aplicado los 52 indicadores adaptados a la legislación, divididos en dos grupos y cinco subgrupos:

1. Transparencia de la corporación

1.1 ¿Quiénes son los representantes políticos?

1.2 ¿Cómo gestionan los recursos colectivos?

1.3 ¿Cómo gestionan los recursos económicos: presupuestos, salarios, contrataciones, subvenciones...?

2. Información para la participación

2.1 ¿Qué información proporcionan sobre el municipio y la gestión de los recursos colectivos?

2.2 ¿Qué herramientas ofrecen para la participación ciudadana?

La relación de indicadores puede consultarse en la web del Mapa. Además, también está disponible la guía de evaluación con los criterios que se aplican en la evaluación de cada indicador. Este documento se ha concebido y redactado pensando tanto en que los evaluadores cuenten con criterios homogéneos, como para que los responsables políticos y técnicos de las webs analizadas entiendan el procedimiento y sepan cuáles son los criterios con los que serán evaluados, y que también cualquier ciudadano, partido político o entidad cívica pueda contrastar los datos de la evaluación con sus apreciaciones. Así, cada indicador se desarrolla en la guía en tres apartados: (a) información, temática y contenido; (b) ubicación o espacio de la web donde debe 
aparecer; y (c) Recomendaciones. En los dos primeros apartados se detallan los aspectos correspondientes, sin determinar una norma única, ya que cada web puede ser diferente en cuanto a su estructura, diseño y otras características. En el tercer apartado se dan algunas sugerencias de calidad de la información. Estos criterios muestran que la metodología no es exclusivamente de tipo cuantitativo sino que se incorporan principios de calidad de la información, entre los que destacan por su importancia que la información ha de ser comprensible y fácilmente accesible. La guía de evaluación se ha ido actualizando, además de para adaptarla al cambio de indicadores en 2015, para mejorar la redacción y para profundizar en algunos aspectos cualitativos, ya que el nivel de exigencia se ha ido elevando.

Contando con estos documentos, los evaluadores analizan las páginas web e introducen los datos en la plataforma utilizando el gestor de contenidos. En la última versión del Mapa se ha incorporado una herramienta para que antes de que los datos sean publicados sean contrastados por una persona experta que hace un control de calidad de la evaluación. Este control puede ser positivo, y entonces la evaluación se publica automáticamente, o puede mostrar discrepancias originadas por diferentes motivos, muchas veces relacionados con la deficiente estructura de las páginas web que impide localizar las informaciones con facilidad o con las características con que las informaciones se publican, que en cada caso son diferentes, de forma que los evaluadores han de valorar si se valida o no el indicador correspondiente. Este control de las evaluaciones no solo mejora la calidad del resultado final, también es un mecanismo que contribuye a formar a los nuevos evaluadores y que genera un proceso de reflexión sobre la casuística.

Una vez validadas las evaluaciones, los resultados se publican georreferenciados en la plataforma web. Sobre el Mapa se sitúa automáticamente una marca gráfica en la localización del municipio con un color definido en una herramienta a la que hemos llamado "Infómetro". El color gris identifica los ayuntamiento que no tienen página web, el blanco a los que han obtenido una evaluación inferior al $25 \%$, el amarillo, a los que están entre el 25 y el 50\%, el verde claro a los que tienen más del 50\% y el verde oscuro a los que superan el 75\%. Además, la marca de los ayuntamientos que han obtenido el Sello 
Infoparticipa tiene una señal en rojo para destacarlos. Todos los indicadores tienen el mismos valor y, por tanto, el porcentaje final indica el de indicadores validados.

Pinchando sobre la marca del municipio se accede a la información sobre su resultado global, en una primera ventana y, en una segunda ventana, al conjunto de la evaluación, indicador a indicador. Estas publicaciones geolocalizadas consiguen despertar interés y competencia en los responsables técnicos y políticos de los ayuntamientos, de forma que incentivan las mejoras.

Además, se comunican los resultados a los ayuntamientos evaluados, se contrastan y verifican y luego se publican informes de resultados por grupos de municipios de una misma comunidad autónoma que se envían también a los medios de comunicación. Esta estrategia de comunicación lleva los resultados hasta las personas responsables en las instituciones, así como hasta los partidos políticos, entidades cívicas y ciudadanía en general. De forma que se producen reacciones e intervenciones que provocan cambios en la información disponible en la web y alienta un diálogo de todos estos colectivos con el equipo investigador.

Las mejoras que se hacen en las webs, cuando son comunicadas al equipo del proyecto, son comprobadas de nuevo para verificar que se ajustan a los criterios de la evaluación y si es así son validadas y se actualizan los datos en la base de datos para que el nuevo resultado aparezca también en el mapa. En caso contrario, se comunica al ayuntamiento cuales son las deficiencias que impiden la validación, tanto como consecuencia de una insuficiente información como de deficiencias en los criterios cualitativos.

El elemento final de la estrategia de incentivación es la concesión de sellos de calidad a los ayuntamientos que mejor cumplen con los criterios. El sello es un reconocimiento anual que se otorga en forma de diploma impreso y de banner que las entidades pueden poner en sus páginas web. Se otorga por comunidades autónomas y hasta ahora se ha dado en Cataluña, Aragón y Murcia.

Para la entrega del Sello Infoparticipa se tiene en cuenta que los ayuntamientos mayores tienen más recursos para aplicar la Ley, por lo que se les exige un porcentaje de cumplimiento mayor que a los más 
pequeños. Las tablas con los porcentajes necesarios, en función del número de habitantes de los municipios y las fechas de cierre de oleada anual para su concesión están también disponibles en la plataforma.

\section{Conclusiones}

La evaluación de la transparencia analizando los contenidos publicados en las páginas electrónicas de las administraciones es una cuestión compleja. Por una parte, requiere analizar múltiples informaciones con características diferentes, ya que provienen de ámbitos especializados como el económico y laboral, del sector de la comunicación, de las diferentes áreas de gobierno, etc. Esta dificultad afecta a la metodología y a la capacitación de los evaluadores. El procedimiento ha de ser capar de definir con precisión las características con que se ha de ofrecer la información relativa a cada indicador para ser validado. Estas características no son solo técnicas y formales, sino que han de considerar otras cualidades de la transparencia como la inteligibilidad de las informaciones y la facilidad de acceso.

Por otra parte, como hemos visto, la metodología será diferente según cuáles sean los objetivos generales y operativos concretos y la definición de transparencia de la que se parta, los destinatarios prioritarios del análisis, el sujeto estudiado, así como el carácter de la misma, es decir, si es concebida estrictamente desde la perspectiva jurídica y legal o si se suman a esta otras relativas a derechos y valores.

Resueltas estas cuestiones, aún se debe determinar si el procedimiento es predominante cuantitativo o mixto cuantitativo-cualitativo y el sistema de valoración-medición. Por último, hay que considerar en qué medida las fórmulas que incentivan las mejoras tras las evaluaciones condicionan el procedimiento.

En este momento se están utilizando diferentes sistemas de evaluación. Hemos descrito específicamente uno de ellos, el del proyecto Infoparticipa, que utiliza una metodología compleja y que se propone intervenir, es decir, conseguir que una evaluación académica trascienda del campo de la investigación para ser un referente de utilidad social. Este procedimiento, sustentado en herramientas innovadoras, ha conseguido establecer un mapa de la transparencia de las administraciones locales en España y ser un referente para políticos, 
técnicos y organizaciones sociales. Desde 2016, el proyecto se ha extendido a Ecuador y se está comenzando a implantar en otros países.

Las características de la metodología Infoparticipa y los resultados obtenidos (Moreno, Molina, Simelio, 2017) muestran su utilidad en los diferentes ámbitos descritos, a pesar de que la falta de una cultura de transparencia en España lastra el imprescindible cambio en las actitudes y está retardando, no solo la aplicación de la Ley, sino fundamentalmente la implantación de las prácticas que garanticen el derecho de la ciudadanía a la información como base para la participación fundamentada.

*Investigación financiada. Este artículo es producto del proyecto de Investigación titulado "Metodologías y modelos de información para el seguimiento de la acción de los responsables de los gobiernos locales y la rendición de cuentas", referencia CSO2015-64568-R, financiado por la Secretaria de Estado de Investigación, Desarrollo e Innovación, del Ministerio de Economía y Competitividad y el Fondo Europeo de Desarrollo Regional (FEDER), dentro del Programa Estatal de Investigación, Desarrollo e Innovación Orientada a los Retos de la Sociedad.

\section{Bibliografía}

TB Anderson (2009): "E-government as an anti-corruption strategy". Information Economics and Policy, 21, pp. 201-210.

P Beltrán-Orenes \& E Martínez-Pastor (2016): "Grado de cumplimiento de las Leyes de transparencia, acceso y buen gobierno, y de reutilización de los datos de contratación de la Administración central española". El profesional de la información, 25 (4), pp. 557-567. http://dx.doi.org/10.3145/epi.2016.jul.05

JC Bertot, PT Jaeger \& JM Grimes (2010): “Using ICTs to create a culture of transparency: E-government and social media as openness and anti-corruption tools for societies". Government Information Quarterly, 27(3) , pp. 264-271

JC Bertot, PT Jaeger \& JM Grimes (2012): "Promoting transparency and accountability through ICTs, social media, and collaborative egovernment". Transforming Government: People, Process and Policy, 6(1), pp. 78-91.

W Cameron (2004): "Public accountability: Effectiveness, equity, ethics". Australian Journal of Public Administration, 63(4), pp. 56-67. 
Catalunya (2003): “Texto refundido de la Ley Municipal y de Régimen Local de Cataluña". Diari Oficial de la Generalitat de Catalunya, 3.887, 20 de mayo, p. 10.237.

Cataluña (2014): "Llei 19/2014, del 29 de desembre, de transparència, accés a la informació pública i bon Govern'. Diari Oficial de la Generalitat de Catalunya, 6.780, sección disposiciones, pp.1-38.

COMISIÓN EUROPEA (2001): "La Gobernanza europea - un libro blanco". Diario Oficial de las Comunidades Europeas [En línea]. 428 final, DOCE C-287, de 12 de noviembre de 2001. < http:/ / eurlex.europa.eu/legalcontent/ES/TXT/PDF/?uri=CELEX:52001DC0428\&rid=1>.

Consejo de Transparencia y Buen Gobierno (2017): Informe de evaluación de los órganos constitucionales y reguladores. Órganos constitucionales y de relevancia constitucional y entes reguladores. Madrid: Consejo de Transparencia y Buen Gobierno < file://C:/Users/Pedro/Downloads/Informe1704def petit $\% 20(1) \cdot \mathrm{pdf}>$

España (2008): "Ley 7/1985, de 2 de abril, Reguladora de las Bases de Régimen Local". Boletin Oficial del Estado, 80, 3 de abril, pp. 89458964

España (2013): "Ley 19/2013, de 9 de diciembre, de transparencia, acceso a la Información pública y buen gobierno". Boletin Oficial del Estado, 295, 10 diciembre, pp. 97922-97952.

EUROPEAN COMISSION (2010): Europe 2020. A strategy for smart, sustainable and inclusive growth. Brussels: European Comission.

LC Fernández-Aquino (2009): E-accesibilidad y usabilidad de contenidos digitales. Por una sociedad de la información y el conocimiento no excluyente. Universitat Politècnica de València. Tesis Doctoral.

S Ganapati \& C Reddick (2012): "Open e-government in U.S. state governments: Survey evidence from Chief Information Officers". Government Information Quarterly, 29(2), pp.115-122

JL Gandía, L Marrahí \& D Huget (2016): "Digital transparency and Web 2.0 in Spanish city councils". Government Information Quarterly, 33, pp. 28-39.

A Garrido, G Ross, N Medina, J Grigera \& S Frimenich (2014): "Improving accessibility of web interface: refactoring to the rescue". Universal Access in the Information Society, 14(4), pp. 387-399. 
M Gértrudix, MC Gertrudis-Casado, \& S Álvarez-García (2016): "Consumption of public institutions' open data by Spanish citizens". El profesional de la información, 25, 4, pp. 535-544.

S Hong, S Trimi, D Kym \& J Hyun (2015): “A Delphi Study of Factors Hindering Web Accessibility for Persons with Disabilities". Journal of Computer Information System, 55(4), pp. 28-34.

Labcompublica (2016) Decálogo de Buenas Prácticas de la Comunicación Pública Local. http:/ / labcompublica.info/es/innovacion/decalogode-buenas-practicas/

P Minguijón \& D Pac-Salas (2012): “15M. Una explicación en clave sociológica”. Prisma social. Revista de Ciencias Sociales, 8: pp. 414-439.

A Moreno Sardà, P Molina Rodríguez-Navas \& N Simelio Solà (2017): "El impacto de la legislación sobre transparencia en la información publicada por las administraciones locales". El profesional de la información, vol. 26, núm. 2.

N Simelio \& P Molina (2014): "Comunicación política y participación ciudadana. El uso de Twitter en los ayuntamientos de Cataluña”. Historia y Comunicación Social, 19, 479-490.

Síndic de Greuges de Catalunya (2016): Informe sobre transparencia, acceso a la información pública y buen gobierno. Julio 2016. Síndic de Greuges, disponible en http://www.sindic.cat/es/page.asp?id=356

UNITED NATIONS (2000): 55/2. United Nations Millennium Declaration. A/RES/55/2 [En línea]. New York: United Nations, General Assembly, 8 de septiembre de 2000. $<$ http://www.un.org/millennium/declaration/ares552e.htm>.

Cómo citar: Molina Rodríguez-Navas P, et al (2017): “Metodologías de evaluación de la transparencia: procedimientos y problemas". Revista Latina de Comunicación Social, 72, pp. 818 a 831. http://www.revistalatinacs.org/072paper/1194/44es.html DOI: $10.4185 /$ RLCS-2017-1194 
Cómo citar: Manfredi Sánchez JL, et al (2017): “Transparencia y diplomacia: nuevas demandas sociales y rutinas profesionales". Revista Latina de Comunicación Social, 72, pp. 832 a 848.

http://www.revistalatinacs.org/072paper/1195/45es.html

DOI: $10.4185 /$ RLCS-2017-1195

\title{
3
}

\section{Transparencia y diplomacia: nuevas demandas sociales y rutinas profesionales}

Juan Luis Manfredi Sánchez - Universidad de Castilla-La Mancha juan.manfredi@uclm.es

José María Herranz de la Casa - Universidad de Castilla-La

Mancha Josemaria.herranz@uclm.es

Luis Mauricio Calvo Rubio - Universidad de Castilla-La Mancha Luismauricio.calvo@alu.uclm.es

\begin{abstract}
s
Introducción. Se analiza el impacto de las nuevas demandas de transparencia en la diplomacia. Metodología. Se estudian los tres niveles de gestión de la información diplomática y cómo les afecta la demanda de transparencia ciudadana. Mediante un análisis descriptivo se evalúa el nivel de transparencia en base a los fundamentos de la Open Government Partnership (OGP), se enumeran las tensiones a las que se somete la labor diplomática y se ofrecen aportaciones prácticas de actores internacionales. Resultados y conclusiones. Los resultados evidencian que no puede validarse un modelo único para evaluar la transparencia en materia diplomática pues se encuentra vinculada a los valores, usos y cultura política en la que está inmerso cada actor implicado. La transparencia no es solo un paradigma legal,
\end{abstract}


sino que ha de fomentarse una cultura que permita adaptar la rendición de cuentas a las particularidades de la gestión de los asuntos globales.

\section{Keywords}

diplomacia; transparencia; globalización; comunicación internacional; ciudadanía.

\section{Contents}

1. Introducción. 2. Metodología. 3. Diplomacia y transparencia. 3.1. Tres niveles de gestión de la información diplomática. 3.2. La creciente demanda de transparencia en materia de diplomacia. 3.3. Riesgos de la transparencia en diplomacia. 4. Resultados. 5. Referencias bibliográficas.

\section{Introducción}

T OS asuntos globales están en la agenda política, mediática y 1 ciudadana. Ha crecido el interés en la medida en que estas cuestiones tienen impacto en la política nacional: el control de fronteras y las migraciones, las importaciones y el proteccionismo, las movilizaciones sociales y la protesta, las acciones contra el cambio climático, la desigualdad, las migraciones y las aglomeraciones urbanas, las pandemias o el uso de las tecnologías digitales (US Departament of State, 2015). Asimismo, nuevos actores de la sociedad internacional compiten en la arena pública por la legitimidad, la atracción y la colaboración/competencia (Mogensen, 2017). En suma, encontramos un escenario global con más actores, más intereses y más instrumentos de poder. La diplomacia en red se organiza bajo tres principios: transparencia, instantaneidad y la interacción en tiempo real (Manfredi, 2016).

En paralelo, la transparencia en los procesos de toma de decisiones, la evaluación de las políticas públicas y la gestión de la información pública se han naturalizado (Villoria, 2016). El desarrollo de los derechos de ciudadanía requiere el acceso a la información, por lo que el Estado tiene que dotar de los instrumentos que asegure tal ejercicio ciudadano. A través de organizaciones no gubernamentales (Transparencia Internacional, Access Info, Sunlight Foundation) e instituciones (Corte Interamericana de Derechos Humanos, consejos 
nacionales de transparencia), se ha articulado la difusión de información pública y se ha construido el derecho de ciudadanía que le acompaña (Guichot, 2014). La demanda de transparencia se ha extendido hacia organizaciones privadas en forma de rendición de cuentas, cumplimiento normativo (Gimeno, 2016), reputación (Cachinero, 2017) y responsabilidad corporativa (Den Hond, Rehbein, De Bakker y Kooijmans-Van Lankveld, 2014).

La suma de cambios estructurales anima a investigar qué impacto tiene la transparencia en la política exterior, en concreto, en la diplomacia. En este momento, se refleja como un conjunto de normas antes que como una cultura que afecta a la actividad diplomática. Se discute cómo conjugar la demanda de más transparencia y la instantaneidad informativa con los tiempos, las cesiones y la discreción que requieren una negociación multilateral. En los sistemas democráticos, este proceso aún se acelera más porque se exige a los líderes políticos que utilicen los medios sociales para explicar los acontecimientos y no se ciñan en exclusiva a los usos parlamentarios. Esta tendencia ha acrecentado el valor la comunicación estratégica en la comunicación institucional (Canel, 2007).

Esta transformación genera tensiones dentro de los propios gobiernos y de éstos con sus aliados por cuanto cada actor considera distintos grados de información en tanto que afectan a sus intereses principales. La transparencia no es un valor absoluto, sino asimétrico, condicionado por los propios valores, usos y cultura política (Lord, 2006).

Dos ámbitos concretos afectan especialmente al diseño de la diplomacia bajo el paradigma de la transparencia. El primer nivel epistemológico se construye en la relación con los medios informativos y otros instrumentos de comunicación. Se conoce el uso de la diplomacia mediada a través del periodismo convencional, la diplomacia intermediada que fomenta acciones con terceros y la diplomacia pública que administra la influencia (Gilboa, 2001). En esta cota, el escrutinio es diario por lo que se requieren nuevos métodos y procedimientos para la comunicación estratégica. La presencia en Twitter de un primer ministro o un canciller ya no es noticia, sino su capacidad de responder a las crisis, persuadir a los periodistas o interactuar con los públicos. 
El segundo nivel es la consolidación del entorno digital como ámbito específico de influencia en el que se defienden los intereses. La digitalización de la comunicación política internacional y la agregación de nuevos actores "han afectado a la agenda pública, al activismo y a la participación política en la arena internacional" (Manfredi, 2014: 343). Para Del Fresno, Daly y Segado (2016), los nuevos influyentes en medios sociales son diseminadores de información, conectores que relacionan distintos nodos de la red, o bien líderes que tienen capacidad de actuar por sí solos. Aplicado al ámbito diplomático, conviene saber si el actor internacional persigue fines de difusión y propaganda, de creación de capital relacional o bien prefiere la imposición unilateral.

En este contexto, el propósito de este artículo es la demostración de dos hipótesis:

La diplomacia se enfrenta a tres niveles de gestión de la información que no pueden asimilar los principios de transparencia con la misma naturalidad que otras áreas de la administración pública. La rendición de cuentas tiene que adaptarse a la particularidad de los asuntos globales.

La transparencia genera nuevos riesgos para la profesión diplomática. Se produce una asimetría en la conceptualización y la gestión de la información frente a nuevos actores de la sociedad internacional que utilizan la opacidad en beneficio propio.

El trabajo revisa la bibliografía reciente, explora los usos y los comportamientos de los líderes internacionales, indica las prácticas de las cancillerías, señala las tensiones del sistema y anuncia nuevos problemas de estudio. Se abren avenidas de investigación en los siguientes ámbitos: el empleo de Twitter como amplificador de la política exterior del presidente Trump, el modo de negociación de los tratados internacionales para ganar la legitimidad social (TTIP y CETA), los límites de la privacidad en redes sociales o la economía política de las alianzas contra la delincuencia digital.

\section{Método}

El estudio de la diplomacia ha encontrado en la comunicación política internacional un marco de interpretación de la realidad y del comportamiento de sus actores. Pero el Estado nación westfaliano no 
está solo en la arena internacional. La comunicación más allá de las fronteras propias vertebra la forma, la función y la ilusión de participar de manera activa en el proceso de toma de posiciones por parte de quienes no tienen las competencias propias asignadas por el derecho internacional (Hocking, 2006). La multiplicidad de fuentes de legitimación, participación y comunicación confirman la teoría de una diplomacia red que emplea técnicas de guerrilla para colocar sus mensajes y vehicular sus preferencias (Copeland, 2009). Cualquier actor con capacidad de obrar en la esfera internacional participa de hecho dentro y fuera de los círculos convencionales de acción diplomática, política y comunicativa. Anker (2017) analiza cómo las empresas multinacionales (Pepsi, Coca Cola o Vodafone) apoyaron las revueltas de la Primavera Árabe con el ánimo de alinear sus valores corporativos con la demanda de democracia. Scherer y Palazzo (2011) califican tales actividades como las propias de quienes son agentes políticos de la globalización.

En el ámbito público, el interés por participar y ofrecer a la opinión pública la mejor visión posible de sí mismos ha llevado a la creación de oficinas con esta tarea específica (London First, 2017), comisionados (el Real Decreto 998/2012, de 28 de junio, crea el Alto Comisionado del Gobierno para la Marca España), equipos dedicados a diplomacia digital (@ranceDiplo), el desarrollo de nuevos programas de intercambio (Japan Exchange and Teaching Programme) o la promoción de la imagen país a través de grandes eventos deportivos (Jarvie, Murray y Macdonald, 2017). Cada uno diseña su estrategia de información, educación y entretenimiento que tiene como objetivo el ejercicio de la influencia sobre un público extranjero. La comunicación política internacional crea contextos y significados que sirven de fundamento al conocimiento de la causa, sea el apoyo a un tratado, la defensa de los derechos humanos, medidas para el control migratorio o la promoción de negocios internacionales (Macnamara, 2011).

En el plano de la comunicación internacional, el debate sobre el efecto CNN ha quedado atrás. La televisión y la política internacional se retroalimentan tanto en el diseño de las operaciones como en la determinación de cuáles son los asuntos críticos para la opinión pública. Por este motivo, la diplomacia en el ámbito digital está en auge. Esta conjetura encuentra acomodo en la obra de Castells (2008:13), 
cuando señala que "las relaciones de poder, es decir, las relaciones que constituyen los fundamentos de toda sociedad, además de los procesos que desafían las relaciones de poder institucionalizadas, se determinan y deciden cada vez más en el campo de la comunicación".

Internet y los nuevos medios promocionan la diplomacia en tiempo real, que es una condición ajena a su conducta histórica (Seib, 2012). El tiempo real reduce la reflexión, afecta a la privacidad de las comunicaciones y transforma las competencias profesionales del diplomático. El uso intensivo de las aplicaciones propias de Internet y los nuevos medios con la finalidad de alcanzar los objetivos diplomáticos convencionales afecta a la relación con la prensa internacional, al catálogo de servicios consulares y a la gestión de la influencia.

Los nuevos medios, los dispositivos móviles y las tecnologías crean campañas más globales en términos de audiencia y más baratas en cuanto a su producción. Castelló, Etter y Årup Nielsen (2016) describen las estrategias de legitimidad empleadas por las corporaciones a través de plataformas digitales abiertas, no monopolizadas, sino dispuestas para la colaboración. No es tarea sencilla, en tanto que existe una brecha entre estos medios digitales y los convencionales, tanto en el framing como en la recepción de las audiencias (Qin, 2015). Si la comunicación es ahora digital, tiene sentido que se produzca la extensión natural de la diplomacia hacia la esfera digital (Manfredi, 2014).

El presente trabajo es un análisis descriptivo. El grado de transparencia de la información que se emplea para la consecución de los fines diplomáticos es el eje de nuestro estudio. Interesa conocer cómo se administra la información y se comunica con los distintos públicos. Analiza las dimensiones de la transparencia en el ejercicio de la diplomacia y cómo ésta ha transformado algunas prácticas.

No existe un corpus legal de transparencia en asuntos diplomáticos, por lo que hemos de recurrir a otros indicadores de actividad. Interesa aquí la idea de transparencia que desarrolla la Open Government Partnership (OGP) que vincula ésta con los principios de la participación, la rendición de cuentas y la innovación tecnológica. La alianza OGP promueve planes nacionales en más de 75 países a favor de la transparencia, la participación ciudadana y la mejora de la 
gobernanza. Utilizaremos sus fundamentos para comprender el comportamiento de los actores y razonar el nivel de transparencia alcanzado, pues consideramos que son más adecuados para categorizar el impacto en la diplomacia en la medida en que éste depende de la cultura política nacional y la tradición antes que de la legislación comparada. Los principios conforman valores, propuestas, plataformas, no reglamentos. Aquí somos partidarios de entender la transparencia como una cultura, y no solo como un paradigma legal.

En relación con los contenidos, el texto no valora los objetivos políticos de los ejemplos mencionados, sino el impacto y el cómo se interpretan en el marco conceptual de la transparencia informativa. La cuestión está en ver si contribuyen a conseguir los objetivos de la política exterior o bien los dificulta.

La investigación se estructura de la siguiente manera. En primer lugar, se estudian los tres niveles de gestión de la información diplomática que se plantean en la primera hipótesis. La naturaleza secreta, reservada o pública de la información plantea escenarios de comunicación estratégica y relaciones específicas con los periodistas y las redes sociales. Se atiende a los distintos actores, su actividad y su relación con los mensajes diplomáticos. A continuación, se analiza cómo afecta la demanda de transparencia a una actividad de naturaleza compleja como es la diplomacia. Una actividad profesional que es propia de los gobernantes, nace en un marco de confidencialidad y se transparenta por las transformaciones del entorno. Cabe preguntarse cómo y cuánta transparencia puede soportar una reunión multilateral, una negociación o un acuerdo comercial.

Por último, se enumeran las tensiones propias de la profesión diplomática y la gestión de la transparencia. Se completa el texto con la muestra de las principales aportaciones prácticas diplomáticas diseñadas y ejecutadas por los actores internacionales. Se cierra el artículo con las principales conclusiones y con una serie de retos futuros de investigación.

\section{Diplomacia y transparencia}

La diplomacia consiste en la dirección y la ejecución de las relaciones internacionales por parte de Estados reconocidos y, en un sentido más 
amplio, de actores con capacidad de obrar en la esfera internacional. Esta labor se basa en una serie de normas, reglamentos, costumbres y usos que han moldeado las relaciones internacionales (Berridge, 2015). En perspectiva histórica, la diplomacia fue una actividad reservada a los dirigentes y las elites políticas, pues la opinión pública no mostraba excesivo interés en la gestión de las cuestiones internacionales. Es conocida la cita de Harold Nicolson (1939): "En la edad de la vieja Diplomacia se habría observado como un acto de vulgaridad apelar a la ciudadanía para tratar los asuntos de política internacional" [In the days of the old diplomacy it would have been regarded as an act of unthinkable vulgarity to appeal to the common people upon any issue of international policy]. Pero esta separación entre la política internacional y actividad local ha cambiado.

La diplomacia es una actividad que emplea la comunicación estratégica en el proceso de construcción de la realidad internacional. Se ha conformado un caudal de información y conocimiento que integran el acervo diplomático en esta materia (Kurbalija, 1999). Corneliu Bjola (2015) entiende la diplomacia como una forma de conocimiento, de revelación de los acontecimientos internacionales a través de hechos que suceden de forma no continuada o no lineal, que no son previsibles. Las reacciones se aprenden y se imitan. Los medios de comunicación, sobre todo la televisión global, ha acelerado el proceso de mímesis a escala macro. En la ciudadanía, el uso intensivo de dispositivos tecnológicos repite el efecto a escala micro.

El nuevo conocimiento adquirido crea condiciones epistémicas para la comunidad internacional que aprende -y desaprende- a crear nuevos mapas cognitivos. La diplomacia cultural fue la primera actividad convenida para el intercambio amistoso de información, costumbres y bienes y servicios culturales. Las actividades educativas e intelectuales conectan sociedades, no gobiernos, de modo que crean la confianza internacional previa que se necesita antes de las relaciones gubernamentales (Rivera, 2015). Ahora bien, la perversión del uso cultural e informativo es la extensión de la propaganda, cuya finalidad es influir en la opinión pública extranjera sin reconocimiento expreso del gobierno. El crecimiento de la transparencia no ha disminuido el efecto de la propaganda en sociedades con menores índices de confianza social. El diseño de una comunicación internacional 
articulada a través de una canal de televisión internacional, campañas de redes sociales, contenidos específicos para Youtube y el despliegue de nuevos formatos audiovisuales ha convertido a la propaganda rusa en el motor de esta actividad (Estrella, 2016).

La comunicación política internacional es, pues, una de las cuestiones fundamentales para el estudio de la diplomacia contemporánea. De acuerdo con la Convención de Viena sobre Relaciones Diplomáticas (1961), la recogida de información sobre los acontecimientos locales por medios lícitos y su transmisión, y el fomento de las relaciones amistosas son dos de las funciones básicas de la actividad diplomática, junto con la representación del Estado, la protección de los intereses y la negociación ante los gobiernos. Conviene estudiar qué efectos tiene la transparencia en el ejercicio de estas funciones.

\subsection{Tres niveles de gestión de la información diplomática}

La comunicación estratégica se compone del manejo de la información y la gestión del conocimiento mediante instrumentos que moldean la realidad y que dan formato a las prácticas y los usos internacionales. Se ordena en tres niveles, en función del rol del emisor en su relación con los públicos extranjeros y la audiencia a la que se dirige el mensaje.

Los asuntos de seguridad y la inteligencia componen información confidencial. No se comparte porque conforma la capacidad de obrar en el exterior, explica las capacidades militares, genera ventajas competitivas significativas y asegura la fiabilidad de las fuentes. En este punto, apenas ha habido cesión voluntaria de información. Este primer nivel encaja en la tradición diplomática moderna, vinculada a la creación del Estado y protectora de los grandes intereses. Colson (2008) considera que el paradigma de la negociación es el secreto, la única vía para proteger los intereses propios. Al mismo tiempo, la negociación es exitosa cuando averigua los secretos de terceras partes. Se plantea como un juego de suma cero.

A menudo, se cita en la construcción europea la necesidad de compartir información relativa a la seguridad y la defensa. No han tenido éxito las iniciativas impulsadas con este fin entre los servicios secretos. La tecnología, en cambio, ha permitido el incremento de las filtraciones masivas, bien sea a través de Wikileaks o bien mediante los documentos 
de la National Security Agency (NSA) revelados por Edward Snowden. En esta categoría sorprende el exceso de sinceridad del presidente Donald Trump cuando utiliza su canal de Twitter para compartir información confidencial de sus reuniones. Es un uso anómalo porque desorienta a sus propios equipos de trabajo. El contenido de la reunión entre Donald Trump y Sergei Lavrov, el Ministro de Asuntos Exteriores de Rusia, fue desmentido en sala de prensa, confirmado por los interesados y tuiteada por el propio Trump en solo unas horas (Trump 'shared classified information with Russia', 2007).

En la actualidad, la inteligencia ha volcado sus esfuerzos en el área económica como el método para la captación y el análisis de la información relacionada con la internacionalización de la economía y la empresa. Tiene un doble uso en tanto que promueve la competitividad como la gestación de alianzas para conseguir contratos, licitaciones, clientes. Okano-Heijmans (2011) ha enumerado los aspectos económicos de la política exterior, sobre todo, de los países occidentales. Éstos han comprendido el peso de la actividad económica y comercial ante la actual crisis fiscal, el aumento de la competencia, la emergencia del capitalismo de Estado, la demanda de transparencia en las organizaciones multilaterales o la revisión de las políticas orientadas a resultados concretos.

Siguiendo los principios de Open Government Partnership, la función inteligencia no puede regirse con los criterios de transparencia de la administración. En cambio, sí es factible elaborar una regulación que facilite la rendición pública de cuentas y mecanismos que actúen de contrapeso. La evaluación ex posty la justificación de las acciones traen consigo riesgos de arbitrariedad, salvo que se articulen las faltas contra el cumplimiento efectivo de las leyes o los compromisos adquiridos.

La información elaborada por los profesionales diplomáticos suele ser de naturaleza reservada. Las rutinas de trabajo incluyen las notas verbales o los informes que envían las misiones en el exterior a la sede central del Ministerio. Leídos numerosos cables diplomáticos difundidos por Wikileaks, éstos se revelan como instrumentos para comprender la realidad de un país, el estado de la economía local, la capacidad de obrar de un gobierno o la emergencia de nuevos líderes políticos a los que conviene tener en cuenta (Bergareche, 2012). 
Marcus Holmes (2015: 24) señala las relaciones personales, la vía burocrática, el contacto individual, la capacidad cognitiva o la comunicación intercultural como parte de las rutinas. En estos casos, el compendio de conocimiento creado por el diplomático sobre el terreno es de naturaleza reservada. Escobar (2016: 46) cree que "en el ámbito político, y en ciertas cuestiones, siempre será necesaria la confidencialidad para garantizar la propia capacidad de interlocución y de acción del diplomático". La reserva es cada vez más compleja porque la diplomacia en red requiere el contacto con profesionales digitales, áreas de trabajo con intereses contrapuestos, tecnologías abiertas y otras dinámicas de trabajo.

Richard Haass (2010), presidente del Council on Foreign Relations, considera que la confianza no se sustenta sólo sobre la transparencia de las conversaciones privadas: "el secreto concede el contexto para la inocencia. La gente puede participar y compartir sus impresiones con honestidad, pueden elevar recomendaciones incluso si éstas resultan controvertidas, solo si alguna vez fuera reveladas" [Secrecy provides a context for candor. It means that people can share their honest impressions, they can make recommendations even if the recommendations might be controversial if they ever saw the light of day]. Para Camilleri (2011), la reserva construye la confianza entre las partes, ya que de otro modo se reduciría la sinceridad, el alcance de los comentarios, la calidad de la información recogida por los diplomáticos directamente de las fuentes y enviada al propio ministerio.

El impacto de las tecnologías, por su inmediatez y visibilidad, ha transformado la actividad profesional del diplomático. No se elabora el mismo producto informativo de estado de la situación cuando la televisión global ofrece emisiones en tiempo real sobre las manifestaciones en la Plaza Tahir de El Cairo, en el Maidan ucraniano o las calles de Hong Kong. El informe que elabora el diplomático es distinto: apenas informa de novedades, sino que interpreta, ofrece una visión a largo plazo, vincula los acontecimientos al propósito de la misión en el exterior. Tom Fletcher (2016), antiguo Embajador del Reino Unido en Líbano, habla de "diplomacia desnuda" porque ha transparentado los objetivos, los medios y los instrumentos. La desnudez afecta tanto a la vida profesional como a la pública. Los diplomáticos no pueden construir su actividad digital sobre la idea de 
“es una opinión personal”. López (2015) explica el caso del diplomático español Juan Carlos Gafo (@jcgafo), quien dimitió de su cargo por publicar un comentario de actualidad política. Gafo pidió disculpas, pero no ha vuelto a las redes sociales con perfil público.

En este nuevo escenario, destaca el apoyo en las herramientas digitales (blog y Twitter) como vehículos preferentes de comunicación. Esto requiere al diplomático la adquisición de nuevas competencias adaptadas al entorno digital y con una fuerte actividad comunicativa con el objeto de conjugar la demanda de información transparente en tiempo real con la negociación diplomática. Para Adler-Nissen (2016):

La personalización y la popularización de la diplomacia vinculada con la emergencia de las nuevas tecnologías de la información y la reclamación de más transparencia en la política mundial ha provocado que la agenda diplomática sea más visible; así se requieren habilidades adicionales y creativas en tanto que los diplomáticos interactúan de modo más proactivo e informal con un mayor rango de públicos transnacionales. (p. 101)

Tabla 1. Cuenta personal de líderes globales con más seguidores (2016)

\begin{tabular}{|l|l|l|}
\hline Cuenta & País & Seguidores \\
\hline @ barackobama & Estados Unidos & 78 millones \\
\hline @ pontifex & Vaticano & 31 millones \\
\hline @ narendramodi & India & 24 millones \\
\hline @realdonaldtrump & Estados Unidos & 13 millones \\
\hline$@$ rt_erdorgan & Turquía & 9 millones \\
\hline
\end{tabular}

Fuente: Twiplomacy (2016)

Entre los diplomáticos, destacan Carl Bildt en su etapa como Ministro de Asuntos Exteriores de Suecia (2006-2014), cuyo blog está activo desde 2005; Alexander Stubb, que mantuvo la cuenta de Twitter bajo gestión personal y un programa en podcast durante su etapa como primer ministro de Finlandia (2014-2015); el presidente de la República de Irán Hassan Rouhani (2013-), que empleó las redes sociales para comentar las negociaciones de Ginebra, o la diplomacia vaticana bajo el Papado de Francisco (2013-), que lidera el número de seguidores en la red social Twitter. El liderazgo digital genera un efecto paraguas: cuando el dirigente participa, el resto de actores de primer nivel sigue 
la estela. La participación real es más efectiva que el mensaje mismo. Un post del blog de Bildt o un tuit de Francisco llega más lejos y a un público más diverso que el uso de los canales convencionales de comunicación internacional.

En el ámbito de los ministerios, la presencia en redes sociales se ha disparado. Desde 2015, hay registro de más de 4.000 perfiles en redes sociales vinculados a embajadas, ministerios de Exteriores y otras instituciones de naturaleza similar (Twiplomacy Study, 2015)

El enfoque de la actividad digital responde al principio de Tecnología e Innovación de Open Government Partnerships. Transparenta la actividad diplomática y provee de información actualizada en formatos abiertos basados en tecnologías de uso común. Por su carácter instrumental, orienta la transparencia y la rendición de cuentas. En las redes sociales, el diplomático tiene la oportunidad de explicar los objetivos de su trabajo, reconocer los errores o establecer alianzas (Archetti, 2012). Esta idea de reconocimiento del trabajo asignado es consistente con la experiencia española. La digitalización de los procesos y las operaciones en las embajadas y consulados se ha dirigido hacia la mejora de la prestación de asistencia a los ciudadanos en el exterior, la reducción de los costes, la renovación de los servicios consulares y la relación con la administración. La embajadora Consuelo Femenía (2016) explica la dimensión del cambio desde su experiencia en el Ministerio de Asuntos Exteriores y Cooperación del Gobierno de España:

Quien no explica la naturaleza de su actividad puede perder su legitimidad social. El diplomático se encuentra en posición idónea para volcar su comunicación, no sólo hacia dentro de su sistema como hasta ahora -esto es, hacia su central- sino hacia fuera, hacia los públicos potencialmente interesados, haciendo el embajador (representante con capacidad de negociar y vincular a su Estado) de "embajador" (representante con capacidad de explicar, persuadir y atraer en un contexto más abierto). (p. 21)

Esta innovación representa un cambio en la forma de ordenar las relaciones con el administrado.

Los instrumentos compartidos con otros actores legítimos crean los tratados y acuerdos internacionales que sí son de naturaleza pública 
(Cornago, 2013). Es recurrente los 14 puntos de Wilson como antecedente de la diplomacia abierta y la publicidad de los acuerdos. Son instrumentos de comunicación diplomática que nacen como documentos públicos con el ánimo de ser difundidos.

De naturaleza pública son las declaraciones, las cumbres, las conferencias, las multilaterales, los instrumentos no normativos y la promoción de la marca país o marca territorio. Impactan en la opinión pública y contribuyen a la discusión de los asuntos internacionales en clave doméstica. Señala Meerts (2015) que en este punto tienen especial relevancia los actores no estatales, como individuos, organizaciones no gubernamentales o gobiernos regionales. Su actividad en las conferencias comprende unas negociaciones más transparentes y, quizás, menos autonomía en el transcurso de las mismas.

Esta capacidad de impactar en los públicos, sin mediar los gobiernos o los medios de comunicación, explica el auge de la estrategia de comunicación internacional de los actores no estatales, que han multiplicado las posibilidades de la diplomacia pública (ManfrediSánchez, Herranz de la Casa y Seoane Pérez, 2016), y de la diplomacia corporativa, que aprende los usos diplomáticos para la defensa de sus intereses. En este campo, las compañías multinacionales, las ciudades, las naciones sin estado, las organizaciones sociales, los movimientos sociales, los individuos o las empresas de tecnología actúan e influyen en la construcción internacional sin cumplir los prerrequisitos establecidos por la costumbre diplomática.

Su participación en los procesos diplomáticos (control de fronteras, establecimiento de estándares digitales, comercio exterior, el cumplimiento normativo internacional, protección de la cadena de suministros) es un hecho recurrente (Manheim, 1994; Gonesh y Melissen, 2005). El poder se dispersa en distintos niveles de acción y comunicación, que se estructuran en torno a la creación de marcos conceptuales que defienden un posicionamiento ideológico y un argumentario concreto. Mención especial merece la difusión de ideas elaboradas por los think tanks, cuyo grado de transparencia está en el debate público. Los think tanks son instituciones que generan conocimiento mediante la investigación aplicada, a mitad de camino entre la academia y la arena política. Son el desarrollo instrumental de partidos políticos, ideologías, grupos de interés o de poder, que 
financian este tipo de comunidades de conocimiento para la producción de documentos de investigación y el desarrollo de estudios. La finalidad es la divulgación de conocimiento accesible al legislador y a la opinión pública, a través del periodismo especializado o la difusión masiva mediante soluciones digitales. En la práctica, son espacios de mediación para las elites de la academia, la política, el negocio, el periodismo y el mundo diplomático (Medvetz, 2012) Los trabajos, las reuniones, las publicaciones, las conferencias y otros instrumentos de naturaleza discreta influyen en el modo en que se diseñan las políticas públicas, se toman decisiones y interpretan las actuaciones políticas. La oferta de conocimiento experto seduce a los tomadores de decisiones (Rich, 2004).

La seguridad y la defensa ha capturado el desarrollo instrumental de la naturaleza pública de los acuerdos. La transparencia ha conducido a cierto grado de colaboración con el ánimo de reducir las diferencias, incrementar la confianza social y entre las instituciones, así como a la construcción de proyectos conjuntos de interés (Cottey y Forster, 2004).

Siguiendo a Nye (2003), los actores no estatales de naturaleza pública y privada emplean sus capacidades para organizar la agenda de acuerdo con los valores mediante instrumentos como la diplomacia corporativa, la responsabilidad social o la influencia en el debate. Por este motivo, su estrategia encaja con el principio de participación de la Open Goverment Partnership. Éste consiste en la movilización de los ciudadanos a través de sí mismos o de los canales que consideren para la mejora del debate público, el avance de la gobernanza y la integración de la rendición de cuentas en la misión de las organizaciones.

En el fondo, los autores beben de la obra de Karl Deutsch. La incertidumbre, la tensión o el miedo condicionan la percepción de la realidad, empobrece la capacidad de juicio de los individuos y favorece la manipulación (Deutsch, 1978). La acertada metáfora de los nervios (Deutsch, 1963) que conecta política, sociedad y gobierno es hoy el último refinamiento de la diplomacia, que ha integrado la comunicación política internacional, la diplomacia pública y la digital en la gestión diaria. 


\subsection{La creciente demanda de transparencia en materia de diplomacia}

La transparencia es el fundamento de la renovación de los sistemas políticos en las democracias contemporáneas. Se ha convertido en un mandato por parte de instituciones internacionales porque la transparencia apalanca la neutralidad de la administración, promueve sistemas de control y crea barreras a la corrupción (Villoria, 2000). En este sentido, ha crecido el número de leyes de transparencia, acceso a la información, gobernanza de la administración pública, gestión de los datos, evaluación de las políticas públicas, publicación de datos en formato abierto y otras medidas de innovación están en la agenda de reforma y transformación de la gestión pública del siglo XXI. La transparencia y la rendición de cuentas plantean nuevos horizontes en la gestión de la información de naturaleza pública (Manfredi, 2017).

La transparencia articula la idea de democracia, eficacia y marco institucional (Longo, 2010). Los poderes públicos responden ante los ciudadanos, quienes informados, toman las decisiones oportunas. Los directivos rinden cuentas de su gestión y sus capacidades, de acuerdo con el mandato que hayan recibido. La institucionalización se refiere a la igualdad de oportunidades, la creación de confianza y capital social, así como a la reducción de la arbitrariedad.

La transparencia tiene efectos en tres niveles de actuación (Diamond y Morlino, 2004). El primero es procedimental, resultado del agregado de normas y reglamentos que explican el funcionamiento de las instituciones. El segundo consiste en el contenido, esto es, la información real, sólida y consistente que se difunde. Se mide aquí el uso de servicios informativos que pasen de la abstracción a productos informativos inteligibles para el ciudadano medio. Los resultados representan el tercer paso: la transparencia favorece la trazabilidad de las decisiones y a asignar responsabilidades propias y ajenas.

Confluyen dos factores en materia de diplomacia que explican los efectos de la transparencia en los tres niveles señalados.

Por un lado, las políticas nacionales se han globalizado y los gobiernos se ven obligados a explicar qué tipo de decisiones se toman en las instituciones internacionales y cómo afectan a la vida cotidiana de los ciudadanos. La diplomacia ha entrado en una fase de escrutinio 
permanente que se vincula con el nivel procedimental. En la práctica, la revelación del estado de las negociaciones o de los puntos de partida no implica un mayor grado de transparencia en tanto que la negociación es un proceso abierto. Aquí, la confusión entre transparencia y negociación ha fomentado la demagogia y ha perjudicado a la creación de confianza entre las partes.

El planteamiento del Tratado de Libre Comercio entre la Unión Europea y Estados Unidos muestra las dificultades de un estilo de negociación basado en el intercambio de documentos entre las partes, pero no accesibles cada uno de éstos a la opinión pública. La Comisión Europea explica que su obligación es informar a los gobiernos de los Estados Miembros y al Parlamento Europeo, cuyos eurodiputados tienen acceso a la documentación. Asimismo, se ha hecho público el mandato de negociación, esto es, las instrucciones dadas a la Comisión por parte del Consejo. En cambio, numerosos grupos de presión, eurodiputados y representantes nacionales contrarios al Tratado, así como periodistas y académicos califican el mismo de oscuro y falto de legitimidad (Llaudes, 2016). Esta tensión no tiene fácil solución cuando, además, Estados Unidos tiene su propia legitimidad e interés en las negociaciones.

En el plano institucional, los procesos de creación de las políticas públicas en materia de política exterior han facilitado el acceso de nuevos actores de modo que se amplía la gama de contenidos y se transforma la gestión de resultados. La campaña internacional para la prohibición de las minas antipersonales, las corporaciones multinacionales, las organizaciones no gubernamentales, los lobbies o las televisiones internacionales son ejemplos recurrentes. El uso de medios y redes sociales ha afectado la forma de organización, los instrumentos de comunicación y participación, la capacidad de impacto en grandes audiencias y la validación de las demandas. La Cumbre Global contra la Violencia Sexual celebrada en Londres en 2014 es un ejemplo de esta nueva aproximación a las negociaciones multilaterales sobre asuntos transnacionales. No se persigue una transparencia procedimental, sino otra orientada hacia resultados. La cumbre, amadrinada por la actriz Angelina Jolie, reunió a 125 países, organizaciones no gubernamentales, activistas, víctimas de esta violencia, periodistas y académicos. 
Por otro, ha crecido la demanda de transparencia y rendición de cuentas de la gestión y las políticas públicas. Se ha apuntalado la demanda ciudadana de información objetiva y de acceso a la documentación para su escrutinio. Como resultado, se accede a la publicación de las cifras presupuestarias desagregadas, la definición de los procesos de elección y renovación de cargos y mandatos (méritos, estabilidad política, responsabilidad, memorias de trabajo, rendición de cuentas), la capacidad de formular e implementar la política exterior (efectividad del mandato, enunciación y cumplimiento de un propósito, comunicación), así como el establecimiento de relaciones con la sociedad (interacción con los ciudadanos en la diplomacia en red), entre otras funciones y atribuciones.

En el ámbito diplomático, el debate es rico (Cornago, 2013). Algunos autores consideran que la diplomacia no puede mantenerse al margen de las demandas de transparencia que atraviesan la sociedad abierta. Sería el final de la diplomacia secreta (Colson, 2009), pero no de las negociaciones El caso de Irán con el grupo de Ginebra demuestra que la discreción en materia de seguridad, defensa y relaciones económicas genera confianza entre las partes.

El uso de las tecnologías para prevención de conflictos, la mejora de la inteligencia y la detección temprana de crisis contribuye a la construcción de dicho escenario (Kalev Leetaru, 2017). En cambio, otros autores son más escépticos. La transparencia en diplomacia, como consecuencia de las filtraciones, ha perdido interés. WikiLeaks y otros acontecimientos parecidos no afectan al desarrollo de aquellas negociaciones políticas que no quedan registradas (Roberts, 2011). Así, el diario The New York Times (What Happened to Transparency?, 2014) denunciaba que WikiLeaks había provocado una consecuencia no deseada: se han endurecido los procedimientos para la difusión de documentos públicos. En el mismo sentido, se pronunció el Committe to Protect Journalists (Downie y Rafsky, 2013), al indicar que la reglamentación de la transparencia iba contra el fomento de una cultura de transparencia, más completa y adecuada para el ejercicio del periodismo.

En cuanto al periodismo, la transparencia en asuntos internacionales ha afectado a las relaciones entre periodistas y diplomáticos, militares $\mathrm{y}$ agentes de inteligencia. El tratamiento de la información tiene 
objetivos diferentes para cada uno de estos grupos. Éstos trabajan con los secretos. El silencio y la discreción son virtudes. En cambio, los periodistas tienen que producir informaciones veraces y objetivas. Los periodistas tienen que demostrar a cada momento la calidad de las fuentes informativas, la vigencia de los hallazgos y la solvencia de las historias. La verificación de las historias se ha convertido en un mandato expreso para la recuperación de la credibilidad del periodismo. El escrutinio público sobre la profesión diplomática se extiende también hacia el periodismo internacional. Esto significa dar espacio a todos los interesados, lo que puede incluir entrevistar a "los enemigos" y a "los otros". Asimismo, la calidad periodística se mide por la credibilidad de las fuentes y la precisión del trabajo.

\subsection{Riesgos de la transparencia en diplomacia}

La transparencia no es un valor absoluto, sino un conjunto de herramientas que favorecen el buen gobierno de los asuntos públicos. Por este motivo, se identifican tres riesgos que emanan de la mala gestión de la información, el exceso de transparencia o la falta de protección de datos relevantes.

El primer riesgo consiste en la ausencia de estándares para los actores de la sociedad internacional. Gobiernos democráticos y autoritarios, grupos insurgentes y terroristas, activistas por los derechos humanos, instituciones europeas, mafias organizadas, contrabandistas de ilícitos o bancos centrales manejan distintos grados de revelación de información o control parlamentario. En el juego de la transparencia, las democracias ofrecen más elementos de control y equilibrio que sus competidores. Se puede criticar el estado del acuerdo de libre comercio porque se accede a la parte europea de la información. En cambio, se desconocen las fuentes de financiación del terrorismo internacionales, las rutas de la trata de blancas, los pagos interesados a un grupo de presión para que mueva una idea en redes sociales o el número real de los movimientos migratorios. En el ámbito de la seguridad, hay que considerar cuánta información se comparte con los aliados o cómo se crean partenariados público-privado para la gestión de la seguridad en la línea de lo sugerido por James Stavridis (citado por Lillie, 2012).

El riesgo se enuncia así: el funcionamiento de los sistemas democráticos y sociedades abiertas requiere un grado de transparencia 
en la gestión de la información internacional que no compete a otros actores. Esta asimetría da ventaja a quienes están dispuestos a no cumplir las normas internacionales. La construcción de la confianza entre las partes no es sencilla. Arriba se mencionan las negociaciones entre Europa y Estados Unidos y la propia del grupo de Ginebra con Irán. No todas las partes están dispuestas a facilitar el mismo grado de información, permitir la entrada de observadores, dar acceso a grupos de interés o permitir que los periodistas hagan su trabajo. Ésta es la asimetría.

El segundo riesgo es la gestión de la confianza. En el ámbito interno, la confianza consiste en la colaboración entre las partes del sistema internacional. A saber, la inteligencia y el espionaje, la información comercial, la seguridad y la defensa y otros activos. En el plano externo, las instituciones y los sistemas de representación presentan bajos índices de confianza social. Se tolera cierto grado de autoritarismo en nombre de la estabilidad (Foa y Mounk, 2016). La elección de socios y aliados influye en la ejecución de los proyectos diplomáticos, así como en la legitimidad de las decisiones que se toman. Cuando crece la desconfianza, disminuye la capacidad de influencia y defensa de los valores democráticos.

El riesgo es el siguiente: la pérdida de confianza social conduce a la elección de aliados que no comparten una visión de las relaciones internacionales. Disminuye la capacidad de liderazgo público ante los desafíos de la gobernanza global (cambio climático, protección de derechos digitales o gestión de la salud pública global). Asimismo, la baja confianza interna perjudica la comunicación entre instituciones de la democracia.

El tercer riesgo gira en torno al control efectivo de las comunicaciones. Interesa aquí el impacto de las filtraciones. Las difundidas por WikiLeaks dañaron antes a los informantes y a los colaboradores de la inteligencia estadounidense que a los propios intereses de Estados Unidos en el exterior. Mediante la publicación del detalle de reuniones o encuentros, se han identificado activistas. En países no democráticos, esa denuncia es muy peligrosa. El sistema de escuchas expuesto por Edward Snowden crea un estado genera de desconfianza entre aliados y mina el diálogo sincero. 


\section{Resultados}

El trabajo de investigación plantea dos hipótesis sobre el impacto de la transparencia en el ejercicio de la diplomacia.

Se confirma la hipótesis 1. El uso de los principios de Open Government Parternship contribuye a entender que la transparencia en diplomacia se mide no solo por la publicación y la difusión de las notas elaboradas por los profesionales diplomáticos, sino también por el grado de participación y apertura social, el uso de innovaciones tecnológicas y la rendición de cuentas. Las cumbres y los encuentros multilaterales, así como el uso de las redes sociales incrementa la trazabilidad de la información diplomática y no se centra, únicamente, en la difusión de documentos que podrían ser confidenciales o que podrían perjudicar a la seguridad de las fuentes. El equilibrio entre los niveles de información se consigue con una transparencia procedimental, de contenidos y de resultados, según el tipo de política internacional o la demanda ciudadana.

La hipótesis 2 se evidencia. La diversidad de actores que operan en la arena internacional provoca la ausencia de estándares. El riesgo de asimetría afecta a la comunicación pública, bien sea por la falta de confianza, el uso malintencionado de la información de naturaleza pública o bien porque se niega la rendición de cuentas. La comunidad epistémica es global, pero con acceso desigual a las fuentes y los recursos. Por este motivo, la diplomacia transparente no es la única herramienta de la comunicación estratégica. Tanto la diplomacia cultural como la propaganda forman parte del puzzle.

En suma, el artículo confirma que la transparencia en materia diplomática requiere un análisis desde distintos puntos de vista. No puede validarse un modelo único de evaluación de las políticas públicas, sino que es preciso compendiar nuevos indicadores, promover buenas prácticas e instrumentos para la integridad y la trazabilidad de la información, aminorar los riesgos e institucionalizar el aprendizaje de la transparencia.

*Investigación financiada. Esta investigación se enmarca en el proyecto "Comunicación pública: poder, derecho y mensaje", referencia ComPublic, grupo de investigación de la Universidad de Castilla-La Mancha en su convocatoria 2017. 
Inicio de la investigación: octubre de 2016.

Conclusión de la investigación: mayo de 2017.

\section{Referencias}

Adler-Nissen, R. (2016): "Diplomatic Agency", en C.M. Constantinou, P. Kerr, y P. Sharp (eds.), The SAGE Handbook of Diplomacy. SAGE Anker, T.B. (2017): "Corporate democratic nation-building: Reflections on the constructive role of business in fostering global democracy". European Management Journal, 35(1), pp. 1-7.

Archetti, C. (2012): "The Impact of New Media on Diplomatic Practice: An Evolutionary Model of Change". The Hague Journal of Diplomacy $_{s}$ 7(2), pp. 181-206.

Bergareche, B. (2012): Wikileaks cofidencial. Madrid: Anaya. Berridge, G.R. (2015): Diplomacy. Theory and Practice. London: Palgrave MacMillan

Bjola, C. (2015): "Diplomatic leadership in times of international crisis: The maverick, the congregator and the pragmatist". Hague Journal of Diplomacy, 10(1), pp. 4-9.

Cachinero, J. (2017): Reputación y generación de valor en el siglo XXI. Editorial Libros.com

Camilleri, V. (2011): "Diplomatic reporting in the Internet era". Comunicación presentada en la Conference on Diplomatic Reporting in the Internet Era, 9 de febrero de 2011. Ginebra, DiploFoundation eDiplomacy Papers.

Canel, J. M. (2007): Comunicación de las instituciones públicas. Madrid: Tecnos España.

Castelló, I., Etter, M. y Årup Nielsen, F. (2016): "Strategies of legitimacy through social media: The networked strategy". Journal of Management Studies, 53(3), pp. 402-432.

Castells, M. (2008): "Comunicación, poder y contrapoder en la sociedad red (I). Los medios y la política". TELOS: Cuadernos de comunicación e innovación, 74, pp.13-24

Colson, A. (2008): "The ambassador between light and shade: the emergence of secrecy as the norm for international negotiation". International Negotiation, 13(2), pp. 179-95. 
Colson, A. (2009): "La négociation diplomatique au risque de la transparence: rôles et figures du secret envers des tiers". Négociations, 1, pp. 31-41.

Convención de Viena sobre las Relaciones Diplomáticas (1961). Recuperado el 25 de abril de 2017 de https://www.oas.org/legal/spanish/documentos/convencionviena.h $\underline{\mathrm{tm}}$

Copelan, D. (2009): Guerrilla diplomacy: rethinking international relations. Boulder: Lynne Rienner Publishers

Cornago, N. (2013): Plural Diplomacies: Normative Predicaments and Functional Imperatives. Amsterdam: Martinus Nijhoff Publishers.

Cottey, A. y Forster, A. (2004): Reshaping Defence Diplomacy: New Roles for Military Cooperation and Assistance. Londres: Oxford University Press Del Fresno, M., Daly, A. J., y Segado, S. (2016): "Identifying the new Influences in the Internet Era: Social Media and Social Network Analysis". Revista Española de Investigaciones Sociológicas, 153, pp. 23-42.

Den Hond, F., Rehbein, K.A., De Bakker, F.G.A. y Kooijmans-van Lankveld, H. (2014): "Playing on Two Chessboards: Reputation Effects between Corporate Social Responsibility (CSR) and Corporate Political Activity (CPA). Journal of Management Studies, 51,5: 791-813. doi: 10.1111/joms.12063

Deutsch, K. (1963): The nerves of government. Nueva York: The Free Press. Deutsch, K. (1978): The Analysis of International Relations. Englewood Cliffs: Prentice-Hall.

Diamond, L.J. y Morlino, L. (2004): “An overview”. Journal of democracy, 15(4), pp. 20-31.

Downie, L. y Rafsky, S. (2013): The Obama Administration and the Press. Leak investigations and surveillance in post-9/11 America. Committee to Protect Journalists. Recuperado el 22 de abril de 2017 de https://cpj.org/reports/2013/10/obama-and-the-press-us-leakssurveillance-post-911.php

Escobar, J.J. (2016): "Diplomacia digital, diplomacia política”, en J.L. Manfredi y C. Femenía (eds), La diplomacia española ante el reto digital (pp. 43-51). Madrid: Secretaria General Técnica. Ministerio de Asuntos Exteriores y Cooperación.

Estrella, R. (2016): "La diplomacia digital de las organizaciones multilaterales: Rusia y la guerra fría en internet", en J.L. Manfredi y C. Femenía (eds), La diplomacia española ante el reto digital (pp. 89-99). 
Madrid: Secretaria General Técnica. Ministerio de Asuntos Exteriores y Cooperación.

Femenía, C. (2016): "El modelo de diplomacia digital en España", en J.L. Manfredi y C. Femenía (eds), La diplomacia española ante el reto digital (pp. 19-16). Madrid: Secretaria General Técnica. Ministerio de Asuntos Exteriores y Cooperación.

Fletcher, T. (2016): Naked Diplomacy: Power and Statecraft in the Digital Age. HarperCollins UK.

Foa, R.S. y Mounk, Y. (2016): “The democratic disconnect". Journal of Democracy, 27(3), pp. 5-17.

Gilboa, E. (2001): "Diplomacy in the Media Age: Three Models of Uses and Effects", Diplomacy and Statecraft, 2001, 12(2), pp. 1-28.

Gimeno Beviá, J. (2016): Compliance y proceso penal. El proceso penal de las personas jurídicas. Adaptada a las reformas del CP y LECrim de 2015, circular FGE 1/2016 y jurisprudencia del TS. Madrid: Thompson Reuters Civitas.

Gonesh, A. y Melissen, J. (2005): Public Diplomacy: Improving Practice. The Hague: Clingendael Diplomacy.

Guichot, E. (2014): Transparencia, acceso a la información pública y buen gobierno. Madrid: Tecnos.

Haass, R. (2010, 1 de diciembre): [Podcast de audio]. Recuperado el 15 de abril de 2017 de http://www.wnyc.org/story/102715-could-webe-entering-age-transparent-diplomacy/

Hocking, B. (2006): "Multistakeholder Diplomacy: Forms, Functions, and Frustrations", en J. Kurbalija y V. Katrandjiev (eds.), Multistakeholder Diplomacy: Challenges and Opportunities (pp. 13-29). Malta y Ginebra: DiploFoundation.

Holmes, M. (2015): "Digital Diplomacy and International Change Management”, en C. Bjola y M. Holmes (eds.), Digital Diplomacy: Theory and Practice. Routledge Jarvie, G., Murray, S., y Macdonald, S. (2017): "Promoting Scotland, Diplomacy and Influence through Sport". Scottish Affairs, 26(1), pp. 1 22. doi: $10.3366 /$ scot.2017.0161

Kalev Leetaru. (2017). Recuperado el 30 de abril de 2017 de http://kalevleetaru.com/

Kurbalija, J. (1999): "Diplomatic in the Age of Information Technology". En J. Melissen (ed.), Innovation in Diplomatic Practice (pp. 171-191). Basingstoke: Palgrave Macmillan. 
Lillie, B. (2012, 26 de junio): “Open-source security: James Stavridis at TedGlobal 2012". Recuperado el 30 de abril de 2017 de http://blog.ted.com/open-source-security-james-stavridis-attedglobal-2012/

Llaudes, S. (2016, 21 de junio): "Transparencia y control democrático del TTIP”. Recuperado el 3 de mayo de 2017 de http://agendapublica.elperiodico.com/transparencia-y-controldemocratico-del-ttip/

London First. (2017). Recuperado el 30 de abril de 2017 de http://londonfirst.co.uk

Longo, F. (2010): "Ejes vertebradores de la gobernanza en los sistemas públicos. Un marco de análisis en clave latinoamericana". Revista del CLAD Reforma y Democracia, febrero, pp. 73.102.

Lord, K. (2006): The Perils and Promise of Global Transparency. Why the information revolution may not lead to security, democracy, or peace. Albany: SUNY University Press.

López García, G. (2015). Periodismo digital. Redes, audiencias y modelos de negocio. Zamora: Comunicación social ediciones.

Macnamara, J. (2011): “Corporate and organizational diplomacy: An alternative paradigm to public relations". Journal of Communication Management, 6 (3), pp. 312-325.

Manfredi-Sánchez, J.L (2014): “Taxonomía de la diplomacia digital en la agenda de las nuevas relaciones internacionales". Historia y Comunicación Social, 19, pp. 341-354.

Manfredi-Sánchez, J.L (2016): "La transformación profesional de la diplomacia en red", en J.L. Manfredi y C. Femenía (eds), La diplomacia española ante el reto digital (pp. 101-110). Madrid: Secretaria General Técnica. Ministerio de Asuntos Exteriores y Cooperación.

Manfredi-Sánchez, J.L. (2017): "Horizontes de la información pública". El profesional de la información, 26 (3).

Manfredi-Sánchez, J.L., Herranz de la Casa, J.M. y Seoane Pérez, F. (2016): "Diplomacia de movilización. Referenda de Cataluña y Escocia en la diplomacia en red". Revista Latina de Comunicación Social, 71, pp. 961-975.

Manheim, J.B. (1994): Strategic Public Diplomacy and American Foreign Policy: the Evolution of the Influence. New York: Oxford University Press.

Medvetz, T. (2012): Think Tanks in America. Chicago: University of Chicago Press. 
Meerts, P.W. (2015): Diplomatic Negotiation: Essence and Evolution. The Hague: Cligendael Institute.

Mogensen, K. (2017): "From public relations to corporate public diplomacy". Public Relations Review.

Nicolson, H. (1939): Diplomacy. Oxford University Press

Nye, J. (2003): La paradoja del poder norteamericano. Madrid: Taurus.

Okano-Heijmans, M. (2011): "Conceptualizing Economic Diplomacy: The Crossroads of International Relations, Economics, IPE and Diplomatic Studies". The Hague Journal of Diplomacy, 6(1), pp. 7-36.

Qin, J. (2015): "Hero on Twitter, Traitor on News. How social media and legacy news frame Snowden". The International Journal of Press/Politics, 2 (2), pp. 166-184.

Rich, A. (2004): Think Tanks, Public Policy, and the Politics of Expertise. New York: Cambridge University Press.

Rivera, T. (2015). Distinguishing Cultural Relations From Cultural Diplomacy: The British Council's Relationship With Her Majesty's Government. Los Angeles: CPD Perspectives on Public Diplomacy.

Roberts, A. (2011): “The WikiLeaks illusion”, The Wilson Quarterly, 35(3), pp. 16-21.

Scherer, A.G. y Palazzo, G. (2007): “Toward a political conception of corporate responsability: business and society seen from a Habermasian perspective". Academy of Management Review, 32(4), pp. 1096-1120.

Seib, P. (2012): Real-time diplomacy: politics and power in the social media era. Springer.

"Trump 'shared classified information with Russia"'. (2007, 16 de mayo): BBC. Recuperado el 29 de abril de 2017 de http://www.bbc.com/news/world-us-canada-39931012

Twiplomacy Study (2015). Burson-Marsteller.

U.S. Department of State (2015): Enduring Leadership in a Dynamic World: Quadrennial Diplomacy and Development Review. Recuperado el 10 de mayo de 2017 de https://www.state.gov/documents/organization/267396.pdf

Villoria, M. (2000): Ética pública y corrupción: Curso de ética administrativa. Madrid: Tecnos.

Villoria, M. (2016): "El papel de la administración pública en la generación de calidad democrática”. Revista del CLAD Reforma y Democracia, junio, pp. 5-38. 
"What Happened to Transparency?” [Editorial] (2014, 7 de junio): The New York Times. Recuperado el 20 de abril de https://www.nytimes.com/2014/01/08/opinion/what-happened-totransparency.html

\section{Otros recursos utilizados}

Open Government Partnership http://www.opengovpartnership.org/

Cómo citar: Manfredi Sánchez JL, et al (2017): "Transparencia y diplomacia: nuevas demandas sociales y rutinas profesionales". Revista Latina de Comunicación Social, 72, pp. 832 a 848.

http://www.revistalatinacs.org/072paper/1195/45es.html

DOI: $10.4185 /$ RLCS-2017-1195 

Cómo citar: Cordón Benito D, et al (2017): "La adaptación de los museos a la transparencia informativa a través de sus webs". Revista Latina de Comunicación Social, 72, pp. 941 a 956.

http://www.revistalatinacs.org/072paper/1201/51es.html

DOI: $10.4185 /$ RLCS-2017-1201

\title{
4
}

\section{La adaptación de los museos a la} transparencia informativa a través de sus webs

\author{
David Cordón Benito - Universidad Internacional de La Rioja - \\ david.cordon@unir.net
}

Lidia Maestro Espínola - Universidad Internacional de La Rioja lidia.maestro@,unir.net

\begin{abstract}
s
Introducción. Las estrategias y herramientas de comunicación corporativa en las instituciones se han transformado en los últimos años. Los casos de corrupción, las prácticas poco éticas y la crisis económica han desembocado en una nueva complejidad en la que las instituciones deben recuperar la confianza perdida. El objetivo de este trabajo es demostrar cómo los museos apuestan por la transparencia para mostrarse como organizaciones de confianza que cumplen con su fin social. Metodología. Se realiza un análisis de contenido a partir de los criterios de transparencia planteados por el informe de la Fundación Compromiso y Transparencia. Resultados y conclusiones. Los museos, como cualquier otro tipo de institución, han apostado por utilizar sus webs como plataformas transparentes, donde se cumplen una serie de criterios que aumentan la confianza y se ofrece información de interés a social.
\end{abstract}




\section{Keywords}

transparencia; museos; comunicación corporativa; nueva complejidad; confianza.

\section{Contents}

1. Introducción. 1.1. El uso de herramientas de comunicación diferenciadoras que permiten la transparencia 1.2. La transparencia al servicio de los museos. 2. Objetivos y metodología de la investigación. 3. Resultados de la investigación. 4. Conclusiones. 5. Bibliografía.

\section{Introducción}

T OS avances tecnológicos que han afectado a la comunicación del Lentorno político, económico y social han llevado a una transformación de la realidad en la que operan las instituciones. El acceso a la información se ha visto multiplicado por Internet y este medio ha modificado la manera en la que las personas se relacionan entre sí. La profunda crisis económica vivida, unida al desencanto de los casos de corrupción destapados han fomentado la pérdida de confianza en las instituciones por parte de los stakeholders (Laporte y Gutiérrez, 2013: 9). Todo esto ha llevado a un hartazgo de la población que se ha visto reflejado en los diversos movimientos ciudadanos acontecidos en todo el mundo como el $15 \mathrm{M}$ o las revueltas estudiantiles en Venezuela pidiendo el cese de Maduro. En definitiva, se ha demostrado, que la sociedad civil puede organizarse de manera activa para exigir derechos e influir en las políticas públicas (Derville, 2005).

Los últimos informes del Trust Edelman Barometer (2016;2017) muestran que la gran mayoría de la población continúa sin confiar en las instituciones analizadas por esta consultora: ONGs, medios de comunicación, empresas privadas y gobiernos. Ambos documentos animan a las organizaciones a apostar por la recuperación de la confianza perdida en ellas por parte de la sociedad poniendo en marcha acciones y desarrollando planes específicos. La confianza es un intangible que servirá a estas organizaciones como un elemento diferenciador ante la competencia y, dado el mercado global en el que cualquier institución compite hoy, los beneficios de aprovechar esta oportunidad son grandes. 


\subsection{El uso de herramientas de comunicación diferenciadoras que permiten la transparencia}

Las organizaciones han comenzado a llevar a cabo una readaptación a los ambientes en los que operan, ante las nuevas posibilidades comunicativas, dejando patente su actuación en un entorno globalizado (Siriamesh, 2010). Internet ha modificado la manera en la que la sociedad interactúa y se comunica entre sí, ofreciendo una mayor pluralidad de opiniones (Castelló et al, 2013). Este hecho ha complicado la gestión de la comunicación de las organizaciones, que deben competir con en un mercado de la información cada vez más saturado (Freeman, 1984; Cortina, 2003).

Las instituciones han comprendido que ante este nuevo panorama social que ha hecho mella en su reputación, sólo pueden readaptarse para hacer frente a un entorno en el que ya no sólo se espera de ellas que sean agentes políticos, sino también sociales y políticos (Scherer et al. 2014). Es aquí donde se pone de relevancia la importancia que en los últimos años han cobrado los activos intangibles para las organizaciones, que desean cumplir con las expectativas de los grupos de interés para recobrar la confianza y legitimidad perdidas.

Un nuevo modelo centrado en el buen gobierno y en la creación de valor compartido para las empresas surge bajo la idea crecimiento. Es lo que algunos autores como Alloza (2011) han dado en llamar 'economía de la reputación'. La reputación, la ciudadanía corporativa y la responsabilidad social corporativa se convierten en elementos protagonistas dentro de la nueva forma de gestión de las organizaciones. Se busca una economía del bien común que genere un valor compartido del que puedan beneficiarse tanto la institución como los diferentes grupos de interés. Por tanto, y tal y como explican Freeman et al. (2010), las empresas integran los intereses de sus stakeholders con los intereses y objetivos que se fijan las instituciones, consiguiendo un nivel de confianza por parte de los públicos muy beneficioso. Como afirma Alloza (2011), las relaciones con los grupos de interés pueden destruir y crear valor, lo que repercute de manera positiva en su reputación y actúa como diferenciador clave para competir contra su competencia. 
En el caso de España, donde la pérdida de confianza en las instituciones por los motivos ya mencionados anteriormente se ha denunciado en medios de comunicación y a través de protestas ciudadanas, el Gobierno nacional decidió tomar una serie de medidas para forzar a las organizaciones a cumplir unos estándares mínimos de transparencia. De esta forma, se instaba a las instituciones a recuperar esa credibilidad perdida.

El Ejecutivo español tomó varias medidas al respecto: En primer lugar, promulgó la Ley 19/2013 de Transparencia, acceso a la información pública y buen gobierno. En segundo lugar, creó en el título III de esta misma norma del Consejo de Transparencia y Buen Gobierno. Y, por último, impulsó la creación a finales del año 2014 del Portal de la Transparencia. Estas decisiones han beneficiado el acceso de los ciudadanos a datos abiertos u open data que las instituciones públicas deciden poner al servicio de la sociedad y que benefician el cambio de tendencia hacia una mejor consideración por parte de la ciudadanía de las organizaciones (Gértrudix et. al, 2016).

Tal y como marca en su preámbulo, la Ley de Trasparencia 19/2013 tiene un triple alcance: "Incrementa y refuerza la transparencia en la actividad pública (...), reconoce y garantiza el acceso a la información (...) y establece las obligaciones de buen gobierno que deben cumplir los responsables públicos así como las consecuencias jurídicas derivadas de su incumplimiento". Con esta declaración de intenciones la norma pretende dar respuesta a las demandas de diversos grupos de interés cada vez más críticos quienes, en los últimos años, solicitan una mayor participación en los poderes públicos. Para desarrollar esta labor, la misma ley establece la creación y regulación del Consejo de Transparencia y Buen Gobierno que nace como: "Órgano independiente al que se le otorgan competencias de promoción de la cultura de transparencia en la actividad de la Administración Pública, de control del cumplimiento de las obligaciones de publicidad activa, así como de garantía del derecho de acceso a la información pública y de a observancia de las disposiciones de buen gobierno". Por último, y como marca el Artículo 5 de esta ley, las Administraciones Públicas que regula esta norma deben publicar de manera periódica la información que se considere relevante para garantizar una total transparencia en sus actuaciones. Para ello, el Gobierno español decide crear a tal fin el 
Portal de Transparencia ${ }^{5}$ donde cualquier ciudadano puede consultar o solicitar información pública de su interés. De esta forma, se cumple el deber de estas instituciones con la sociedad por explicar las decisiones tomadas de manera razonada y proveer a los grupos de interés de datos para su consulta (Arenilla, 2011; La Rosa et al., 2016; Beltrán et al., 2016).

Siguiendo esta apertura a los datos por la que apuesta de manera firme el Gobierno de España y dejando de lado a los expertos que aseguran que la Ley de Transparencia no es todo lo exhaustiva que debería (Lizcano, 2013; Magallón, 2013; La Rosa et al, 2016), lo cierto es que esta norma ha impactado de manera directa sobre las instituciones públicas. Son muchos los investigadores que han abordado la necesidad, implementación y la evaluación de ejercicios de transparencia por diferentes administraciones (Woo Yoo y Gil de Zúñiga, 2014; Beltrán et al., 2016; Cabezuelo et. al. 2016; Rebolledo et. al, 2016; Carey, 2017;).

Sin embargo, y a pesar del interés que despierta esta apuesta por la transparencia en las Administraciones Públicas, lo cierto es que en organizaciones más alejadas del mundo de la política también se realiza actualmente un esfuerzo por mostrarse abiertas a los grupos de interés, aportar información relevante y recuperar la confianza perdida. En los últimos años, son varias las investigaciones que se están llevando a cabo sobre transparencia y organizaciones menos relacionadas con la política (Craig et al, 2016; López et al., 2017; Karlson et al., 2017; Suárez-Villegas et al., 2017).

Siguiendo este interés por investigar la transparencia y la forma de gestionarla por organizaciones que van más allá de las Administraciones Públicas, este artículo centra su atención en el mundo de los museos. Estas instituciones centenarias se han adaptado a un entorno cambiante a lo largo de los años y han querido mostrar que, en su caso, también pueden apostar por la transparencia como herramienta diferenciadora y que repercute de manera positiva en su reputación (Villafañe, 2004; 2013; Huang, 2015).

\footnotetext{
${ }^{5}$ El portal de transparencia puede consultarse en la siguiente dirección web: http://transparencia.gob.es/ (Recuperado el 28/5/2017).
} 


\subsection{La transparencia al servicio de los museos.}

En lo que concierne a los museos, lo cierto es que este acercamiento al público es una realidad. De ser organizaciones centradas en la colección, con la llegada de la nueva museología, el foco de interés se desplaza y se coloca sobre el visitante de la organización (AriasSerrano, 2015). Los motivos son diversos: desde su naturaleza cambiante, que ha dejado patente gracias a su adaptación a los cambios ocurridos desde su nacimiento en plena Revolución Francesa; pasando por su redefinición hacia espacios dialógicos y de encuentro de comunidades tanto presenciales como virtuales (Black, 2012; De la Iglesia et al.; Cordón et. al., 2016) o, en último lugar, su propia definición.

Con respecto a este último punto, lo cierto es que la última definición de museo ofrecida por el International Council of Museums (ICOM) ${ }^{6}$ en el año 2007 fija que: "Un museo es una institución permanente, sin fines de lucro, al servicio de la sociedad y abierta al público, que adquiere, conserva, estudia, expone y difunde el patrimonio material e inmaterial de la humanidad y su ambiente con fines de estudio, educación y recreo." Por tanto, esta aportación deja patente que el museo, de manera intrínseca, es una organización abierta a la sociedad, con unos fines enfocados a la misma y que, por tanto, necesita entablar y mantener relaciones de confianza y mutuo beneficio con sus grupos de interés.

Para ello, las instituciones museísticas apuestan por la comunicación como una herramienta de gestión que incide, principalmente, en la confianza de los grupos de interés y en la reputación de la organización (Cornelissen, 2004; Doorley et. al., 2007).

\section{Objetivos y metodología de la investigación}

La hipótesis que se plantea este artículo es si los museos, como instituciones con un marcado carácter social, se preocupan por

\footnotetext{
${ }^{6}$ La definición de museo más reciente que ofrece el International Council of Museums (ICOM) puede consultarse en la siguiente dirección web: http://icom.museum/lavision/definicion-del-museo/L/1/ (Recuperado el 28/05/2017).
} 
recuperar la confianza perdida mostrándose transparentes a través de sus webs corporativas. A pesar de que algunos autores se hagan eco de su concepción como organizaciones obsoletas y elitistas (HooperGreenhill, 1989, 1992, 2000; Bennett, 1996), lo cierto es que son instituciones adaptables a los cambios que acontecen en su entorno.

De esta hipótesis se derivan varios objetivos como, en primer lugar, analizar la importancia que las instituciones museísticas otorgan a la transparencia; en segundo lugar, analizar el uso de las webs corporativas para publicar información relevante para los públicos y, en tercer lugar, averiguar si existe relación entre la transparencia ofrecida a través de la web y el número de visitantes conseguido.

Teniendo en cuenta la hipótesis y objetivos planteados, esta investigación desarrolla un análisis de contenido de las webs de los museos más visitados en España, EEUU, Inglaterra y Francia para averiguar lo transparentes que resultan ser. La elección de estos países viene justificada por la cantidad de público que acude a estas organizaciones para visitar las diferentes exposiciones programadas. Tal y como se ha observado en la introducción al artículo, las instituciones buscan mantener o mejorar sus índices de reputación a través de la comunicación que realizan. La web es un instrumento más para la comunicación corporativa de cualquier organización. Por ello, el artículo intenta demostrar los museos más visitados del mundo desarrollan unas webs corporativas transparentes.

A lo largo del periodo de documentación se descubre la publicación internacional de referencia para el sector del arte y los museos The Art Newspaper, de periodicidad mensual, y publicada por el grupo editorial Umberto Allemandi \& Co. Esta revista publica anualmente desde 1996 su estudio: Visitor Figures: Exhibition \& Museum Attendance Survey, ${ }^{7}$ donde se reflejan los museos más visitados en los últimos 12 meses y las exposiciones más populares por afluencia de público en todo el mundo. Debido a la imposibilidad de encontrar otros estudios con la misma tradición donde se refleje el volumen de visitas a diferentes

\footnotetext{
${ }^{7}$ Los informes Visitor Figures and Attendance Numbers, desarrollados por The Art Newspaper, pueden consultarse en la siguiente dirección web: http://theartnewspaper.com/reports/ (Recuperado el 28/05/017).
} 
museos internacionales, se decide tomar como base para la selección de la muestra a los museos incluidos en esta encuesta.

La selección de las unidades de análisis presenta un carácter no aleatorio, y se toma para la misma un museo francés, británico, estadounidense y español que registran desde hace diez años un mayor número de visitantes. Los tres primeros encabezan siempre el ranking de museos más visitados en el mundo y, en el caso del español, su situación en la lista varía desde el décimo al duodécimo puesto en los años contemplados. Sin embargo, ostenta la distinción de ser el centro de arte más visitado de España. La inclusión del mismo en la muestra se justifica dado el interés de este artículo en establecer una comparativa y extraer unos resultados de interés. Por tanto, el estudio analiza las webs corporativas de los siguientes museos: Museo del Louvre (París), British Museum (Londres), Metropolitan Museum of Art (Nueva York) y Museo Nacional Centro de Arte Reina Sofía (Madrid).

Tabla. 1: Evolución del número de visitantes de los museos analizados (2013-2016)

\begin{tabular}{|l|c|c|c|c|}
\cline { 2 - 5 } \multicolumn{1}{c|}{} & $\mathbf{2 0 1 3}$ & $\mathbf{2 0 1 4}$ & $\mathbf{2 0 1 5}$ & $\mathbf{2 0 1 6}$ \\
\hline Musée du Louvre & 9.334 .036 & 9.260 .000 & 8.600 .000 & 7.400 .000 \\
\hline British Museum & 6.701 .036 & 6.695 .213 & 6.820 .686 & 6.420 .395 \\
\hline $\begin{array}{l}\text { Metropolitan Museum of Art } \\
\text { (MET) }\end{array}$ & 6.226 .727 & 6.162 .147 & 6.533 .106 & 7.006 .859 \\
\hline $\begin{array}{l}\text { Museo Nacional Centro de Arte } \\
\text { Reina Sofía (MNCARS) }\end{array}$ & 3.185 .413 & 2.673 .745 & 3.249 .591 & 3.646 .598 \\
\hline
\end{tabular}

Fuente: Elaboración propia a partir de los datos de visitantes aportados por la publicación

The Art Newspaper.

Antes de detallar el trabajo realizado, conviene mostrar la evolución del número de visitantes de los cuatro museos analizados desde el año 2013 hasta el año 2016.

Para el análisis de contenido realizado se toman las categorías e indicadores diseñados y empleados por el Informe a través del espejo: Transparencia en la web de los museos españoles, desarrollada por la 
Fundación Compromiso y Transparencia ${ }^{8}$. Esta organización analiza a través del documento citado lo transparentes que resultan las webs de las instituciones museísticas españolas teniendo en cuenta la información que reflejan. El primer informe se publicó en el año 2010 $\mathrm{y}$, a este, han seguido otras actualizaciones que miden el grado de mejora o empeoramiento de la información publicada en estos portales.

Las nueve categorías que se miden son: misión, estrategia, actividades, actos de disposición, estructura organizativa, políticas, órgano de gobierno, información económica y evaluación de resultados. Éstas se dividen en veinticuatro ítems que facilitan la evaluación de la transparencia puesta en práctica por los museos analizados haciendo pública información corporativa relevante.

Gráfico. 1: Evolución del número de visitantes de los museos analizados (2013-2016)

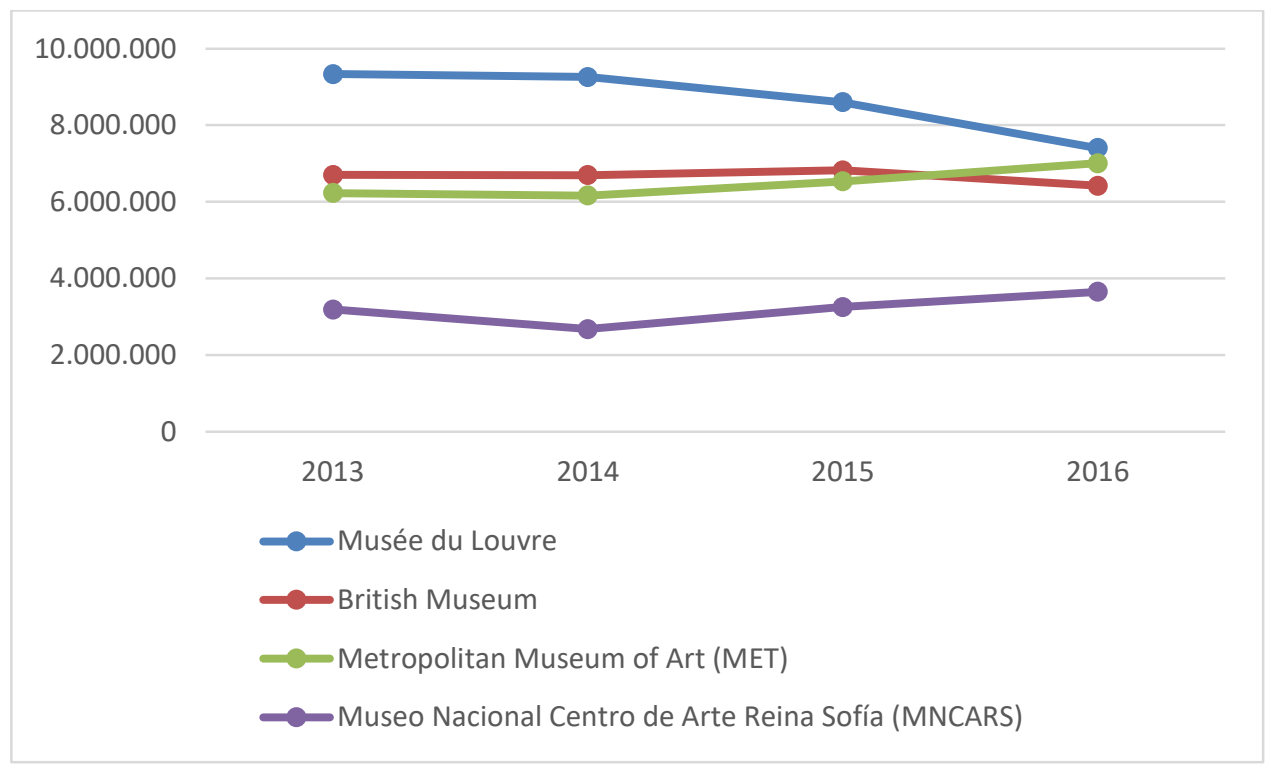

Fuente: Elaboración propia a partir de los datos de visitantes aportados por la publicación

The Art Newspaper.

\footnotetext{
${ }^{8}$ Los informes elaborados por la Fundación Compromiso y Transparencia pueden consultarse en la siguiente dirección web:

http://www.compromisoytransparencia.com/conocimientos/informes/ (Recuperado el 28/05/2017).
} 
El análisis de contenido de las webs institucionales tuvo lugar entre el 26 de abril y el 3 de mayo de 2017. De manera sistemática, se estableció una plantilla para corroborar que las categorías anteriormente enunciadas se cumplían o no en cada uno de los museos que conforman la muestra. De la decodificación de los datos obtenidos se extraen los siguientes resultados que se presentan a continuación.

\section{Resultados de la investigación}

Los resultados se estructuran conforme a los parámetros analizados en las diferentes webs los museos que conforman la muestra.

Todos los museos analizados cuentan con un apartado corporativo dentro de su arquitectura web que permite encontrar información relevante en cuanto a su historia, estructura, informes desarrollados, entre otros datos relevantes. En todos los casos que conforman este artículo, las instituciones formulan de manera explícita su misión. Si bien es cierto que muchas de ellas se adhieren a la definición propuesta por ICOM de lo que debe ser un museo, cada una es diferente a la anterior, y se adapta a las circunstancias o idiosincrasia propia de cada una de las organizaciones.

En lo que respecta a la publicación del plan estratégico, no todos los centros disponen de un documento específico en el que se detallen cuáles son las principales guías maestras que seguirá cada uno de ellos en un periodo de tiempo determinado. En el caso del British Museum y el Museo Nacional Centro de Arte Reina Sofía (MNCARS), los tres cuentan con un plan en el que se formula la estrategia de futuro. En el caso del museo londinense, el documento recibe el nombre de: Towards 2020: The British Museum's Strategy, y puede encontrarse dentro del apartado de 'Management and Governance' dentro de la web. En el caso del MNCARS recibe el nombre de 'Plan General de Actuación 2014-2017', y puede encontrarse dentro del apartado 'Misión' de la web.

El MET no cuenta con un escrito específico, aunque dentro de su informe anual sí que hace referencia a los valores nucleares de la organización y a los objetivos estratégicos que el museo se propone en los próximos cinco años. El Louvre, por su parte, no cuenta con un plan estratégico público en la web, aunque sí que difunde a través de ella su estrategia específica de responsabilidad social 2015-2017. 
En lo referente a la publicación en la web de las actividades del museo, la pregunta se divide en dos partes para una mejor estructuración de los resultados. En primer lugar, se pregunta por la descripción que los centros hacen de dos de sus principales actividades, destacando entre documentación, conservación, investigación y difusión. En todos los casos analizados se pueden observar en la web espacios relativos a información relacionada con estas cuatro principales tareas de las instituciones museísticas, siendo las más comunes las de documentación y difusión, entendiendo esta última como la comunicación desarrollada por los departamentos de prensa de estas organizaciones.

En segundo lugar, se busca en los espacios web información sobre las actividades educativas desarrolladas en estos centros y el público al que van destinadas. Lo cierto es que en todos los museos se puede encontrar en la web un espacio destinado a la educación, donde se destacan todos los programas educativos diseñados por el museo y cada uno de los grupos de interés a los que van destinados. Un ejemplo interesante es el del MNCARS, que publica en el propio site un documento llamado Programación Educativa: programa completo en formato pdf y descargable. Además, en la versión web ofrece la posibilidad de filtrar estas actividades por tipo de público: escolares (con su nivel educativo correspondiente), niños (familias o actividades infantiles), jóvenes (con diferentes franjas de edad), adultos (con tipologías diferentes) y accesibilidad (pudiendo filtrar por el tipo de dificultad que afecta al visitante).

Otra de las variables analizadas es la relacionada con los actos de disposición de la colección, es decir, si se ofrece información acerca de las adquisiciones, préstamos, cesiones, depósitos o compras. En tres de los cuatro museos no se publica información específica sobre este tipo de datos. Sí que se comunican hechos acerca de la historia de los museos y su colección, pero no se hace mención de manera específica a qué tipo de obras son propiedad de la institución y cuáles cesiones, préstamos, etc. Sin embargo, debe destacarse que, a pesar de no ofrecer esa información en un apartado específico de las páginas web, sí que pueden consultarse estos datos en las memorias anuales, donde aparecen explicados todos estos puntos. El único museo en el que esta 
información cuenta con un apartado propio es en el British Museum, donde se ha diseñado el microsite: 'Annual Reports and Accounts'.

$\mathrm{Al}$ analizar la estructura organizativa se diferencia entre la publicación del nombre y apellidos del gerente y director artístico; el nombre y apellidos de los principales departamentos y la aparición de un organigrama que explique la estructura departamental. En los casos consultados sí que se reflejan el nombre y apellidos del director o del gerente de la institución, ya que es un dato de referencia a la hora de conocer a la cabeza de cualquier tipo de organización. No ocurre lo mismo con el nombre y apellidos de los principales responsables de los diversos departamentos que conforman los museos ya que, en este caso, en dos de los cuatro museos o bien no aparece la información o, por el contrario, sólo se publican los datos de contacto a través de una dirección de correo electrónico genérica. Los únicos museos que sí que hacen pública esa información son el British Museum y el MNCARS en las secciones: 'Freedom of Information Publication Scheme' y 'Equipo', respectivamente.

Ofrecen los nombres y apellidos, así como el cargo de los miembros y, en el caso del museo británico, se acompaña la información con una pequeña biografía y la dirección de correo electrónico de contacto personal del responsable del departamento. Por último, dos de los cuatro museos analizados hacen referencia a su organigrama: Musée du Louvre y MNCARS. Lamentablemente, el enlace a esta información que ofrece la primera institución presenta problemas técnicos que impide poder consultarse, resultando sólo válido el organigrama ofrecido por el museo español. En su web sí se pone a disposición del visitante la estructura y organización de las diferentes áreas o departamentos que componen este centro de arte. Esto ayuda a una mejor comprensión de la composición de la institución y la interdependencia de las áreas.

$\mathrm{Al}$ analizar la normativa que regula el funcionamiento de cada uno de estos centros, así como las políticas a las que deben circunscribirse las áreas, los resultados son muy homogéneos. Los cuatro museos analizados disponen de una sección en sus webs en las que se hace referencia a las diversas leyes que regulan su funcionamiento general y específico por áreas (adquisiciones, cesiones, conservación, etc.). En el caso del MET la información se publica en su sección: 'Policies and 
Documents; en el British Museum esta documentación puede encontrarse en el apartado: 'Management and Governance', donde se publican un total de 22 regulaciones al respecto; en el caso del Louvre se dispone de esta legislación en: 'Documents juridiques et marchés publics' y, por último, el MNCARS almacena estos datos en el apartado: 'Misión'.

En lo referente al órgano de gobierno de cada uno de estos centros, el MET no publica en su web los componentes del mismo, al contrario que el resto de museos analizados que presentan a todos los miembros que forman parte de la cúpula directiva de cada organización. De todos los centros de arte, sólo el British Museum publica en su web una pequeña biografía de cada una de estas personas especificando, además, su cargo dentro del órgano de gobierno, algo que también comparte el MNCARS. Sin embargo, ninguno de los museos describe las responsabilidades de estos dentro de los comités de los que forman parte. Con respecto a las reuniones de estos órganos de gobierno, sólo el British Museum y el Louvre publican las actas de las reuniones que mantienen con los asistentes, puntos del orden del día tratados y los acuerdos tomados.

Todos los centros de arte analizados desarrollan su labor dentro de un código de buen gobierno al que se adhieren. El Louvre dispone de un microsite llamado 'Documents juridiques et marchés publics' en el que consultar todos los reglamentos que regulan su quehacer diario. En el caso del MET se guían por la propia ley específica del museo y una serie de políticas que pueden encontrarse en su apartado 'Policies and Documents'. El British Museum, como se ha comentado anteriormente, recoge en su sección 'Freedom of Information Publication Scheme' diversas políticas y códigos que regulan su actuación y se amparan bajo la Freedom of Information Act. Y en el caso del MNCARS, pueden consultarse en el espacio 'Misión' y en el espacio 'Carta de Servicios' tanto la Ley 34/2011 de 4 de octubre reguladora del museo, como sus estatutos o la normativa aplicable que enmarca las buenas prácticas para el trabajo que se realiza en esta institución.

En lo referente a la información económica volcada en las webs corporativas de las organizaciones analizadas, puede destacarse que todas ellas publican el presupuesto del que disponen para el ejercicio en curso, así como los ingresos percibidos. Este tipo de información 
viene recogida, principalmente y en el caso del Louvre, British Museum en las memorias anuales que publican todos los años. En ella se explican todos los pormenores de las cuentas del museo diferenciando los ingresos y gastos imputados al presupuesto anual con el que cuentan. Por un lado, el MET ofrece informes anuales de gastos, diferenciados de su memoria anual, así como el Internal Revenue Service (IRS) Form 990, un documento específico solicitado por el Departamento del Tesoro estadounidense y de obligado cumplimiento. Por otro, el MNCARS no sólo ofrece explicación de su información financiera en las memorias anuales que publica sobre la actividad del museo, sino que, además, como se explicaba en el marco teórico de esta investigación, al ser una institución pública transmite toda esta información en el Portal de Transparencia del Gobierno español. Resulta reseñable que sólo el MET publica un informe completo de sus cuentas firmado por un auditor externo, lo que aumenta la objetividad de los datos plasmados en sus informes económicos.

Por último, todos los centros analizados hacen referencia en sus informes anuales al cumplimiento de los objetivos fijados para ese periodo de tiempo. Se hace referencia en los mismos al grado de cumplimiento del presupuesto general y del destinado a cada partida dentro de las instituciones. Sin embargo, resulta revelador que, en toda la información recogida en estos informes anuales donde se evalúan los resultados obtenidos por el museo, no se haga mención en ninguno de los casos analizados al número de visitantes de cada institución en el año sobre el que versa el documento. Estos datos sí están disponibles en las webs institucionales, pero no en informes, sino en forma de notas de prensa distribuidas por los departamentos de Comunicación de las organizaciones que forman parte de la investigación.

Además, en la mayoría de los casos se ofrece una comparativa con los resultados del año anterior y los actuales, haciendo especial hincapié en si la cifra de público ha incrementado o disminuido. Sin embargo, no se ofrece un análisis más pormenorizado de los públicos o del número de visitas mensuales, a pesar de que todos ellos, además de las visitas físicas, también contabilizan el número de seguidores en las diferentes redes sociales en las que los museos disponen de perfiles públicos.

Analizados los veinticuatro ítems que se proponía este trabajo, los porcentajes de transparencia en los museos analizados superan el 70\%, 
siendo el British Museum (83\%) la institución que más requisitos relacionados con la transparencia cumple, seguido del museo español MNCARS $(80 \%)$ y quedando, en último lugar y compartiendo posición, el museo del Louvre y el MET (71\%).

Una vez expuestos todos los resultados obtenidos de la investigación desarrollada, cabe ofrecer una serie de conclusiones que den respuesta a la hipótesis y objetivos planteados.

\section{Gráfico. 2: Porcentaje de transparencia de los museos analizados}

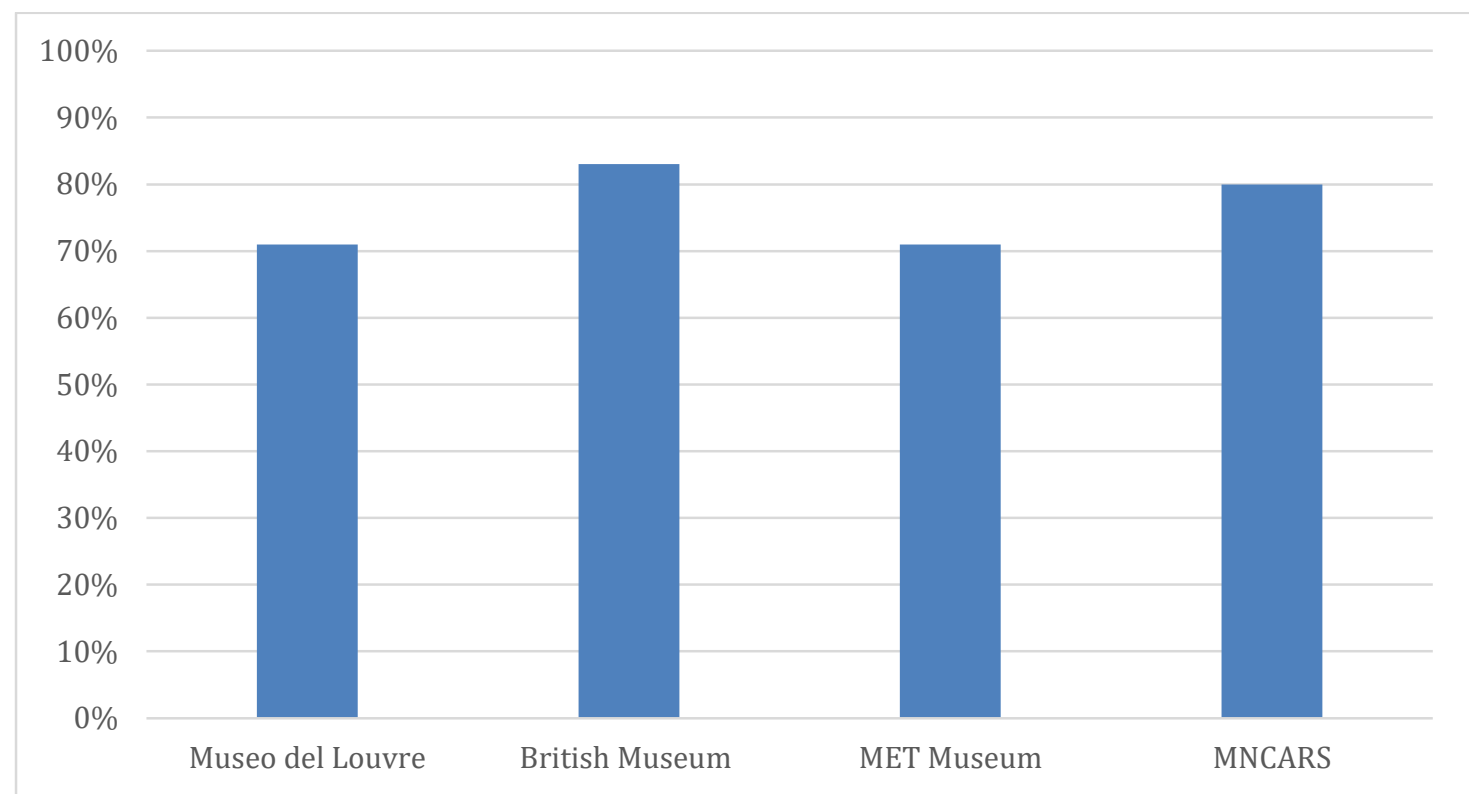

Fuente: Elaboración propia a partir de los ítems de transparencia marcados por la Fundación Compromiso y Transparencia en su informe A través del espejo.

\section{Conclusiones}

La hipótesis principal que se planteaba esta investigación se confirma porque las instituciones museísticas han comenzado a realizar un uso de sus webs centrado en la transparencia y publicación de información relevante relacionada con su actividad.

Los datos presentados en el trabajo y los ítems analizados, se muestra un interés por estas organizaciones en hacer visible no sólo sus principios corporativos, sino también información relativa a su estructura organizativa, sus órganos de gestión, los marcos normativos de referencia bajo los cuales desarrollan su labor, sus buenas prácticas 
o el estado de sus presupuestos y las partidas a las que se destinan. Al igual que ocurre con otros tipos de instituciones como, por ejemplo, las Administraciones Públicas, que han protagonizado tantas publicaciones científicas relacionadas con transparencia, los museos también se adaptan a esa nueva complejidad.

La investigación realizada confirma un buen uso de las webs corporativas por parte de los museos como herramientas para demostrar transparencia. Sin embargo, todavía queda camino por recorrer. A pesar de que la tendencia es buena, existen datos que se guardan con recelo. Resulta llamativo que la composición de los órganos de gobierno continúa siendo, en algunos casos, un misterio, así como la identidad y formación de los miembros que las componen, así como las responsabilidades de cada uno de ellos. Los datos económicos, a pesar de publicarse, todavía no cuentan con el aval de una agencia independiente que certifique que la información volcada, que suele ser considerada sensible, es objetiva y veraz. Este hecho repercutiría de manera positiva en la credibilidad de los datos aportados. Tampoco cuentan con espacios donde puedan consultarse de manera global o desglosada las cifras totales de visitantes, algo que, sorprendentemente, este tipo de instituciones no dudan en hacer público en publicaciones especializadas, como la tomada para justificar la muestra en este estudio. Por último, llama la atención que no en todos los casos analizados se publiquen las actas de las reuniones que mantiene el patronato, los temas tratados y las decisiones tomadas, ya que aportarían una mayor claridad a los procesos de toma de decisión que tienen lugar en esos encuentros.

Los datos analizados demuestran objetivamente que de los museos analizados, tan solo el British Museum dispone de un espacio en su web: 'Government transparency agenda', en el que se hace referencia de manera explícita a la palabra transparencia y donde queda patente su interés por mostrarse como una institución traslúcida ante el público. Cabe destacar en este punto que otros museos que no han formado parte del estudio por no cumplir con los requisitos establecidos para la selección de la muestra como, por ejemplo, el Museo ThyssenBornemisza de Madrid, sí que disponen de una sección específica para 
tal fin. En el caso de esta pinacoteca madrileña este apartado web recibe el nombre de: 'Portal de la transparencia'.

De las webs corporativas de museos analizadas, a pesar de contar con información relevante que las hace translúcidas para el público, lo cierto es que no resulta suficiente para cumplir los veinticuatro ítems planteados. Algunos no aparecen recogidos y la mayor parte de la información directamente relacionada con los índices de transparencia se encuentran distribuidos por diferentes espacios dentro de la web. Por tanto, ninguno de los museos analizados dispone de un solo apartado dentro de su arquitectura web en el que se concentren todos los datos analizados. De esta forma, debe recurrirse a la localización de los mismos de forma manual o, en ocasiones, utilizando los motores de búsqueda internos de las propias webs.

De los veinticuatro ítems analizados en esta investigación y relacionados con el índice de transparencia, todos los museos superan el $70 \%$ de su cumplimiento. Sin embargo, si se establece una relación entre su porcentaje de transparencia y el número de visitantes registrado a lo largo de los años, es el MNCARS el que obtiene un mejor resultado aumentando el registro total, especialmente en el año 2016. Esto hace plantear una futura línea de investigación, y es la relación que existe entre la obtención de unos buenos índices de transparencia y el número de visitantes a este tipo de organizaciones. Resulta de interés investigar si, dadas las características de este tipo de institución, mostrarse como organizaciones transparentes es suficiente para obtener unos buenos resultados en la cifra de público que disfruta de nuestros servicios. Parecen existir otros elementos como el atractivo de la oferta expositiva, los servicios del propio museo, o la comunicación que realiza de su labor diaria la propia institución que parecen influir en este número.

Como cualquier otro tipo de organización al servicio de la sociedad, tal y como reza su definición, queda patente que los museos son instituciones dinámicas, permeables a la sociedad y han entendido la necesidad de adaptarse a los cambios promovidos por una nueva

\footnotetext{
${ }^{9}$ El Portal de la Transparencia del Museo Thyssen-Bornemisza de Madrid puede consultarse en la siguiente dirección web:

http://transparencia.museothyssen.org/ (Recuperado el 28/05/2017).
} 
complejidad a la que deben hacer frente. A través de diferentes herramientas de comunicación como, en el caso analizado, sus webs corporativas, se aproximan a sus stakeholders proveyéndoles de información relevante y de su interés. De esta forma, demuestran que son una institución que, al igual que las Administraciones Públicas, apuestan por la transparencia y la entienden como una necesidad para recuperar la confianza perdida por parte de la sociedad hacia las instituciones.

Fechas:

- Inicio de la investigación: marzo de 2017

- Término de la investigación: ju nio de 2017

- Esta actividad ha sido financiada por UNIR Research (http:/ / research.unir.net), Universidad Internacional de La Rioja (UNIR, http://www.unir.net), dentro del Plan Propio de Investigación, Desarrollo e Innovación [2015- 2017], Grupo de Investigación "COYSODI- Comunicación y Sociedad Digital"

\section{Bibliografía}

M. Arenilla, J.C. Redondo (2011): "Ética, transparencia y participación”. En M. Arenilla (Dir.). Crisis y reforma de la administración pública. Oleiros: Netbiblo.

L. Arias-Serrano (2015): "New Museological Approaches in Contemporary Art Museums: From the First Critiques of the Museum in the Early Twentieth Century to Today's Micronarratives". Complutum. Vol. 26, n. 2, pp. 133-143.

A. Alloza, (2011): "La emergencia de la economía de la reputación corporativa". Revista Uno, 5, pp. 1-7.

http://www.revista-uno.com/numero-5/la-emergencia-delaeconomia-de-la-reputacion-corporativa/

P. Beltrán-Orenes, Pilar; E. Martínez-Pastor (2016): “Grado de cumplimiento de las leyes de transparencia, acceso y buen gobierno, y de reutilización de los datos de contratación de la 
Administración central española". Elprofesional de la información, v. 25, n.4, pp. 557-567.

G. Black (2012): Transforming Museums in the Twenty-First Century. London and New York: Routledge.

F. Cabezuelo-Lorenzo, P. Rey-García, A. Tapia-Frade (2016): "Análisis de las herramientas de control ciudadano sobre los representantes públicos: La transparencia informativa municipal en Castilla y León”. Revista Latina de Comunicación Social, 71, pp. 1.2611279.

M. C. Carey (2017): "Transparency and the lobbying efforts of newspaper associations in the United States". Journalism Studies. Vol. 18, n. 4, pp. 409-429.

I. Castelló, M. Morsing y F. Schultz (2013): “Communicative Dynamics and the Polyphony of Corporate Social Responsibility in the Network Society". Journal of Business Ethics, 118(4), pp. 683-694.

D. Cordón-Benito, D. González-González (2016): "Museos y comunicación: los nuevos medios como herramienta de diálogo y sociabilidad de la institución. El uso de Twitter por el Museo del Prado, Museo Thyssen-Bornemisza y Museo Reina Sofía”. Fonseca Journal of Communication. Vol. 1, nº12, pp. 149-165.

J. Cornelissen (2004): Corporate Communication: A Guide to Theory and Practice. California-Londres: SAGE.

A. Cortina, (Ed.) (2003): Construir confianza: ética de la empresa en la sociedad de la información y las comunicaciones. Madrid: Editorial Trotta.

C. Craig, P. Ngondo, M.A. Flynn (2016): "How firm is your digital handshake?: Mission statements and transparency". Public Relations Review, Vol. 42, n. 4, pp. 692-694.

B. De la Iglesia, M.R. Roselló-Ramón (2014): "Identificación de las barreras de acceso a la información, a la participación y al aprendizaje en el Museo Es Baluard". Arte, Individuo y Sociedad, Vol. 26, $\mathrm{n}^{\circ} 1$, p. $21-38$.

T. Derville (2005): "Radical Activist Tactics: Overturning Public Relations

Conceptualizations". Public Relations Review, 31(4), 527-533.

J. Doodey, H.F, García (2007): “Reputation Management”. En J. Doorley, H.F. García (Eds.). Reputation management: the key to successful public relations and corporate communications, pp. 1-26. Nueva York y Londres: Routledge 
Edelman (2016): Edelman Trust Barometer Executive Summary. http://www.edelman.com/insights/intellectual-property/2016edelman-trust-barometer/executive-summary/

Edelman (2017): Edelman Trust Barometer Executive Summary. http://www.edelman.com/executive-summary/

R. E. Freeman (1984): Strategic management: a stakeholder approach. Boston: Pitman.

R. E. Freeman, J. S. Harrison, A. C. Mechas, B. L. Parmar y S. De Colle. (2010): Stakeholder theory: the state of the art. Cambridge: Cambridge University Press.

M. Gértrudix, M.C. Gertrudis-Casado, S. Álvarez-García (2016): "Consumption of public institutions. Open Data by Spanish citizens". El profesional de la información, v. 25, n.4, pp. 535-544.

E. Gutiérrez; M.T. Laporte (Eds.) (2013): Tendencias emergentes en la comunicación de instituciones. Barcelona: UOC Press.

E. Hooper-Greenhill, (1989): "The museum in the disciplinary society", in S. Pearce (Ed.). Museum Studies in Material Culture, pp. 61-72. London: Leicester University Press.

E. Hooper-Greenhill (1992): Museums and the Shaping of Knowledge. London: Routledge.

E. Hooper-Greenhill (2000): Museums and the Interpretation of Visual Culture. London: Routledge.

T. Bennett (1996): The Birth of the Museum, London: Routledge.

N.C. Huang-Horowitz (2015): "Public relations in the small business environment: creating identity and building reputation". Public Relations Review. Vol. 41, n. 3, pp. 345-353.

M. Karlsson, C. Clerwall, L. Nord (2017): "Do not stand corrected: Transparency and users' attitudes to inaccurate news and corrections in online journalism". Journalism \& Mass Communication Quarterly, Vol. 94, n. 1, pp. 148-167.

M. Lizcano (2013): "La nueva Ley de Transparencia: un importante desafío social". Abogacía.es. España.

http://www.abogacia.es/2013/12/23/la-nueva-ley-de-transparenciaun-importante-desafio-social/

L. La-Rosa, T. Sandoval-Martín (2016): "La insuficiencia de la Ley de Transparencia para el ejercicio del periodismo de datos en España”. Revista Latina de Comunicación Social, 71, pp. 1.208-1.229. 
P. C. Lopez-Lopez, I. Puentes- Rivera, J. Ruas-Araujo (2017):

"Transparency in public televisions: development of indicators and case analysis in Spain and Chile". Revista Latina de Comunicación Social, Vol. 72, n.3, pp. 253-272.

R. Magallón (2013): "Por qué es importante una buena Ley de Transparencia para el periodismo y para los periodistas". Instituto para la Innovación Periodística. España.

http://www.2ip.es/wp-

content/uploads/2013/01/Ley trasnparencia.pdf

M. Rebolledo, R. Zamora-Medina, J. Rodríguez-Virgili (2016):

"Transparency, accountability and participation in local governments: a comparative study of Spanish council Websites". Medijske Studije-Media Studies, Vol. 7, n.14, pp. 48-64.

A. G. Scherer, G. Palazzo y D. Matten (2014): "The Business Firm as a Political Actor: A New Theory of the Firm for a Globalized World”. Business \& Society, 538(2), pp. 143-156.

K. Sriramesh, (2010): "Globalization and Public Relations.

Opportunities for Growth and Reformulation". En R. Heath (Ed). The SAGE Handbook of Public Relations, pp. 691-707. CaliforniaLondres: SAGE.

J.C. Suárez-Villegas, R. Rodríguez-Martínez, M. Mauri-Ríos, A. López-Meri (2017): "Accountability and Media Systems in Spain: real impact and good practices in Spanish media". Revista Latina de Comunicación Social. Vol. 72, n. 3, pp. 321-330.

J. Villafañe (2004): La buena reputación: claves del valor intangible de las empresas. Madrid: Pirámide.

J. Villafañe (2013): La buena empresa: propuesta para una teoría de la reputación corporativa. Madrid: Pearson.

S.W. Yoo, H. Gil de Zúñiga (2014): “Connecting blog, twitter and Facebook use with gaps in knowledge and participation.

Communication \& Society, Vol. 27, n. 4, pp. 33-48.

\section{Fuentes}

General

- Musée du Louvre, Paris

- Metropolitan Museum of Art (MET), Nueva York

- British Museum, Londres

- Museo Nacional Centro de Arte Reina Sofía (MNCARS), Madrid 
- Portal de Transparencia

- International Council of Museums (ICOM)

Normativas

- Ley 19/2013, de 9 de diciembre, Transparencia, acceso a la información pública y buen gobierno

- Ley 34/2011, de 4 de octubre, reguladora del Museo Nacional Centro de Arte Reina Sofía

- Freedom of Information Act (U.K.)

- Internal Revenue Service (IRS) Form 900 (USA).

Cómo citar: Cordón Benito D, et al (2017): "Las webs corporativas de museos como herramientas para la transparencia". Revista Latina de Comunicación Social, 72, pp. 941 a 956.

http://www.revistalatinacs.org/072paper/1201/51es.html DOI: $10.4185 /$ RLCS-2017-1201 
Cómo citar: JV García Santamaría, J Martín Matallana (2017): “La transparencia municipal en España: análisis de los factores que más influyen en el grado de transparencia”. Revista Latina de Comunicación Social, 72, pp. 1.148 a 1.164. http://www.revistalatinacs.org/072paper/1212/62es.html DOI: $10.4185 /$ RLCS-2017-1212

La transparencia municipal en España: análisis de los factores que más influyen en el grado de transparencia

José Vicente García Santamaría - Universidad Carlos III de Madrid - josevicente.garcia@uc3m.es

Jesús Martín Matallana - Universidad Carlos III de Madrid 100079379@alumnos.uc3m.es

\begin{abstract}
s
Introducción. Este artículo tiene como objetivo fundamental determinar los factores que más pueden influir en el grado de transparencia municipal de los ayuntamientos españoles, de acuerdo con el ITA. En particular, nos centraremos en el análisis pormenorizado de cuatro posibles factores de influencia: signo político, dimensión del municipio, ubicación geográfica y nivel de renta per cápita. La conclusión es que, en estos momentos, y dada la evolución de este Índice, ninguno de ellos constituye un factor determinante. Pero para llevar a cabo un análisis más amplio y preciso sería necesario que ampliarse los procedimientos metodológicos que sigue el ITA, e incluso incluir nuevos factores de estudio. Metodología. Revisión bibliográfica. Investigación con entrevistas en profundidad a un panel de expertos y estudio de aquellos factores que más pueden influir en el grado de transparencia municipal. Resultados y conclusiones. Aun
\end{abstract}


reconociendo el significativo avance que ha tenido la transparencia municipal sería aconsejable también evaluar y mejorar los procedimientos del ITA.

\section{Keywords}

Transparencia, Transparencia municipal, Portales de transparencia, Buen Gobierno Corporativo, Rendición de cuentas.

\section{Contents}

1. Introducción y estado de la cuestión. 2. Objetivos. 3. Metodología. 4. Herramientas al servicio de la transparencia. 5. Resultados del ITA 2017. 5.1. Signo político. 5.2. Número de habitantes. 5.3. Nivel de renta per cápita. 5.4. Ubicación geográfica. 6. Conclusiones. 7. Referencias bibliográficas.

\section{Introducción y estado de la cuestión}

L

A transparencia es un efectivo instrumento transformador de la gestión pública que permite a los ciudadanos comprobar cuáles son los referentes de actuación y los intereses de los poderes públicos -en concreto de las Administraciones Locales-, fortaleciendo así el debate político y la democracia (Conejero Paz, 2014). Entendida como principio vertebrador de cualquier Estado, la trasparencia pública acerca las instituciones a los ciudadanos y permite que éstos confíen en los centros de decisión política. Aún más, puede ser una herramienta esencial para combatir la corrupción y mejorar la calidad de nuestras democracias, signadas por una cultura de secretismo público (Álvarez, 2007:6).

La transparencia puede ser definida, por tanto, como el deber que tienen todos los poderes públicos para dar cuenta de sus actos y explicar, razonada y razonablemente, su actuación (Arenillas y Redondo, 2011:360). Pero está claro también que la transparencia no se puede entender exclusivamente como la consecución de un fin concreto, sino como un medio para lograr que las decisiones sean motivadas y razonables y que la información que sirve para la adopción de decisiones sea accesible al público (Jiménez et alt, 2012). Moreu Carbonell (2005:65) ha llegado incluso a afirmar que la evaluación de 
las instituciones supone interpretar la información obtenida de ellas basándose en evidencias que sean creíbles, fiables y útiles.

Transparencia e información van de la mano (Cotino, Sahuquillo y Corredoira, 2015, Guichot Reina, 2011a, Hollrah, 2005). Tanto es así que De Ferranti et alt. (2009) la definen como la disponibilidad y creciente flujo de información oportuna, comprensiva, relevante y de alta calidad relacionada con las acciones gubernamentales. Así, la transparencia pasa a ser una divulgación activa de información de carácter público, y resultan de obligada publicación todas aquellas decisiones públicas que toman los gobiernos o las diferentes administraciones públicas. La transparencia estaría así íntimamente ligada a la rendición de cuentas (Ackerman, 2008).

Pero sin duda lo más relevante es que los ciudadanos puedan evaluar el rendimiento de las instituciones y mantener su confianza en ellas (Labeaga y Muñoz, 2013). Y esta evaluación de las instituciones supone interpretar la información de las instituciones basándose en evidencias creíbles, fiables y útiles (Garde Roca (2006).

El concepto de transparencia comienza a estar presente en el debate político español con el surgimiento de la crisis económica al percibir gobierno e instituciones la deslegitimación que sufren en su actuación y la necesidad de superarla (Morales García et alt, 2016). En muy pocos años, este concepto prende en el ideario de todos los partidos políticos y de las Administraciones en su conjunto. En muchos casos va ligado incluso a conceptos conexos como la "regeneración democrática", la lucha contra la corrupción administrativa, el Buen Gobierno o el acceso a la información pública.

La transparencia supone también la implicación activa de la ciudadanía en la gestión de lo público mediante una auditoría cívica; legitimidad y responsabilidad de los gobernantes en virtud de la rendición de cuentas; herramienta discursiva de legitimación de actuaciones y decisiones políticas y, por supuesto, acaba siendo la más efectiva de las barreras frente a la corrupción administrativa. Como afirmaba el que fuera alcalde de Madrid, Enrique Tierno Galván, "los bolsillos de los gobernantes han de ser de cristal".

La transparencia gubernamental municipal adquiere así una doble vertiente. Una vertiente activa, en virtud de la cual las Administraciones 
Públicas municipales están legalmente obligadas a poner a disposición de los ciudadanos información de carácter público, desde procedimientos o actos administrativos a resoluciones o partidas presupuestarias. Y una vertiente pasiva, en la que son los propios ciudadanos los que, por iniciativa propia, solicitan a las administraciones la información que estimen conveniente para ejercer el rol de contrapoder (O’Leary, 2011).

Con independencia del consustancial elemento cultural y educacional que lleva implícito la transparencia municipal -en tanto en cuanto exige un paso al frente de la ciudadanía para ejercerse en toda su plenitud-, la regulación legal del fenómeno es siempre el primer paso para convertir en obligatorio lo que tradicionalmente ha sido una simple alternativa adoptada de forma minoritaria por nuestros gobiernos (Cendejas Jáuregui, 2007).

En este sentido conviene apuntar que, en el caso de España, la regulación legal sobre transparencia ha sido especialmente tardía: hasta el año 2013 carecíamos de una ley ad hoc que la regulase. Partíamos únicamente de la regulación constitucional del artículo 105.b de nuestra Carta Magna como marco de referencia para que tanto ciudadanos como administraciones supieran a qué atenerse, en términos de transparencia y acceso a la información pública. No hemos de perder de vista que el mencionado precepto se limitaba a sentar las bases de un derecho de acceso a la información que requería, necesariamente, del pertinente desarrollo legal a través de una ley ordinaria (Guichot Reina, 2011b).

El 9 de diciembre de 2013 se promulgó en España la Ley 19/2013 de transparencia, acceso a la información pública y buen gobierno corporativo; treinta años después de que la Constitución sentara las bases del derecho de acceso a la información en su artículo 105.b (Mendel, 2006). Pese a que la demora regulatoria constituía una enorme oportunidad para que nuestro país promulgase una ley de transparencia avanzada y modélica - a la vista de los numerosos modelos de referencia que constituían las leyes vecinas-, la realidad fue bien distinta: la Ley 19/2013 no solo fue tardía, sino que además se consideró mayoritariamente como una "ley de mínimos", que se limitaba a consolidar una serie de estándares básicos del discurso político. 
Como consecuencia de sus múltiples carencias se convirtió en blanco de numerosas críticas: desde la no catalogación del derecho de acceso a la información como un derecho fundamental; la excesiva cantidad de excepciones absolutas; el silencio administrativo negativo; la ausencia de mecanismos de control, inspección y sanción autónomos y de garantías; las exclusiones subjetivas inadmisibles, o la existencia de una única ley para regular dos ámbitos tan diferenciados $\mathrm{e}$ independientes como son la transparencia y el buen gobierno corporativo.

En cualquier caso, y con independencia de las críticas que la colocan a la cola de la regulación sobre transparencia en el marco de la Unión Europea, es indudable que la promulgación de la Ley 19/2013 ha supuesto un avance que, difícilmente podrá volver tras sus pasos, en tanto en cuanto ha convertido en "obligatorio" lo que antes era tan facultativo como minoritario.

En definitiva, un gobierno es transparente cuando ofrece información sobre su funcionamiento, rinde cuentas, explica sus acciones y se responsabiliza de sus actos (Morales et alt, 2016). Y esta acción resulta esencial para fomentar una cultura de la transparencia y de la rendición de cuentas (FEMP, 2010).

\section{Objetivos}

El objetivo principal del presente artículo consiste en determinar los factores que más pueden influir en el grado de transparencia municipal de los ayuntamientos españoles. En particular, nos centraremos en el análisis pormenorizado de cuatro posibles factores de influencia: signo político, dimensión del municipio, ubicación geográfica y nivel de renta per cápita. Factores que, a priori, y según consenso de expertos consultados, pueden ser decisivos a la hora de determinar este nivel.

Entre los objetivos secundarios cabe destacar la comparativa entre los resultados del Índice de Transparencia de los Ayuntamientos (ITA) 2017 y los de pasadas ediciones; así como el análisis de algunos posibles factores de influencia de carácter secundario, como el género del regidor o la fortaleza política del consistorio. 
Por otra parte, un objetivo final de la investigación es determinar si la metodología imperante que se aplica en España, condicionada por el ITA, es suficiente o podría ser sustancialmente mejorada con la ayuda de otros indicadores o la inclusión de nuevos factores de estudio.

\section{Metodología}

La metodología parte del empleo de tres herramientas: a) una revisión de la literatura académica sobre transparencia, Buen Gobierno y rendición de cuentas. b) el estudio de aquellos factores que más pueden influir en la transparencia municipal, para lo que nos basaremos en el análisis pormenorizado de los resultados ofrecidos por el ITA en su informe de los años 2014 y 2017, así como en indicadores anteriores. La muestra analizada se compone de los 110 ayuntamientos pertenecientes a los municipios españoles de mayor tamaño; cuyos niveles de puntuación en términos de transparencia dependen de un total de 80 indicadores, agrupados en seis Áreas de Transparencia.

De acuerdo con lo anteriormente expuesto, y en relación a los factores que influyen en el mayor o menor grado de transparencia municipal de los ayuntamientos españoles, podemos plantearnos la hipótesis de que el grado de transparencia municipal depende de cuatro factores: signo político del gobierno de cada ayuntamiento; dimensión del municipio en cuestión, esto es, del número de habitantes del mismo; nivel de riqueza del municipio, entendido como PIB por habitante, y, por último, zona geográfica en la que se ubique el municipio.

Debemos subrayar también la existencia de diferentes entidades que han diseñado sistemas de evaluación y medición diferentes para valorar la transparencia municipal, pero no se dispone de una homogeneización de estos sistemas, y esta disparidad de criterios de medición y metodologías ofrece variaciones sustanciales en los resultados (Delgado, 2015). Por tanto, y aunque la aceptación del ITA sea amplia, hemos recurrido a un panel de seis expertos para determinar tanto las limitaciones del ITA como para determinar si nos encontramos o no ante niveles de transparencia razonables en los ayuntamientos españoles. Los expertos pertenecen a los ámbitos de la administración municipal, la economía, la sociología y el derecho. A través de un focus group y de la realización de entrevistas en 
profundidad, con un cuestionario semiestructurado de diez preguntas, hemos extraído también un informe que nos lleva a conclusiones interesantes sobre las técnicas utilizadas actualmente.

El motivo de recurrir al panel de expertos obedece igualmente a la opinión relevante de un puñado de autores académicos, que ha considerado conveniente abordar la transparencia desde un enfoque integral; un enfoque que permitiría llegar a conocer cuáles son las variables políticas y administrativas que más influyen en su institucionalización (Ackerman, 2008, Albassam, 2016, Ferejohn, 1999, Gaventa y McGee, 2013).

De forma complementaria, no podemos perder de vista que el acceso a la información pública pivota, en último término, sobre el mundo digital y los nuevos medios. Así, las páginas web emergen como el elemento decisivo para interconectar a la ciudadanía con las Administraciones Públicas en pro de una transparencia gubernamental verdaderamente efectiva. Se requiere así de una web intuitiva, interactiva, de fácil navegación y, por supuesto, accesible para todos los ciudadanos, y sin ningún tipo de restricción.

Por tanto, el estudio aleatorio que hemos realizado de webs de ayuntamientos españoles de diferente tamaño, ubicación geográfica y pertenencia a diferentes formaciones políticas, aunque no sea una muestra exhaustiva, permitirá apreciar también cuál es la utilidad de la información que ofrecen y si realmente ese principio de transparencia encuentra su equivalente en el tratamiento pormenorizado y accesible al ciudadano común de la información más relevante ofrecida por nuestros municipios. Es preciso que los datos sean accesibles, relevantes y de calidad (Ferejohn y Kuklinski, 1990). Al igual que resultan relevantes, como objeto de estudio, otros factores, que, a veces, carecen de la necesaria relevancia, como es el caso de la visibilización de las agendas institucionales (Méndez Juez, 2017).

En conclusión, no se trata solo de poner en marcha sistemas de Administración electrónica que acerquen las instituciones a los ciudadanos, sino también que se generen procedimientos válidos para poder interactuar con los gestores públicos (Beltrán y Martínez, 2016). 


\section{Herramientas al servicio de la transparencia}

El Portal de Transparencia, a nivel estatal, es la plataforma que permite el acceso a la información pública de la Administración General del Estado, categorizada en tres niveles: a) institucional: organización, estructura y funciones de los Ministerios, b) económico: gestión administrativa y presupuestaria, y c) normativo: información jurídica y textos normativos aplicados por los respectivos Ministerios.

Como ya ocurriera con la Ley 19/2013, el Portal de Transparencia tampoco se ha librado de convertirse en blanco de diversas críticas, como consecuencia de las deficiencias en sus opciones de búsqueda al no indexar sus datos de conformidad con las convenciones informáticas básicas-, de forma que solo permite filtrar documentos por ministerio y fecha, lo que dificulta enormemente la tarea; la imposibilidad de extracción de datos en formatos reutilizables, lo que obliga a buscar y transcribir manualmente la información, o la exigencia del DNI electrónico para su acceso, que obedece a un evidente finalidad disuasoria, en tanto en cuanto menos de la mitad de la población española dispone del mencionado DNI. Similares críticas reciben, en términos generales, sus homólogos a nivel autonómico y local.

Con carácter paralelo a los mencionados Portales de Transparencia gubernamentales y de titularidad pública, contamos igualmente con diversas plataformas de acceso a la información pública con carácter privado, como por ejemplo las promovidas por la Fundación Civio. Entre ellas podemos destacar algunas como Tu derecho a saber, una web que intermedia entre los ciudadanos y administraciones, unificando las solicitudes repetidas; El BOE nuestro de cada día, plataforma que analiza, relaciona y simplifica el contenido del Boletín Oficial del Estado, a fin de hacerlo comprensible para la ciudadanía, o Dónde van mis impuestos, una herramienta que permite visualizar en qué se emplea el dinero público.

\subsection{Transparencia municipal: el ITA}

Cuando se habla de transparencia a nivel municipal parece indispensable referirse al ITA (Transparencia Internacional España), un estudio que desde el año 2008 mide el grado de transparencia de los 110 mayores ayuntamientos españoles, que son categorizados también 
en un ranking. Para llevar a cabo esta clasificación, el ITA analiza un total de 80 indicadores diferentes, agrupados en seis grandes categorías: Información sobre la Corporación Municipal, Relaciones con los ciudadanos y la sociedad, Transparencia económico-financiera, Transparencia en las contrataciones y costes de los servicios, Transparencia en materia de urbanismo, obras públicas y medioambiente e Indicadores de la Ley de Transparencia. A partir de ahí, cada consistorio obtiene una puntuación final.

Nos encontramos, por tanto, ante un estudio que sirve como incentivo para que los ayuntamientos mejoren su nivel de transparencia en cada una de sus ediciones al propiciar un mayor acercamiento entre la Administración Local y la ciudadanía (Piñar Mañas, 2010). Ahora bien, es un estudio que guarda también ciertas debilidades al no ser tenida en cuenta la utilización de formatos abiertos para la difusión de la información pública y el acceso individualizado a la misma, así como otros aspectos que pueden parecer tangenciales, como la grabación de los plenos municipales, pero que en muchos casos no son permitidos.

En base a la clasificación del último informe de transparencia municipal, publicado por el ITA en el año 2017, podemos esgrimir los siguientes resultados:

a) La inmensa mayoría de los ayuntamientos, pertenecientes a la muestra, crearon dentro de su respectiva web una página especial dedicada a la transparencia, con una sección específica para los indicadores del ITA. Todo esto viene a corroborar que la apuesta por la transparencia por parte de nuestros consistorios es ya un hecho generalizado, respondiendo así a una demanda de la sociedad civil por tener acceso a mayor volumen de información. Si bien existen limitaciones que no conviene soslayar y de las que daremos cuenta.

b) Un número significativo (25) de los 110 ayuntamientos evaluados ha publicado la totalidad de los 80 indicadores que integran el ITA 2017, lo que viene a evidenciar la importancia que las corporaciones locales -debido a la demanda ciudadana y a la regulación normativa- otorgan a la transparencia municipal, que ya es un hecho generalizado en nuestros consistorios. No obstante, no deja de ser preocupante que, en 
torno a un $44 \%$ de los ayuntamientos, no alcancen una puntuación mínima de 90 puntos sobre 100.

c) Las puntuaciones medias alcanzadas por el conjunto de los ayuntamientos evaluados han sido más altas que las de la edición precedente (2014), que a su vez había sido superior a la de los años anteriores. Así, la puntuación media general de los 110 ayuntamientos en el año 2017 ha alcanzado los 89,7 puntos sobre 100; los 85,2 conseguidos en 2014; y de 70,9 (2012), 70,2 (2010), 64,0 (2009) y 52,1 (2008). Además, en cada una de las seis Áreas de Transparencia analizadas, las puntuaciones medias del conjunto de los Ayuntamientos han sido igualmente superiores a las de la pasada edición. De todo ello cabe deducir, atendiendo a los datos del ITA, que la transparencia municipal mejora año tras año en España.

d) En cuanto a la evolución histórica del ITA, cabe recordar que en la primera edición de 2008 solo hubo un ayuntamiento -el de Bilbao, pionero en transparencia- que obtuviese la máxima calificación posible (100 puntos sobre 100). Frente a los 19 consistorios de la pasada edición del año 2014; en el estudio de 2017 fueron 25 los ayuntamientos que han conseguido la mencionada puntuación: Alcobendas, Alicante, Barakaldo, Barcelona, Bilbao, Getxo, Gijón, Girona, Huelva, Jerez de la Frontera, Las Palmas De Gran Canaria, Las Rozas, León, Lérida, Logroño, Madrid, Manresa, Oviedo, Pozuelo de Alarcón, San Cristóbal de la Laguna, Soria, Terrassa, Torrejón de Ardoz, Torrenty Vitoria.

e) En lo que respecta a las seis Áreas de transparencia evaluadas, cabe señalar que todavía se pueden considerar asignaturas pendientes: la Transparencia en las contrataciones (con una puntuación de 85,8 puntos) y la Transparencia en materias de urbanismo y obras públicas $(86,0)$. Las mayores puntuaciones residen en Transparencia económico-financiera $(93,1)$ y Transparencia Activa $(92,7)$. 


\section{Resultados del ITA 2017}

En base al análisis de los resultados publicados en el informe del ITA 2017 podemos resaltar las siguientes conclusiones en relación a la hipótesis de partida:

\subsection{Signo político:}

Desde una perspectiva estrictamente teórica (Guillamón et alt, 2011), los municipios gobernados por partidos progresistas son más transparentes que los gobernados por conservadores. En esta misma línea, Ferejohn (1999) sostiene que aquellos políticos que deseen incrementar el tamaño del sector público deben aumentar la transparencia con el fin de que los votantes les confíen una mayor cantidad de recursos. Por lo tanto, dado que los gobiernos progresistas abogan por un mayor sector público, estarán dispuestos a implementar mayores niveles de transparencia que los gobiernos conservadores.

Pese a que desde una lógica estrictamente teórica pudiéramos pensar que efectivamente el signo político es una variable determinante en términos de transparencia municipal, a la luz de los datos ofrecidos por el ITA 2017 no podemos afirmar categóricamente que nos encontremos ante un factor decisivo. Sí estamos ante un reparto equitativo de partidos políticos en los diferentes niveles de transparencia, lo que equivale a decir que consistorios encabezados por las diferentes ideologías políticas imperantes en nuestro país obtienen puntuaciones similares.

En este sentido, Jesús Lizcano Álvarez (2012) asegura, en relación con los resultados del ITA 2009, que "la transparencia no es una cuestión de color político, es una cuestión de actitud, de que alguien quiera ser transparente" (1).

Tal y como podemos apreciar en el cuadro 1, no existe un determinado partido político que de por sí sea más transparente o más opaco que otro. Las proporciones se mantienen similares en todas las categorías, especialmente en la relativa a Transparencia Alta; la más representativa y fiable al contener una muestra mucho mayor que las otras dos. Por ejemplo, el Partido Popular gobierna ayuntamientos con puntuaciones sobresalientes (Las Rozas, León o Santander), así como ayuntamientos 
con pobres niveles de transparencia, como es el caso de Badajoz, con una puntuación de 75,6 puntos sobre 100 .

Dicho de otra forma, entre los 25 ayuntamientos que han obtenido en el año 2017 la máxima puntuación posible encontramos partidos políticos de muy diferente signo político, si bien existe una ligera inclinación hacia otras opciones distintas a las del Partido Popular.

Cuadro $\mathbf{N}^{\circ}$ 1: Influencia del signo político en la transparencia municipal

\begin{tabular}{|c|c|c|c|}
\hline \multicolumn{3}{|c|}{ SEGUN EL SIGNO POLÍTICO } \\
\hline & PP & PSOE & $\begin{array}{c}\text { OTROS } \\
\text { (PODEMOS, C'S, } \\
\text { NACIONALISTAS) }\end{array}$ \\
\hline TRANSPARENCIA & 30 & & 32 \\
ALTA & MUNICIPIOS & MUNICIPIOS & 35 MUNICIPIOS \\
(75-100) & DE 97: & DE 97: & DE 97: \\
& $31 \%$ & $33 \%$ & $36 \%$ \\
TRANSPARENCIA & 4 & 3 & 3 MUNICIPIOS \\
MEDIA & MUNICIPIOS & MUNICIPIOS & DE 10: \\
(50-75) & DE $10:$ & DE $10:$ & $30 \%$ \\
TRANSPARENCIA & $40 \%$ & $30 \%$ & 2 MUNICIPIOS \\
BAJA & MUNICIPIO & MUNICIPIOS & DE 3: \\
(MENOS DE 50) & DE 3: & DE 3: & $\mathbf{6 7 \%} \%$ \\
\hline
\end{tabular}

Fuente: elaboración propia con datos del ITA (2017)

Según la quinta edición del informe Transparencia, el mejor eslogan (2017), llevado a cabo por la Fundación Compromiso y Transparencia, ningún partido político nacional alcanza todavía la categoría de "transparente", mientras que se incrementa el número de fundaciones translúcidas con respecto a las ediciones anteriores. Pese a que estos resultados contrasten con los discursos pro transparencia enarbolados por los diferentes líderes políticos, la realidad es que, tras una ligera y positiva evolución, los partidos tradicionales se han estancado en la mejora de sus acciones de rendición de cuentas; al tiempo que los nuevos partidos incorporados a la muestra tampoco han aportado datos positivos para 
el cumplimiento de los indicadores de transparencia. Pero, en general, los partidos políticos no salen bien parados en sus evaluaciones ${ }^{10}$.

Cuestiones distintas son el género del regidor, hombre o mujer, y el grado de fortaleza política del consistorio. Aunque para algunos expertos no sea un factor determinante, de los 110 ayuntamientos evaluados en el ITA 2017 encontramos una mayoría de alcaldes frente a alcaldesas; concretamente 81 frente a 29. Pese a que a nivel de resultados los ayuntamientos gobernados por alcaldesas hayan obtenido puntuaciones medias superiores en relación a las obtenidas por alcaldes $(90,3$ frente a 89,4), la diferencia es tan escasa que no podemos considerar el género del regidor como un factor determinante en términos de transparencia.

En lo que respecta a la fortaleza política del consistorio, Guillamón et alt (2011) señalan que "una mayor fragmentación del gobierno local conlleva un mayor nivel de transparencia (...), lo que pone de manifiesto que aquellos partidos políticos que gobiernan en solitario hacen uso de su poder mayoritario para obstaculizar la apertura informativa de los ayuntamientos que dirigen (...)”. Según diversos autores, la competencia política entre los partidos integrantes de la coalición fomenta la publicación de información pública, debido al afán de los políticos de limitar la capacidad de actuación de los miembros del gobierno que no pertenecen a su partido (Kaumann y Kraay, 2002, Pierre, 2010 y Rodríguez Pallarés y Pérez Serrano, 2017).

\subsection{Número de habitantes:}

Otro factor bastante recurrente a la hora de valorar las diferencias de transparencia entre ayuntamientos es la dimensión del municipio en cuestión. A priori, puede pensarse que en una localidad con mayor número de habitantes la gestión de lo público estará mucho más estandarizada y controlada, por lo que la transparencia será mayor. De la misma manera que podríamos aventurar, desde el ángulo contrario, que un entramado más complejo, derivado de una mayor dimensión, acabará desembocando, irremediablemente, en una mayor opacidad.

\footnotetext{
${ }^{10}$ http://www.laopiniondemurcia.es/cartagena/2017/07/08/cartagena-ciudad-transparenteregion/843753.html
} 
Pero el tamaño del municipio, sobre todo en las grandes ciudades, añade nuevas y enormes complejidades de gestión.

Si bien es cierto que a la luz de los datos ofrecidos por el estudio del ITA 2017 los ayuntamientos más grandes son los que han obtenido una mayor puntuación media en términos de transparencia, partimos, sin embargo, de un sesgo inherente al propio estudio, cuya muestra selecciona, precisamente, a los 110 municipios españoles de mayor dimensión.

\section{Cuadro $\mathrm{N}^{\circ}$ 2: Influencia de la dimensión del municipio en la transparencia municipal}

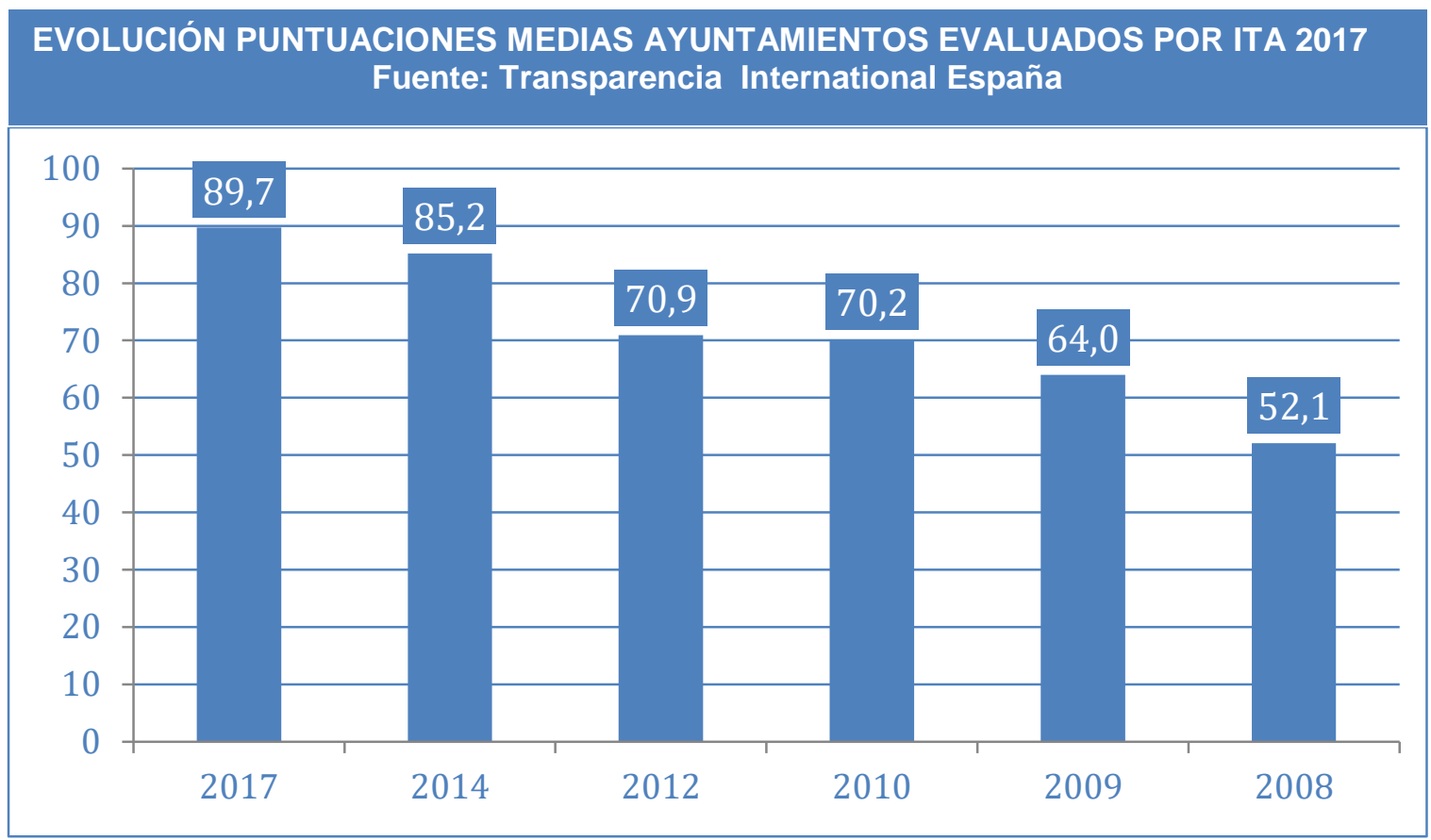

Fuente: elaboración propia, con datos del ITA 2017

Podemos concluir, por tanto, que el grado de transparencia municipal no presenta una relación de causalidad directa con el número de habitantes del municipio. Encontramos así elevadas puntuaciones de transparencia, tanto en localidades de gran dimensión -con Madrid, Barcelona o Bilbao a la cabeza- como en aquellos municipios con un número de habitantes significativamente menor, como pueda ser el caso de San Cugat del Vallés, con apenas 88.000 habitantes, o los de Pozuelo de Alarcón y Las Rozas, incluso con menor número de habitantes. 
En este sentido, es especialmente revelador el hecho que entre los 25 ayuntamientos que obtuvieron la máxima puntuación en el ITA 2017, cerca de la mitad ni tan siquiera sean capitales de provincia: Alcobendas, Barakaldo, Getxo, Jerez de la Frontera, Las Rozas, Manresa, Pozuelo de Alarcón, San Cristóbal de la Laguna, Terrassa, Torrejón de Ardoz y Torrent.

\begin{tabular}{|c|c|c|}
\hline \multicolumn{2}{|c|}{ SEGUN EL NÚMERO DE HABITANTES } \\
\hline & MÁS DE 100.000 & MENOS DE 100.000 \\
\hline TRANSPARENCIA & 63 MUNICIPIOS DE & 34 MUNICIPIOS DE 97: \\
ALTA & $97:$ & $35 \%$ \\
(75-100) & $65 \%$ & 7 MUNICIPIOS DE 10: \\
\hline TRANSPARENCIA & 3 MUNICIPIOS DE & $70 \%$ \\
MEDIA & $10:$ & 1 MUNICIPIO DE 3: \\
(50-75) & $30 \%$ & $33 \%$ \\
TRANSPARENCIA & 2 MUNICIPIOS DE 3: & \\
BAJA & $67 \%$ & \\
(MENOS DE 50) & & \\
\hline
\end{tabular}

Fuente: elaboración propia, con datos del ITA 2017

\subsection{Nivel de renta per cápita}

Podríamos pensar también que el nivel de riqueza del municipio podría determinar, o cuanto menos influir, en el nivel de transparencia de un ayuntamiento. Guillamón et alt (2011) comentan que diferentes autores (Piotrowski y Van Ryzin 2007) han demostrado que el nivel económico está relacionado positivamente con la transparencia fiscal. Es decir, la situación económica del municipio posee una influencia significativa en el nivel de transparencia financiera. Parece claro para estos autores que los municipios con menores tasas de desempleo, y, por tanto, que disponen de una sólida situación económica, acabarán siendo más transparentes. Y según el ITA, lo observamos en numerosas localidades que ni tan siquiera son capitales de provincia, como es el caso de Getxo, San Cugat del Vallés, Pozuelo de Alarcón o Las Rozas. 
Por otra parte, el gasto total per cápita es superior en los municipios más transparentes. Se cumple así un conocido axioma de que nivel de renta y educación están íntimamente ligados: uno es consecuencia del otro y viceversa.

Ahora bien, si atendemos exclusivamente a los datos del ITA 2017, no nos encontramos ante un factor decisivo, en tanto en cuanto el grado de transparencia mantiene proporciones similares, con independencia del nivel de riqueza de la localidad en cuestión:

\section{Cuadro $\mathrm{N}^{\circ}$ 3: Influencia de la renta per cápita en la transparencia municipal}

\begin{tabular}{|c|c|c|c|}
\hline \multicolumn{4}{|c|}{ SEGÚN LA RENTA PER CÁPITA } \\
\hline & $\begin{array}{l}\text { MENOS } \\
\text { DE } 20.000 \\
\text { EUROS }\end{array}$ & $\begin{array}{c}\text { ENTRE } \\
20.000 \text { Y } 40.000 \\
\text { EUROS } \\
\end{array}$ & $\begin{array}{l}\text { ENTRE } 40.000 \mathrm{Y} \\
60.000 \text { EUROS }\end{array}$ \\
\hline $\begin{array}{c}\text { TRANSPARENCIA } \\
\text { ALTA } \\
(75-100)\end{array}$ & $\begin{array}{c}12 \\
\text { MUNICIPIOS } \\
\text { DE } 97: \\
13 \%\end{array}$ & $\begin{array}{c}78 \\
\text { MUNICIPIOS } \\
\text { DE } 97: \\
80 \%\end{array}$ & $\begin{array}{c}7 \text { MUNICIPIOS } \\
\text { DE 97: } \\
7 \%\end{array}$ \\
\hline $\begin{array}{c}\text { TRANSPARENCIA } \\
\text { MEDIA } \\
(50-75)\end{array}$ & $\begin{array}{c}2 \\
\text { MUNICIPIOS } \\
\text { DE 10: } \\
20 \% \\
\end{array}$ & $\begin{array}{c}8 \\
\text { MUNICIPIOS } \\
\text { DE 10: } \\
80 \% \\
\end{array}$ & $\begin{array}{l}0 \text { MUNICIPIOS } \\
\text { DE 10: } \\
\mathbf{0} \%\end{array}$ \\
\hline $\begin{array}{c}\text { TRANSPARENCIA } \\
\text { BAJA } \\
\text { (MENOS DE 50) }\end{array}$ & $\begin{array}{c}1 \\
\text { MUNICIPIO } \\
\text { DE 3: } \\
33 \% \\
\end{array}$ & $\begin{array}{c}2 \\
\text { MUNICIPIOS } \\
\text { DE 3: } \\
67 \%\end{array}$ & $\begin{array}{l}0 \text { MUNICIPIOS } \\
\text { DE 3: } \\
\mathbf{0} \%\end{array}$ \\
\hline
\end{tabular}

Fuente: elaboración propia, con datos del ITA 2017

\subsection{Ubicación geográfica:}

Nos planteamos finalmente si existen en España territorios que sean, a priori, más transparentes que otros. Aunque en nuestro país los mayores casos de corrupción se concentren en los gobiernos locales de los municipios costeros, próximos a los grandes núcleos urbanos, los niveles de transparencia no parecen regirse por criterios territoriales. Los datos del ITA 2017 señalan, por ejemplo, que, dentro de una misma Comunidad Autónoma, como por ejemplo Andalucía, encontramos 
municipios con una transparencia alta (Huelva), una transparencia media (Jaén) y una transparencia baja (Almería).

Asimismo, tampoco parece existir una correspondencia absoluta entre transparencia municipal y transparencia autonómica: según los datos del ITA 2014, el Ayuntamiento de Madrid obtuvo una puntuación sobresaliente con 92,5 puntos sobre 100, mientras que la Comunidad de Madrid, según los datos del Índice de Transparencia de las Comunidades Autónomas, obtuvo unos resultados mediocres en relación a las demás autonomías, con una puntuación de 65 puntos sobre 100.

No obstante, esta brecha se ha reducido hoy día: según el ITA 2017, el ayuntamiento de Madrid obtiene una puntuación de 100 puntos sobre 100 en términos de transparencia municipal, mientras que, según INCAU, la Comunidad de Madrid alcanza una puntuación de 98,1 puntos sobre 100.

\section{Gráfico $\mathrm{N}^{\mathrm{o}}$ 1: Dispersión de Municipios con Índice de Transparencia 100 según población y renta per cápita}

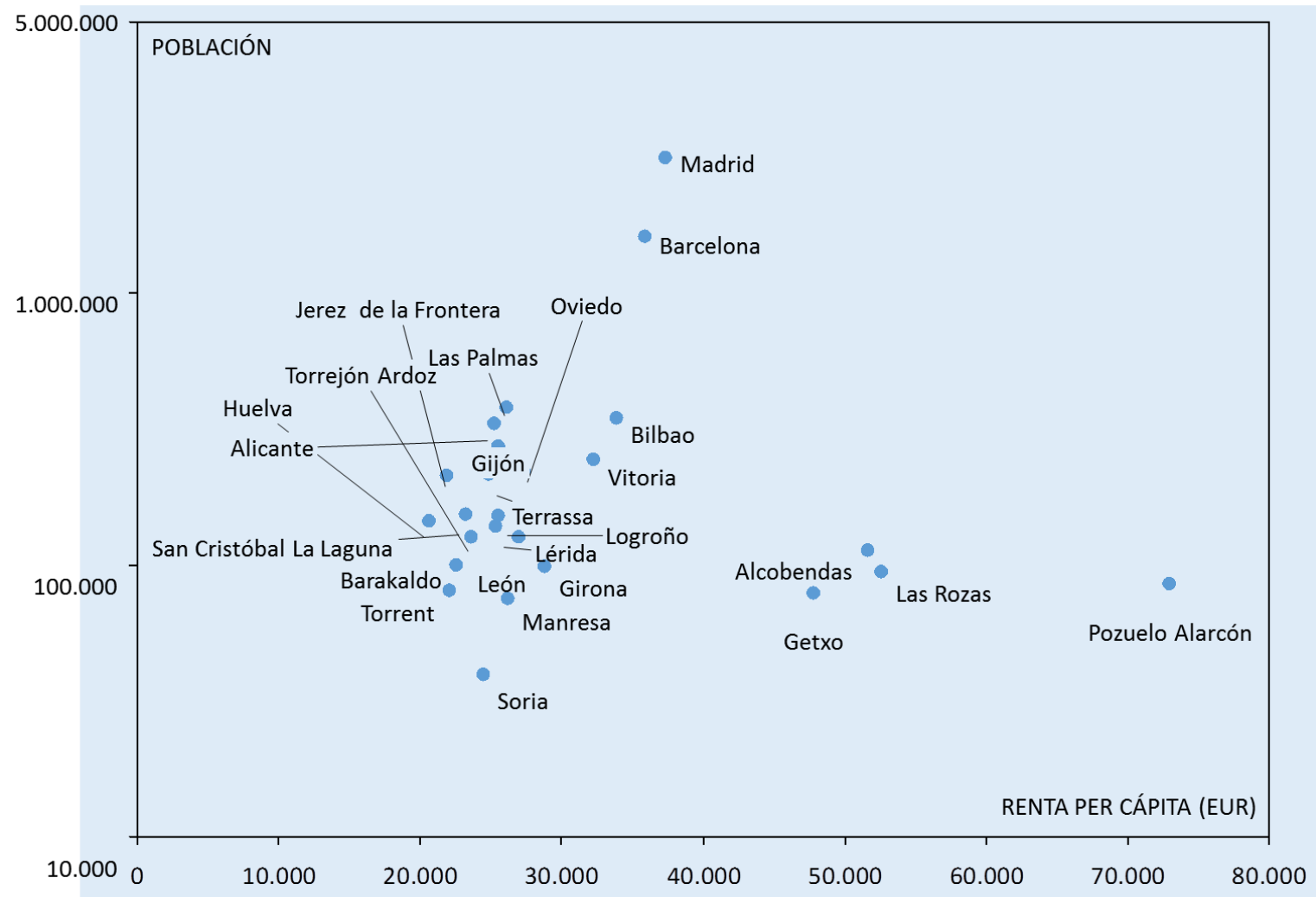

Fuente: Elaboración propia con datos INE 2016 e ITA 2017 
Por otra parte, si efectuásemos una dispersión de los 25 municipios con Índice de Transparencia 100 (ITA 2017), según población y renta per cápita, podemos observar que aquellos municipios con mayor Índice de Transparencia se sitúan entre cien mil y 1 millón o más de habitantes, y que la mayor parte de ellos tienen una renta per cápita que oscila entre 20.000 y 35.000 euros. De tal manera que, por ejemplo, una población como Soria, con apenas 40.000 habitantes y una renta per cápita de casi 25.000 euros (ocupa la 425 posición por renta) se sitúa al mismo nivel que Pozuelo de Alarcón, el municipio con mayor renta de España, con más de 70.000 euros y una población cercana a las 85.000 personas.

En otras palabras, y atendiendo a los datos del INE 2016, el ITA no tiene en cuenta en su listado de los 25 municipios más transparentes a algunos consistorios que figuran entre los diez primeros de España (Majadahonda, San Cugat, San Sebastián o San Sebastián de los Reyes), así como a otros que, por renta, se encontrarían entre los veinte primeros, caso de Casteldefells, Cerdanyola del Vallés, Ceuta o Pamplona. De esta forma, deja de tener validez la hipótesis de que, a mayor renta se produce un mayor nivel de transparencia, o bien, que, tal vez no se haya verificado de manera precisa esta variable Parece como si el hecho de cumplir con las indicaciones precisas que exige el ITA fuese la parte fundamental de la elaboración del ranking.

\section{Conclusiones}

Creemos que los factores que hemos analizado poseen una incidencia decisiva en el grado de transparencia de los municipios. Pero según el ITA, ninguno de ellos es tan importante como para llegar a ser determinante en la muestra de los 110 ayuntamientos seleccionados. De esta forma, podemos colegir que, en la mayor parte de los casos, la adscripción a un determinado partido político no constituye un factor determinante, como tampoco lo es la renta per cápita ni la distribución territorial y mucho menos la propia dimensión del municipio. Existe, por tanto, un factor humano a considerar. Esto es, el libre albedrío del alcalde y los concejales que forman la Corporación, por lo que investigaciones futuras deberían determinar el marco de identidades y formación de los ediles que componen estos grupos. 
No obstante, los datos en los que suelen apoyarse estas conclusiones deberían de ampliarse y sus procedimientos metodológicos, como señalan sus críticos, tendrían que renovarse, tomando en consideración nuevos indicadores. En este sentido, las opiniones de nuestro panel de expertos son claras:

- Aunque el ITA es un gran paso, convendría centrarse también en análisis más profundos, considerando otros aspectos importantes como la institucionalización de la transparencia; el grado de bondad de la rendición de cuentas; una mayor difusión de las agendas institucionales o la claridad expositiva -sujeta a tratamiento previode las grandes cuentas y las grandes cifras. Disponer, en suma, de archivos con una información de calidad y al mismo tiempo comprensible para el ciudadano ${ }^{11}$. Hay además otras preguntas que quedan sin respuesta: ¿cómo convive el ITA con la corrupción y con tramas organizadas como Púnica? ¿Cómo afectan estos casos a los ayuntamientos implicados? ¿Existe pérdida de reputación? Y si es así, como debería estar reflejada en el Índice.

- Pese a la buena evolución del ITA, existe todavía un elevado número de ayuntamientos (44\%), que no cumple los estándares de calidad señalados. De la misma forma, y además de los 110 ayuntamientos seleccionados, habría que disponer al menos de una muestra representativa del alcance de la implantación de transparencia y rendición de cuentas en los municipios de menos de 50.000 habitantes para conocer el gap que les separa de la élite. Es más, alguno de nuestros expertos considera que es precisamente en los pequeños municipios en donde más se aprecia la necesidad de una mayor transparencia.

\footnotetext{
${ }^{11}$ El Ránking 2017 sobre la calidad democrática de los partidos políticos españoles es un trabajo de investigación, dirigido por José Antonio Gómez Yáñez, profesor de la Universidad Carlos III de Madrid. Dispone de un cuestionario de 41 indicadores, agrupados y ponderados en cinco capítulos: democracia interna, sistemas de selección de candidatos, derechos de los afiliados y su protección, información pública sobre el partido y publicidad de los códigos éticos. Y llega a la conclusión por tercera vez, que ningún partido político español cumpliría con las normas de funcionamiento requeridas por la Ley de Partidos Alemana o con los usos de Gran Bretaña en cuanto a: congresos bienales o anuales, celebración de los congresos a fecha fija, elección de candidatos a cargos públicos por votación de los afiliados del partido residentes en el distrito, reuniones periódicas de los parlamentos internos (comités, consejos, juntas directivas), etc.
} 
- El ITA no permite verificar que los datos aportados por los ayuntamientos sean ciertos. Es decir, los datos sobre contrataciones de personas o el nivel de remuneración de ediles y concejales no se verifica obligatoriamente por un equipo de auditoría externa. Para muchos de estos expertos, es necesario auditar las páginas web, que son, en algunos casos, claros instrumentos de propaganda. De la muestra recogida de las páginas web de ayuntamientos menores de 30.000 habitantes cabe destacar, en primer lugar, que casi ningún ayuntamiento de más de 5.000 -10.000 habitantes desea perder el tren de la transparencia. Todos disponen de algo parecido a un portal de transparencia, pero en muchos casos -en ayuntamientos de todos los colores políticos- falta información esencial sobre contrataciones de personal, cv de los concejales, presupuestos municipales, etc.

- La transparencia necesita imperiosamente de la participación ciudadana para consolidarse. ¿Cómo promover esta participación? ¿Qué pasos se siguen y qué métodos se adoptan, al menos en ayuntamientos de una cierta dimensión, para poner a disposición de sus ciudadanos resúmenes comprensibles de aquellas disposiciones, estados de cuentas, etc, que les conciernen? Esto es, no basta únicamente con trasladar esa información a los Portales de Transparencia; el reto es también hacerla comprensible para la ciudadanía.

- Según el panel de expertos, no se trata, esencialmente, del cumplimiento estricto de las obligaciones y deberes por parte de los servidores públicos. Hay que ir algo más allá: fomentar la participación de la ciudadanía; extender los referentes éticos en todos los ámbitos del gobierno municipal y contar con mejores controles de los servidores públicos. Promover, en resumen, la adquisición de una cultura de la transparencia. Y no olvidar tampoco qué significa realmente un proceso de rendición de cuentas.

- Para algunos de los expertos, que reconocen el avance conseguido con la introducción del ITA, la mayor parte de los ayuntamientos españoles no son transparentes aún y les falta cierto recorrido para llegar a serlo. Reconocen, sin embargo, que aquellos municipios que cuentan con un funcionariado competente y una motivación por 
parte del alcalde y concejales para posicionarse adecuadamente en el ITA, consiguen mejores resultados.

- Por último, los expertos subrayan que el hecho de cumplir con los indicadores del sistema no garantiza que las corporaciones sean objetivamente transparentes, al menos que exista una auditoría profesional e independiente que respalde lo que reflejan esos indicadores.

\section{Referencias bibliográficas:}

A. Morales García et alt (2016): "La Transparencia en la política española: análisis de sus influencia y presencia en medios sociales". Ibersid. 10(2), pp. 91-96.

B. A. Albassam (2016): "The influence of Budget Transparency on quality of Governance”. Mediterranean Journal of Social Sciences, Vol. 7, $\mathrm{N}^{\circ} 1$.

D. De Ferranti et alt. (2009): How to improve Governance. Washington, D.C.: The Brooking Institution Press.

D. Kaumann y A. Kraay (2002): "Growth without Governance". The World Bank: World Bank Development Research Group. Policy Research Working Paper.

E. Conejero Paz (2014): "Rendimiento, evaluación y rendición de cuentas de las administraciones públicas en España”. RIPS, Vol. 13, no 2, pp. 77-101. Disponible en:

file:///C:/Users/Administrador/Downloads/2239-9521-1PB\%20(1).pdf (3-2-2017)

E. Guichot Reina (2011a): Transparencia y acceso a la información en el Derecho europeo, Svilla: Editorial Derecho Global/Global Law Press,

E. Guichot Reina (2011b): “Transparencia y acceso a la información pública en España: análisis y propuestas legislativas”. Madrid: Fundación Alternativas.

E. Guichot Reina (Coord.) (2014): Transparencia, acceso a la información pública y buen gobierno. Estudio de la Ley 19/2013, de 9 de diciembre. Madrid: Tecnos.

E. Moreu Carbonell (2005): La Administración anunciante. Madrid: Editorial Aranzadi. 
FEMP (2010): Calidad democrática y Buen Gobierno. Madrid:

AEval/Ministerio de Política Territorial y Administración Pública. Disponible en:

file:///C:/Users/Administrador/Downloads/Calidad\%20Democr \%C3\%A1tica\%20y\%20Buen\%20Gobierno.pdf (12-5-2017)

F. Delgado Morales (2015): "Sistemas de medición y transparencia en los Ayuntamientos". Revista Española de la Transparencia, No 0, pp. 12- 17. Disponible en: https://issuu.com/acreditra/docs/ret 0.

F. Vallespín (2010): "Responsabilidad política y rendición de cuentas". En FEMP: Calidad democrática y Buen Gobierno, pp. 96-106. Disponible en:

file:///C:/Users/Administrador/Downloads/Calidad\%20Democr $\%$ C3\%A1tica $\% 20 \mathrm{y} \% 20$ Buen $\% 20$ Gobierno.pdf $(5-3-2017)$

I. Álvarez (2007): Relatoría especial para la libertad de expresión. Comisión Interamericana de los Derechos Humanos, Washington D.C.: OEA.

J. Ackerman (eds.) (2008): Más allá del acceso a la información.

Transparencia, rendición de cuentas y estado de derecho. México: Siglo XXI Editores.

J.A. Ferejohn y J.H. Kuklinski (1990). Information and democratic processes. Urbana: University of Illinois Press.

L.A. Ferejohn (1999): "Accountability and authority: towards a model of political accountability". En Przeworski, A., Stokes, S. C. y Manin, B. (Eds.): Democracy, Accountability and Representation. New York: Cambridge University Press, pp. 131-153.

J.A. Garde Roca (2006): "La institucionalización de la evaluación de las políticas públicas en España". Auditoría Pública, no 39, pp. 17-26.

J. Gaventa y R. McGee (2013): "The Impact of Transparency and Accountability Initiatives”. Development Policy Review, 31 (s1), pp. 328.

J. Lizcano Álvarez (2010): "El Indice de Transparencia Municipal”. En FEMP: Calidad democrática y Buen Gobierno. Madrid: AEval/Ministerio de Política Territorial y Administración Pública. pp. 139-150. Disponible en:

file://C:/Users/Administrador/Downloads/Calidad\%20Democr \%C3\%A1tica $\% 20 \mathrm{y} \% 20$ Buen $\% 20$ Gobierno.pdf $(10-3-2017)$

J.L. Piñar Mañas (2010): "Transparencia y protección de datos: las claves de un equilibrio necesario", en Ruiz Ojeda, A. L., (coord.): 
El gobierno local. Estudios en homenaje al profesor Luis Morell Ocaña, Iustel, Madrid, pp. 1023-1044.

J.M. Labeaga Azcona y C. Muñoz Martínez (2013): “La evaluación de políticas públicas en España: aprendizaje y prácticas institucionales". Revista de Evaluación de Programas y Políticas Públicas, $\mathrm{n}^{\mathrm{o}} 1$, pp. 31-53.

J. Pierre (edic.) (2010). Debating Governance. Oxford: Oxford University Press.

L. Vila i Vila (2013): "Determinantes de la transparencia contable en los municipios". Auditoría Pública, nº 60, pp. 57-64.

L. Cotino Hueso, J.L. Sahuquillo Orozco, L. Corredoira Alfonso (eds.) (2015): El paradigma del gobierno abierto. Retos y oportunidades de la participación, transparencia y colaboración. Madrid: Universidad Complutense.

Ley 19/2013, de 9 de diciembre de Transparencia, Acceso a la Información Pública y Buen Gobierno. BOE n 295, de 10 de diciembre de 2013. Disponible en Http://www.boe.wa/buscar/act.php?id=BOE-A-2013-12887 (8-32017)

M. Arenilla Sáez y J. C. Redondo Lebrero (2011): “Ética, transparencia y participación". En Arenilla Sáez, M.: Crisis y reforma de la Administración Pública. A Coruña: Netbiblo.

M. Cendejas Jáuregui (2007): "Evolución histórica del derecho a la información". Derecho Comparado de la Información, no. 10, pp. 57-84.

M. Guillamón López, A. Ríos Martínez y C. Vicente Oliva (2011): "Transparencia financiera de los municipios españoles. Utilidad y factores relacionados". Auditoría Pública, no 55, pp. 109-116.

Disponible en: http://asocex.es/transparencia-financiera-de-losmunicipios-espanoles-utilidad-y-factores-relacionados (18-5-2017)

M. Méndez Juez (2017): "Transparencia pública en la regeneración democrática". Cuadernos de Gobierno y Administración Pública, 4-1, pp. 89-105.

M. Rodríguez Pallares y M.J. Pérez Serrano (2017): “Decisión y transparencia en información y conocimiento. Estudio de caso de las empresas de comunicación cotizadas españolas". Revista Latina de Comunicación Social, 72, pp. 719 a 736. http://www.revistalatinacs.org/072paper/1188/38es.html (12-62017) 
R. Hollrah (2005): "La protección de la privacidad frente a la transparencia gubernamental". Derecho Comparado de la Información, n $\mathrm{n}^{\mathrm{o}}$, pp. 103-154

R. Jiménez Asencio, J. Lizcano Álvarez y M. Villoria Mendieta (2012): "La transparencia en los gobiernos locales: una apuesta de futuro. Fundación Democracia y Gobierno local. Disponible en: http://www.gobiernolocal.org/docs/publicaciones/Transparencia ponencias2.pdf (4-5-2017)

R. O'Leary et al (eds.). The Future of Public Administration Around the World. Washington, D.C., Georgetown University Press.

S.J. Piotrowski y G. Van Ryzin (2007): "Cirizen attitudes toward transparency in local government". The American Review of Public Administration. Vol, 37, $\mathrm{n}^{\circ}$ 3, pp. 306-323

T. Mendel (2006): "Consideraciones sobre el estado de las cosas a nivel mundial en materia de acceso a la información”, Derecho Comparado de la Información, No 8, pp. 3-15.

Transparency International. Corruption Perceptions Index (2015). Disponible en http://www.transparency.org/cpi2015. (11-5-2017)

Transparency International España (2017): "Índice de Transparencia de los Ayuntamientos". Disponible en: http://transparencia.org.es/indices-transparencia-espana/

P. Beltrán Orene y E. Martínez Pastor (2016): “Grado de cumplimiento de las leyes de Transparencia, Acceso y Buen Gobierno y de reutilización de los datos de contratación de la Administración central española”. El Profesional de la Información, vol. 25, no 4, pp. 557-567.

Portal de Transparencia Gobierno de España. Disponible en: http://transparencia.gog.es/ (12-2-2017)

Cómo citar: JV García Santamaría, J Martín Matallana (2017): “La transparencia municipal en España: análisis de los factores que más influyen en el grado de transparencia". Revista Latina de Comunicación Social, 72, pp. 1.148 a 1.164 .

http://www.revistalatinacs.org/072paper/1212/62es.html DOI: $10.4185 /$ RLCS-2017-1212 
Cómo citar: L Alonso-Muñoz, A Casero-Ripollés (2017): “Transparencia y monitorización en el entorno digital. Hacia una tipología de las plataformas impulsadas por la ciudadanía". Revista Latina de Comunicación Social, 72, pp. 1.351 a 1.366 .

http://www.revistalatinacs.org/072paper/1223/73es.html

DOI: $10.4185 /$ RLCS-2017-1223

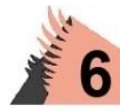

\title{
Transparencia y monitorización en el entorno digital. Hacia una tipología de las plataformas impulsadas por la ciudadanía
}

\author{
Laura Alonso-Muñoz \\ Universitat Jaume I de Castelló (España) lalonso@uji.es \\ Andreu Casero-Ripollés \\ Universitat Jaume I de Castelló (España) casero@,uji.es
}

\begin{abstract}
s
Introducción: El entorno digital ha permitido el desarrollo de nuevos mecanismos de ejercicio de la transparencia por parte de la ciudadanía. Ésta se vincula a la monitorización y contribuye a redefinir la comunicación y la participación política. Metodología: El objetivo es analizar las modalidades adoptadas por las plataformas digitales vinculadas a la sociedad civil basadas en la transparencia y orientadas hacia la monitorización de los centros de poder. La metodología se basa en el estudio de caso, aplicado a cinco iniciativas. Resultados y conclusiones: Los resultados permiten identificar cinco tipos de plataformas según la finalidad principal y la dimensión de la transparencia que cubren. Estas modalidades se centran en los datos de gobierno abierto, las noticias de interés público, la circulación de ideas y puntos de vista variados, las respuestas de actores políticos y la
\end{abstract}


participación ciudadana en los procedimientos vinculados a la toma de decisiones políticas.

\section{Keywords}

comunicación política; transparencia; monitorización; medios digitales

\section{Contents}

1. Introducción: monitorización y transparencia ciudadanas en el entorno digital 2. Método 3. Resultados 3.1. Osoigo: el diálogo entre representantes y representados 3.2. Kuorum.org: la conexión con los procesos de toma de decisiones políticas 3.3. Wikitribune: el periodismo transparente y colaborativo 3.4. Deba-t.org: la transparencia en el fomento del debate y la discusión pública 3.5. OpenKratio: el fomento del gobierno abierto y la transparencia 3.6 Tipología de plataformas digitales ciudadanas basadas en la transparencia 4. Conclusiones 5. Notas 6. Bibliografía.

\section{Introducción: monitorización y transparencia ciudadanas en el entorno digital}

$\mathrm{L}$ entorno digital ha impulsado numerosos procesos de
transformación de la comunicación y la participación política. La consolidación y popularización de los medios sociales ha contribuido decisivamente a ello, ya que ha generado nuevas formas de intermediación y conectividad que están reconfigurando el espacio comunicativo (Fuchs, 2014; Bunz, 2014). Una de las principales novedades está asociada a la emergencia de la monitorización como nuevo mecanismo de implicación digital de la ciudadanía en la vida política (Feenstra et al., 2017). Este fenómeno supone la articulación de mecanismos, principalmente a través de la web 2.0, que permiten escrutar y fiscalizar a los centros de poder social, favoreciendo una dinámica de rendición de cuentas respecto a su actuación (Keane, 2009; Feenstra, 2012). La monitorización digital presenta una considerable variedad de expresiones y posee una fuerte potencialidad para la innovación política. En este sentido, está conectada al cambio y la regeneración de la democracia. 
La puesta en práctica de la monitorización está vinculada al concepto de democracia monitorizada (Keane, 2009). Éste plantea que en el actual contexto de abundancia informativa y de expansión de las tecnologías digitales vinculadas a las redes sociales emergen nuevos mecanismos de supervisión para escrutar la actuación de los centros de poder, no sólo políticos sino también económicos y mediáticos (Feenstra, 2012; Keane, 2013). La monitorización persigue la rendición de cuentas y la erradicación de los abusos de poder. Se configura, así, como una forma de participación política extrarepresentativa que permite a los ciudadanos implicarse directamente en la vida política y contribuir, potencialmente, a alcanzar la calidad democrática (Rosanvallon, 2011).

Pese a la creciente importancia asumida por la monitorización política en diversos contextos geográficos, entre los que se encuentra España (Feenstra et al. 2017), no se ha avanzado en el estudio de un factor clave asociado a su puesta en práctica: la transparencia. Ésta puede entenderse como la facultad de que cualquier persona pueda acceder a la información pública y a los datos relevantes para el ejercicio de los derechos políticos de la ciudadanía (Manfredi, 2017). En este sentido, se configura como una de las bases de la gobernanza del sector público y privado y, a la vez, como una precondición para el desarrollo de la participación política de una ciudadanía democrática. A través del acceso a la información, ésta puede activar la rendición de cuentas (accountability) de los centros de poder de una sociedad y exigir, si es el caso, responsabilidades por malas prácticas. De esta forma, se establece una conexión entre transparencia y monitorización ya que la primera se sitúa como prerrequisito de la segunda. El acceso libre, sencillo, estructurado y comprensible a los datos de interés público es una exigencia para poder escrutar y fiscalizar la actividad de los centros de poder. Transparencia y monitorización aparecen indisolublemente unidas desde este punto de vista.

Este vínculo otorga a la transparencia la condición de activo para la democracia. Un reducido nivel de transparencia puede ser visto como un síntoma de una baja calidad democrática (Manfredi, 2017). Sin embargo, un exceso de transparencia también ha sido identificado como un potencial mecanismo que puede conducir a la generalización 
de la vigilancia digital, a la pérdida de la privacidad y, en suma, al surgimiento de actitudes totalitarias (Han, 2013). No obstante, más allá de estas críticas, la lucha contra la opacidad y la exigencia de transparencia puede contribuir a una monitorización que afecte positivamente a la democracia previniendo la corrupción (Schiavi, 2017; Dabbagh-Rollán, 2016) e implantado una cultura de rendición de cuentas entre las élites sociales que fomente el buen gobierno. En este sentido, la transparencia no es un fin es si misma, sino un mecanismo para promover otras acciones, entre las que destacan la activación de la monitorización.

La implantación de la transparencia exige la articulación de dos dimensiones: la legal y la comunicativa. La primera tiene que ver con el desarrollo de disposiciones normativas que hagan posible el acceso público a la información y obliguen a las instituciones y organizaciones a favorecerla o proveerla. El despliegue de este tipo de medidas se ha generalizado en los últimos años en diversos países. Entre ellos, se encuentra España, dónde en diciembre 2013 se aprobó la Ley 19/2013 de transparencia, acceso a la información pública y buen gobierno que regula y establece las obligaciones de publicidad para los organismos e instituciones públicas y garantiza el derecho de acceso a la información. De esta forma, se establece el contexto legal que permite su implantación que, entre otros aspectos, ha provocado la proliferación de portales web de transparencia (Moreno-Sardà et al., 2017). Por su parte, la dimensión comunicativa tiene que ver con la forma en la que llegan los datos a los ciudadanos. La elevada cantidad de información generada por las organizaciones públicas, la acelerada velocidad de producción de datos y la facilidad de difusión de los mismos a través del entorno digital (Mayer-Schönberger, Cukier, 2013) demanda que el acceso se complemente con herramientas comunicativas que permitan a los ciudadanos consumir la información pública de una forma sencilla y comprensible. Ofrecer los datos desagregados en bruto puede conducir a la desinformación al inundar a los ciudadanos con grandes volúmenes de datos. No se trata sólo de recolectar y difundir datos, sino que éstos deben procesarse comunicativamente para, así, poder ser transformados en conocimiento público. Aquí el periodismo de datos juega un papel destacado (Gray et al., 2012; Casero-Ripollés, López-Meri, 2015). 
El entorno digital ofrece nuevas oportunidades para la transparencia. La facilidad de acceso a la información para cualquier persona se ve favorecida por Internet. De esta forma, los ciudadanos pueden obtener la información necesaria para poder fiscalizar la acción de los centros de poder. En este sentido, las tecnologías digitales permiten, potencialmente, la ampliación del ejercicio de la transparencia por parte de los ciudadanos. Esto conecta con la monitorización cívica, entendida como aquella que es protagonizada por la sociedad civil y que es una novedad derivada de la web 2.0 (Feenstra, Casero-Ripollés, 2014).

En el escenario digital, la ciudadanía asume un rol renovado en el ámbito de la comunicación política. Las posibilidades que ofrecen los medios sociales para que cualquier persona se convierta en productor y difusor de contenidos de forma autónoma abre las puertas a esta redefinición. La web 2.0 ofrece mayores opciones para el empoderamiento ciudadano (Jenkins, 2006; Castells, 2012). Así, las élites políticas y periodísticas tienen más dificultades para mantener el control sobre la esfera pública y han de enfrentarse a un panorama mucho más competitivo que el existente en las décadas anteriores (McNair, 2006). Los ciudadanos pueden ejercer el contrapoder mediante las redes y medios digitales (Castells, 2009; Sampedro, 2014). Una de las vías de expresión del mismo es la monitorización cívica (Feenstra, Casero-Ripollés, 2014). Para la puesta en marcha de esta nueva forma de participación política, la transparencia se configura como un elemento imprescindible. En este sentido, el entorno digital está propiciando la aparición de diferentes iniciativas impulsadas por la sociedad civil y que se basan en la transparencia orientada hacia la monitorización política.

El objetivo de este trabajo es analizar esta clase de plataformas para establecer una tipología clasificatoria. En este sentido, sigue la línea de otros trabajos anteriores que han catalogado las diferentes formas que puede adoptar la monitorización (Feenstra, Casero-Ripollés, 2014). Sin embargo, esta investigación traslada este esfuerzo al campo de la transparencia, aportando, así, una novedad. Este trabajo pretende ir más allá de la literatura previa que se ha ocupado de verificar el nivel 
de transparencia de organizaciones públicas como ayuntamientos (Moreno-Sardà et al. 2017; Rebolledo et al. 2017), televisiones públicas (López-López et al. 2017) o empresas privadas (Rodríguez-Pallares, Pérez-Serrano, 2017). Al centrarse en las iniciativas ciudadanas, por un lado, y plantear una tipología de las mismas, por otro, ofrece una contribución original a la investigación de la transparencia en el contexto digital y las diferentes formas que ésta puede adoptar.

\section{Método}

El objetivo de esta investigación es analizar las modalidades que adoptan las plataformas digitales vinculadas a la sociedad civil que se basan en la transparencia y se orientan hacia la monitorización de los centros de poder. En concreto, se busca conocer cuáles son sus objetivos y su actividad, así como los efectos de su actividad en la sociedad.

El método empleado en esta investigación es el estudio de caso, que permite a partir del análisis de ejemplos concretos extraer las principales características de las diferentes tipologías de plataformas (Eisenhardt, 1989). La utilización de esta técnica la facilita la exploración en profundidad de estas formas de fiscalización del poder, así como la obtención de un conocimiento más amplio, de naturaleza cualitativa, sobre ellas (Simons, 2011). Concretamente, se analizan cinco iniciativas: Osoigo, Kuorum.org, Wikitribune, deba-t.org y OpenKratio. La selección de la muestra responde a un triple criterio. En primer lugar, a su novedad, ya que estas iniciativas son de reciente creación. En segundo término, a su vinculación con la sociedad civil, puesto que son iniciativas impulsadas por la ciudadanía. Y, finalmente, a su carácter innovador, puesto que introducen nuevas dinámicas comunicativas en relación con la transparencia en el entorno digital.

El empleo del estudio de caso es, especialmente, pertinente para el análisis de fenómenos que se hallan en las fases preliminares de su desarrollo y sobre los que existen pocos estudios previos (Cepeda, 2006). Las plataformas digitales ciudadanas basadas en la transparencia responden a esta situación. Esta metodología permite comprender los objetos de estudio dentro de sus contextos y dar respuesta al cómo y 
al porqué. Es decir, a cómo son y a cómo funcionan comunicativamente las plataformas estudiadas. Pese a su capacidad limitada de generar conclusiones generalizables estadísticamente, las evidencias derivadas del estudio de caso poseen un interesante potencial a nivel teórico y analítico y permiten establecer las bases para estudios posteriores (Yin, 2014). Por ello, resulta especialmente apropiado para establecer tipologías sobre fenómenos sociales, objetivo que persigue esta investigación.

\section{Resultados}

En este apartado se ofrecen, inicialmente, el estudio de caso de las cinco iniciativas analizadas: Osoigo, Kuorum.org, Wikitribune, debat.org y OpenKratio. Tras ello, se plantea una propuesta de tipología para catalogar las diferentes formas que pueden adoptar las plataformas digitales ciudadanas basadas en la transparencia y orientadas a la monitorización.

\subsection{Osoigo: el diálogo entre representantes y representados}

Osoigo es una plataforma web surgida en 2014 de la mano de Eneko Aguirre. Su objetivo es tender puentes entre los representantes y los representados para que puedan dialogar entre ellos de forma directa, sin intermediarios. Busca tener una incidencia directa en la política. Su fundador reconoce haber puesto en marcha esta iniciativa tras observar que la mayoría de políticos españoles tenían perfil en Twitter, y en otras redes sociales, pero generalmente no respondían a las preguntas y comentarios que les planteaban sus seguidores.

Tal como se definen en su página web (https://www.osoigo.com/), en Osoigo tienen cabida todos los políticos, sin importar su ideología, que se comprometan a escuchar las preguntas planteadas por los ciudadanos. En la actualidad, 642 políticos de 51 partidos distintos has contestado a las preguntas realizadas por la ciudadanía. Entre ellos, hay más de 60 diputados y presidentes autonómicos como, por ejemplo, Íñigo Urkullu (Euskadi), Uxue Barcos (Navarra), Javier Lambán (Aragón) o la presidenta de la Comunidad de Madrid, Cristina 
Cifuentes. Precisamente esta última es la más activa, ya que ha dado respuestas a más de 500 cuestiones.

El funcionamiento de la plataforma es sencillo. Por un lado, los políticos que quieran participar en esta iniciativa deben rellenar un formulario para que el equipo de Osoigo pueda verificar todos los datos y crear un perfil oficial. En la sección 'Políticos' de la página web aparece el nombre de todos los políticos que están inscritos, así como el de aquellos que ya se han dado de baja. En el perfil de cada uno se especifica el partido al que pertenecen, los cargos que ostentan, el número de preguntas que les han planteado los ciudadanos y el número de respuestas que han dado. $\mathrm{Al}$ respecto, ofrecen listas con las nuevas incorporaciones, el top ten de la semana y el top cinco del mes y del año. Asimismo, se puede filtrar la información por partidos y por provincias.

Por otro lado, los usuarios que quieran preguntar también deben inscribirse. Una vez realizado este paso pueden plantear las cuestiones que deseen. Tras enviar la pregunta por la página web, Osoigo notifica al usuario el número de apoyos que debe conseguir en los siguientes diez días para que su pregunta sea planteada al político seleccionado. Para conseguir los apoyos de la forma más rápida posible, es necesario o bien difundir la pregunta a través de las redes sociales o bien enviársela por e-mail a todos los contactos. Una vez conseguido el apoyo, la pregunta se plantea al político. Antes de hacerla pública, la respuesta es notificada al usuario que la ha formulado, así como a los inscritos que le han dado su apoyo. De la misma forma que las preguntas, las respuestas también son valoradas por la comunidad de usuarios registrados (en la actualidad hay unos 15.000 inscritos). De esta forma, se pretende conocer la influencia de sus respuestas. Es decir, si el actor político logra convencer al público con su contestación o si, por el contrario, genera rechazo. Todo el proceso se realiza de forma transparente.

Con el objetivo de preservar el respeto y el buen hacer por parte de los usuarios y los políticos participantes, Osoigo cuenta con un decálogo de normas de uso de la plataforma (https://www.osoigo.com/es/normas-de-uso.html) en el que se 
detalla explícitamente qué actitudes son tolerables y cuáles no. De esta forma, la plataforma se reserva el derecho a poder bloquear aquellos perfiles que no respeten los criterios establecidos. El objetivo es que el diálogo que se cree entre el usuario y el político sea constructivo y nunca caiga en el insulto o la descalificación.

Osoigo se presenta a los usuarios como una herramienta cuyo fin es fomentar el diálogo entre la ciudadanía, los políticos y las asociaciones para fomentar la acción y el compromiso político. En este contexto, la plataforma considera clave la participación de las asociaciones, quiénes pueden crear acciones, respaldar las preguntas de la ciudadanía y fomentar el compromiso por parte de los actores políticos. Para ello, Osoigo les otorga un espacio propio dentro de la plataforma que da visibilidad a todas las acciones que plantean y que les permite dar a conocer más información sobre sus propuestas.

Pese a que anteriormente era una herramienta gratuita, Osoigo ha decidido monetizar su sistema. La cantidad a abonar depende de las notificaciones a usuarios que se envíen. Según destacó su fundador, Eneko Aguirre, en una entrevista en el diario El País, el precio de las mil primeras notificaciones sería de unos seis céntimos. En caso de que, por ejemplo, las notificaciones ascendieran a 5.000 el precio se situaría aproximadamente en los 120 euros mensuales. De esta forma, los partidos y las asociaciones podrán dar a conocer sus acciones a la ciudadanía por una pequeña cantidad de dinero. Al respecto Aguirre argumentaba que "será algo así como un change.org pero involucrando a los políticos a tomar una postura. Y la monetización vendrá a través de notificaciones. Los usuarios que apoyen las dudas y las iniciativas de las asociaciones para que los políticos lleven a cabo determinadas acciones recibirán notificaciones sobre el recorrido que siguen estos asuntos" $^{12}$.

Osoigo cuenta además con la sección 'Ágora', en la que se realizan debates digitales a petición de los usuarios (https://agora.osoigo.com/). Estos debates, que pueden incluir la participación de uno o más políticos, se centran en un tema concreto. A este respecto, las cinco preguntas que se les plantean son aquellas

${ }^{12}$ https://elpais.com/elpais/2017/07/21/talento_digital/1500658253_369685.html 
que han obtenido un mayor número de apoyos entre los usuarios. Entre los últimos debates destaca el organizado por el Huffington Post sobre la gestación subrogada o los referentes a la economía y política vasca.

Hasta el momento Osoigo únicamente está disponible en España, pero su equipo, ahora formado por cinco socios, está trabajando en dos proyectos piloto en América Latina. En concreto, uno en el estado de México y otro en la provincia argentina de Córdoba.

\subsection{Kuorum.org: la conexión con los procesos de toma de decisiones políticas}

Kuorum.org nace en 2013 como una empresa social de la mano de Matías Nso, Iñaki Domínguez y José María García, con el objetivo de conectar a políticos y ciudadanos. Se trata de una herramienta de participación ciudadana que busca acercar a representantes y representados, rompiendo la distancia existente entre ellos y superando la mera presencia en redes sociales. Su misión es mejorar la comunicación entre los ciudadanos y sus representantes políticos. Sus fundadores hablan de esta plataforma como el LinkedIn de los políticos.

En su inicio, Kuorum.org buscaba transformar la desilusión colectiva generada por los casos de corrupción y de mal gobierno en una actitud reivindicativa que ayudara a la sociedad a recuperar las instituciones. En una entrevista Nso, CEO y cofundador de la plataforma, declaraba que "algunas iniciativas vienen de partidos políticos y otras pretenden institucionalizar la democracia directa. Kuorum.org, en cambio, es una plataforma ciudadana que sólo pretende despertar conciencias y mantener a los usuarios informados para estimular una acción política más responsable"13.

En una primera fase, su funcionamiento se basaba en la publicación en la plataforma de las leyes que se iban a presentar en el Congreso de los Diputados para que los ciudadanos pudieran votarlas e introducir propuestas de mejoras si lo consideraban necesario. Una vez realizado

\footnotetext{
${ }^{13} \mathrm{http}: / /$ www.lainformacion.com/asuntos-sociales/nace-kuorum-una-plataforma-espanolaen-busca-de-una-democracia-2-0_uZLstjDCNoiDnIdNTr1Fk4/
} 
este paso, los políticos con perfil abierto en Kuorum.org recogían las propuestas y las podían tramitar en el Congreso en forma de enmiendas. De esta forma, se potenciaba una transparencia en los procesos legislativos y, además, la ciudadanía colaboraba en la creación y mejora de las leyes, indicando, asimismo, a la clase política qué temas le interesaban realmente. Entre los líderes que han hecho un uso más intenso de esta plataforma destaca el caso de Manuela Carmena, alcaldesa de Madrid, que lanzó una petición para que la normativa española recogiera y legislara sobre las fundaciones vinculadas a partidos o movimientos. En su campaña a la alcaldía de Madrid, Carmena hizo una fuerte defensa de plataformas como Kuorum.org al considerar que es necesario que la ciudadanía participe en la creación de aquellas leyes que rigen el país ${ }^{14}$. Otra de las posibilidades que ofrecía la plataforma era la posibilidad de que un ciudadano expusiera sus propias ideas sobre un proyecto político concreto, de tal manera de que el político podía apadrinarlas y comprometerse a llevar a cabo esas iniciativas.

En la actualidad Kuorum.org ha implementado una nueva fase en la que se define como una herramienta de la gestión de la influencia para una nueva generación de líderes (https://kuorum.org/es). La plataforma ya no sólo permite la participación de líderes políticos, sino también la de organizaciones, como Intermon Oxfam o Unicef, y corporaciones como IBM. En esta nueva etapa, la plataforma ayuda a individuos, empresas y organizaciones a convertir su presencia digital en movimientos fuera de la red. Es decir, buscan que todo lo que sucede en el mundo online tenga una repercusión positiva fuera de internet. Así, ofrecen a sus clientes un panel de control desde el que pueden monitorizar el compromiso de sus audiencias en diferentes redes sociales; y un perfil público que les permite interactuar con ellas a través de debates, encuestas, peticiones y eventos.

A los políticos les ofrecen encontrar a otras personas que trabajen en las mismas causas. La plataforma les proporciona acceso a herramientas de campaña digital que les ayudan a segmentar a sus audiencias y a transmitir sus mensajes de la forma más efectiva posible. A las organizaciones les ofrecen un lugar desde el que comunicarse con

\footnotetext{
${ }^{14}$ https://www.youtube.com/watch?v=LlJKrQf9Oww
} 
su público de forma más directa. Se les proporciona la posibilidad de segmentar el público al que se dirigen para lanzar campañas más específicas y darle a cada usuario información sobre lo que realmente le interesa. A las empresas, Kuorum.org les ayuda a encontrar a sus clientes o empleados más comprometidos e involucrarlos en la toma de decisiones para aumentar su confianza y sentido de pertenencia a la empresa y poder convertirlos, así, en embajadores de la marca.

Pese a que su fin es social, Kuorum.org no se financia a través de subvenciones o donaciones, si no de lo que reciben por los servicios que prestan. Los clientes pagan una suscripción mensual para poder hacer uso de la plataforma. Esta cuota les permite lanzar información a su público de forma segmentada, recibir datos sobre la respuesta que obtienen sus iniciativas y conseguir crear vínculos con sus públicos.

La plataforma, que empezó a operar en España, ha obtenido una buena respuesta por parte del público, y ha conseguido expandirse fuera del territorio nacional. Entre los líderes que tienen presencia en Kuorum.org destacan diversos diputados británicos del Partido Conservador y del Partido Laborista, que han incorporado la plataforma a sus estrategias comunicativas con el fin de acercarse a sus votantes.

Pese a que en esta segunda fase, Kuorum.org se aleja de la búsqueda de la transparencia para centrarse en la gestión de la conectividad social asociadas a las redes sociales, en su concepción inicial se configuraba como una plataforma digital basada en la transparencia. Mediante su actividad daba visibilidad a la tramitación de iniciativas legales y políticas y hacía partícipe a la ciudadanía de la definición de las mismas. Con ello, introducía a los ciudadanos en el proceso de toma de decisiones y les otorga un espacio en el que escuchar y proponer mejoras.

\subsection{Wikitribune: el periodismo transparente y colaborativo}

Wikitribune es una organización sin ánimo de lucro lanzada en mayo de 2017 y creada por el fundador de Wikipedia, Jimmy Wales. El objetivo de esta plataforma es conseguir transparencia informativa y 
evitar la publicación de noticias falsas que puedan confundir a la ciudadanía. Busca crear productos informativos en los que cada hecho esté corroborado y confirmado por las correspondientes fuentes, eliminando la opinión y los sesgos ideológicos. "Las noticias están rotas y nosotros podemos arreglarlas", defienden en su página web (https://www.wikitribune.com/).

La plataforma reúne tanto a periodistas como a una gran comunidad de voluntarios, interesados en mejorar la calidad de la información, que elaboran las noticias conjuntamente. En un momento en el que cualquiera puede crear y difundir información, sin necesidad de que ésta haya sido contrastada previamente, a través de Internet, la plataforma fundada por Wales busca poner el foco en los hechos, dejando de lado el ruido que generan las informaciones contradictorias que proliferan por el entorno digital.

Según defiende Wales, existen cuatro claves sobre las que radica la razón de ser de Wikitribune. Primero, exponer de forma transparente las fuentes que corroboran los hechos de los que se habla en las noticias. Wikitribune se asegura que sus periodistas únicamente escriban artículos basados en hechos que hayan sido previamente verificados. En este sentido, los voluntarios pueden actuar como fuente, si son conocedores de lo sucedido en primera persona, o pueden ayudar al periodista a buscarlas. Además, cualquier persona puede marcar o corregir un artículo y enviarlo para su revisión.

Segundo, Wikitribune es una plataforma 100\% libre de anuncios, por lo que toda la información es gratuita para todas aquellas personas que quieran consultarla. No se recurre ni a la publicidad ni muro de pago mediante la subscripción para acceder a los contenidos. Para financiarse cuentan con un sistema de donaciones desde el que se puede contribuir de forma puntual, de forma mensual o de forma anual. Además de decidir la forma de pago, cada usuario puede acordar la cantidad con la que quiere colaborar para financiar este proyecto.

Tercero, la comunidad de usuarios y los periodistas tienen la misma importancia. Ninguna persona es más importante que el resto. Pese a que, en la mayoría de los medios convencionales, el público sólo 
dispone de un pequeño espacio para comentar las noticias, en Wikitribune la comunidad puede desempeñar un papel muy destacado en la elaboración de la información. Así, todos las noticias son escritas y verificadas por periodistas profesionales y por miembros de la comunidad que trabajan conjuntamente para mejorar la calidad del contenido que llega al público. Según afirman en su página web, el hecho de que no dependan de anunciantes para financiarse hace que se deban únicamente a sus lectores y no vayan en busca del clic fácil.

Cuarto, la transparencia total en sus cuentas. Wikitribune se compromete a publicar el estado de sus finanzas de forma regular, de manera que cada suscriptor podrá saber a qué se ha destinado todo el dinero recaudado. Según afirma la plataforma, dedicarán los fondos para pagar el salario de los periodistas profesionales que trabajen para este proyecto. En este sentido, Wikitribune se ha propuesto tener al menos diez periodistas contratados. En caso de no conseguirlos, aseguran que devolverán todo el dinero recaudado a sus seguidores.

Wikitribune pretende ser un medio de comunicación que se centre en los estándares de calidad propios del periodismo profesional, pero incorporando la colaboración de una comunidad de voluntarios propia del mundo Wiki que mejore los artículos y luche por la fiabilidad de la información (https://medium.com/wikitribune).

En la actualidad cuentan con 11.514 suscriptores que financian el proyecto. Entre los consejeros que forman parte esta plataforma destacan el periodista y crítico de televisión Jeff Jarvis, el abogado y académico Larry Lessig, la actriz y activista social Lily Cole y el especialista en márquetin de Apple Guy Kawasaki. Ellos también formarán parte del comité que selecciona los temas diariamente.

Con Wikitribune, su fundador, Jimmy Wales, pretende reinventar el modelo de negocio del periodismo. Pretende hacer frente al hecho que los medios convencionales únicamente se deben a sus anunciantes y no a sus audiencias, priorizando aquellas historias que consiguen un mayor número de clics por encima del periodismo riguroso y de calidad basado en el interés público. Además, el proyecto otorga un papel esencial a las audiencias, quiénes adquieren la capacidad de generar y 
editar noticias, de decidir qué temas deben publicarse y cuáles no, algo que antes era una función exclusiva de los periodistas profesionales. Este proyecto tiene que objetivo último garantizar el futuro para el periodismo de calidad.

\subsection{Deba-t.org: la transparencia en el fomento del debate y la discusión pública}

Deba-t.org es una plataforma juvenil independiente fundada en 2009 en la Universidad Pompeu Fabra de Barcelona por estudiantes de distintas disciplinas universitarias y sensibilidades ideológicas. Su objetivo es generar capital social a través del fomento del debate sobre las cuestiones que realmente afectan a la sociedad actual. Para ello, organizan una serie de actividades en la universidad dirigidas, principalmente, a estudiantes como, por ejemplo, conferencias y debates públicos, mesas redondas o coloquios.

Promueven la creación de distintos puntos de encuentro con el fin de abrir un espacio para la reflexión y el diálogo entre personas con sensibilidades ideológicas distintas. Según afirma Nacho Corredor, cofundador de la iniciativa, "en este país hace falta un gran debate internacional", por lo que, a través de la organización de distintas actividades, la asociación está "promoviendo entornos de debate y reflexión que sirven de nexo de unión entre el mundo político y la universidad"15.

Según definen en su página web (http://www.deba-t.org/) la organización se rige por los valores de la tolerancia, la pluralidad y la libertad de expresión. Consideran que únicamente la inclusión de diferentes puntos de vista puede enriquecer el patrimonio intelectual y cultural de los participantes. Para ello resulta imprescindible promover la participación de los ciudadanos, en su caso de los estudiantes, en el análisis de las decisiones políticas y los temas cruciales para la sociedad a través del diálogo y de una perspectiva crítica. La transparencia aparece aquí como un ingrediente clave para conseguir esos objetivos. Se concreta en la exposición y circulación de diferentes ideas y puntos de vista.

\footnotetext{
${ }^{15}$ http://www.elperiodico.cat/ca/gent/20130409/deba-torg-celebra-4-anys-2360023
} 
Para promover la transparencia y el pluralismo, Deba-t.org organiza tres tipos de actividades: coloquios, actos y mesas redondas. Los coloquios son el formato más característico de la asociación y los que se realizan con una mayor frecuencia. Se trata de una pequeña reunión en la que 15 socios se sientan a conocer a un personaje relevante del mundo de la política o el periodismo e intercambian opiniones sobre los temas de mayor actualidad en ese momento. Han realizado coloquios con dos ex presidentes de la Generalitat de Catalunya como Artur Mas y José Montilla, con periodistas como Jordi Basté e Ignacio Escolar y con juristas como Santiago Vidal u Oriol Rusca, entre otros.

Los actos son conferencias abiertas a toda la comunidad universitaria. Este tipo de formato suele realizarse tres veces al año y suelen durar unas dos horas, aproximadamente. Bien sea en directo o a través de las redes sociales, la participación de los asistentes es fundamental. Entre los actos más señalados, destacan especialmente los debates preelectorales en los que los candidatos de las principales fuerzas políticas discuten sobre cuestiones de gran relevancia social. También suele utilizarse este formato para debatir sobre temas de interés para la comunidad universitaria, como el paro juvenil, la inmigración o las elecciones presidenciales de Estados Unidos.

En honor a su nombre, las mesas redondas plasman el late motiv de la organización, el debate. En ellas, el objetivo deja de ser conocer en profundidad a un distinguido miembro de la sociedad para informarse sobre una cuestión de reciente actualidad, formarse una opinión al respecto y dialogar con el resto de asistentes. Se trata de que, en petit comité, ya que estas sesiones están reservadas para grupos reducidos de socios, todo el mundo pueda expresar sus opiniones con libertad, fomentando el pluralismo como elemento enriquecedor del pensamiento humano. Entre los temas sobre los que se han debatido destacan especialmente el de la dación en pago o el conflicto de Ucrania.

La plataforma cuenta ya con más de 100 socios, de entre los cuales se escoge al equipo que coordina la asociación. A los siete miembros que componen la Junta Directiva les acompañan los ocho que conforman el Consejo Asesor, entre los que destacan los tres cofundadores de la asociación (Nacho Corredor, Gerard Sensat y Paris Grau), el actual 
conceller de Salut de Catalunya, Toni Comín, o el diputado del Partido Demócrata Catalán (PDeCAT), Carles Campuzano. En los actos organizados por Deba-t.org han intervenido ya más de 80 personalidades distintas provenientes del mundo de la economía, como Xavier Sala i Martín, del derecho, como Miquel Roca, del periodismo, como Àngels Barceló y Antoni Bassas, y de la política, como Carles Puigdemont o Patxi López.

\subsection{OpenKratio: el fomento del gobierno abierto y la transparencia}

OpenKratio (anteriormente denominada Opendata Sevilla) es una organización que surge para dar respuesta a las inquietudes de un grupo de ciudadanos que buscan inculcar en la sociedad y, especialmente, en las administraciones públicas, los principios del gobierno abierto (open government) y de los datos abiertos (open data).

El propósito de OpenKratio (https://openkratio.org/) es crear una comunidad de usuarios de ámbito nacional que, a través de las iniciativas de participación, colaboración y desarrollo de proyectos dentro del espacio público y político, ayuden a tejer una red de intereses y transformación social para la mejora de la democracia en base a la adopción de los principios del movimiento open: transparencia, participación ciudadana y reutilización de la información. La finalidad es mejorar la democracia a través del fomento de la transparencia de los gobiernos y las administraciones públicas.

La organización alude al hecho de que la información que comparten los gobiernos y las instituciones con la ciudadanía está sesgada por los criterios de la Administración. Con su acción, pretenden concienciar a la sociedad de que la información pública no es sinónimo de datos abiertos. Cuando la administración pone al servicio de los ciudadanos los datos en bruto, éstos pueden desgranarlos para extraer la información que es, realmente, de interés público.

OpenKratio colabora con el Consejo de Transparencia y Buen Gobierno en el desarrollo de un plan estratégico de fomento de la transparencia. Concretamente, el acuerdo firmado en abril de 2016 se 
centra en cuatro puntos de acción ${ }^{16}$. Primero, formar sobre transparencia y derecho de acceso a la información pública, dirigido a colectivos sociales. Segundo, participar en eventos y foros de debate para divulgar la transparencia, dirigido a profesionales y asociaciones ciudadanas. Tercero, colaborar para simplificar los procedimientos administrativos relacionados con la información pública que los estos datos sean más accesibles. Y, cuarto, elaborar documentos para la divulgación de la cultura de la transparencia.

Entre los proyectos más relevantes ejecutados por OpenKratio destaca, por ejemplo, el que da a conocer los residuos, producto de las actividades industriales, que se vierten en el agua en España. También han ayudado a redactar la proposición de ley de Cuentas Claras y Abiertas al grupo Podemos Andalucía con el objetivo de conseguir que los ingresos y gastos de las Administraciones se publiquen de forma detallada. Además, se han convertido en una autoridad de votación. Es decir, como defensores del voto electrónico facilitan los sufragios de este tipo a través de plataformas como AgoraVoting, asegurando el secreto del voto y realizando su recuento para que no se produzca ningún tipo de fraude en el proceso.

Desde la organización defienden y aplican la gestión abierta: se estructuran de forma horizontal y sin cargos. Su actividad se organiza y desarrolla en Internet de forma pública y transparente y la iniciativa se lidera de forma meritocrática. Además, la actividad de OpenKratio no tiene ánimo de lucro y la participación es libre y voluntaria.

\subsection{Tipología de plataformas digitales ciudadanas basadas en la transparencia}

A partir del análisis de los cinco casos considerados, se puede constatar que las plataformas digitales ciudadanas basadas en la transparencia y orientadas a la monitorización pueden adoptar formas diversas. El criterio que permite establecer una distinción es la finalidad principal a la que se dirige cada plataforma y la dimensión de la transparencia que

\footnotetext{
${ }^{16} \mathrm{http}: / /$ www.eldiario.es/politica/Transparencia-protocolo-colaboracion-OpenKratiosensibilizar_0_504999981.html
} 
cubre cada una. En este sentido, podemos establecer una tipología basada en cinco modalidades diferenciadas:

a) Plataformas de rendición de cuentas (Osoigo): Plataformas en las que un individuo o un colectivo de personas realizan labores de seguimiento y vigilancia de las acciones y de la toma de decisiones desempeñadas por el poder político. Su objetivo es, mediante la transparencia, fomentar que los actores políticos den explicaciones y justifiquen sus actuaciones ante la ciudadanía.

b) Plataformas de conectividad social y política (Kuorum.org): Plataformas que permiten la incorporación de la ciudadanía a los trámites políticos y legales, como, por ejemplo, la discusión sobre proyectos de ley. Es decir, que conectan a la ciudadanía a los procesos de toma de decisiones políticas y fomentan el contacto directo entre gobernantes y gobernados. No sólo favorecen la participación política de los ciudadanos, sino también una mayor visibilidad social en la tramitación de las normativas.

c) Plataformas de periodismo colaborativo (Wikitribune): Plataformas orientadas a introducir la transparencia en la producción de informaciones de actualidad. Pretenden ofrecer noticias de calidad basadas en los valores básicos del periodismo y en la colaboración entre periodistas profesionales y ciudadanos. Introducen transparencia en las fuentes, los procesos de verificación y la financiación. Apuestan por temas de interés público y luchan contra las noticias falsas.

d) Plataformas de fomento del debate y la discusión pública (Debat.org): Plataformas que actúan como un ágora de discusión política, social y cultural cuya máxima es abrir un espacio para el diálogo y la reflexión sobre los temas que más interesan a la ciudadanía. Incorporan la transparencia como mecanismo para dar visibilidad a temas relevantes de debate en la sociedad y a diferentes puntos de vista e ideas, que amplían potencialmente su radio de circulación. Persiguen el fomento de la pluralidad, la tolerancia y la libertad de expresión, que son valores que permiten avanzar hacia una democracia de calidad. 


\section{Tabla 1. Diferentes tipos de plataformas ciudadanas digitales basada en la transparencia}

\begin{tabular}{|c|c|c|c|}
\hline Tipo & Definición & Concepto clave & Ejemplo \\
\hline $\begin{array}{l}\text { Plataformas } \\
\text { de rendición } \\
\text { de cuentas }\end{array}$ & $\begin{array}{l}\text { Plataformas en las que la ciudadanía } \\
\text { realizan funciones de seguimiento y } \\
\text { vigilancia al poder político con el } \\
\text { objetivo de que éste se responsabilice de } \\
\text { sus actuaciones. Se trata de que la clase } \\
\text { política informe, explique y justifique } \\
\text { sus actos para que la ciudadanía pueda } \\
\text { evaluarlos y actuar en consecuencia. }\end{array}$ & $\begin{array}{l}\text { Rendición de } \\
\text { cuentas } \\
\text { (accountability) }\end{array}$ & Osoigo \\
\hline $\begin{array}{l}\text { Plataformas } \\
\text { de } \\
\text { conectividad } \\
\text { social y } \\
\text { política }\end{array}$ & $\begin{array}{l}\text { Plataformas que fomentan el contacto } \\
\text { directo entre gobernantes y gobernados } \\
\text { con el objetivo de que ambos actores } \\
\text { puedan dialogar e interactuar de forma } \\
\text { abierta y transparente en los procesos de } \\
\text { toma de decisiones políticas como la } \\
\text { elaboración de leyes. }\end{array}$ & Interacción & Kuorum.org \\
\hline $\begin{array}{l}\text { Plataformas } \\
\text { de periodismo } \\
\text { colaborativo }\end{array}$ & $\begin{array}{l}\text { Plataformas en las que periodistas } \\
\text { profesionales y ciudadanos trabajan } \\
\text { juntos con la finalidad de publicar } \\
\text { noticias de interés para la sociedad } \\
\text { alejadas de sesgos políticos y } \\
\text { económicos, fomentando la } \\
\text { transparencia en la elaboración de la } \\
\text { información. }\end{array}$ & Noticias & Wikitribune \\
\hline $\begin{array}{l}\text { Plataformas } \\
\text { de fomento } \\
\text { del debate y la } \\
\text { discusión } \\
\text { pública }\end{array}$ & $\begin{array}{l}\text { Plataformas cuyo objetivo es fomentar } \\
\text { la circulación de ideas en la sociedad. } \\
\text { Aplican la transparencia para dar a } \\
\text { conocer temas y puntos de vista } \\
\text { dispares, promoviendo la pluralidad de } \\
\text { visiones sobre los problemas sociales. }\end{array}$ & Debate público & Deba-t.org \\
\hline $\begin{array}{l}\text { Plataformas } \\
\text { de fomento } \\
\text { del gobierno } \\
\text { abierto y } \\
\text { transparente }\end{array}$ & $\begin{array}{l}\text { Plataformas cuya finalidad es fomentar } \\
\text { el gobierno abierto dando acceso a la } \\
\text { ciudadanía a la actuación y gestión de } \\
\text { los gobernantes de forma comprensible, } \\
\text { accesible y didáctica. En estas } \\
\text { organizaciones, la transparencia es } \\
\text { concebida como un mecanismo para } \\
\text { evitar el fraude y la corrupción. }\end{array}$ & Gobierno abierto & OpenKratio \\
\hline
\end{tabular}

e) Plataformas de fomento del gobierno abierto y transparente (OpenKratio): Plataformas que aplican la transparencia para potenciar el desarrollo del gobierno abierto. Su objetivo es fomentar el buen 
gobierno, la implicación de la ciudadanía y la supresión del fraude y la corrupción. Persiguen ofrecer a la ciudadanía los datos necesarios para conocer, y posteriormente valorar, la actuación y gestión de los gobernantes de forma comprensible, accesible y didáctica. Pretenden que el derecho de acceso a la información pública sea la base de una actuación más responsable de las instituciones políticas y que los ciudadanos se involucren en su fiscalización para mejorar la gestión de los recursos públicos.

\section{Conclusiones}

Esta investigación aporta una tipología original y novedosa de las iniciativas impulsadas por la sociedad civil en el entorno digital que se basan en la transparencia y en el acceso a la información de interés público y se orientan hacia la práctica de la monitorización. Esta propuesta constituye un punto de partida dotado de un interesante potencial analítico para futuras investigaciones que se centren en la transparencia digital.

Supone, además, un avance para la construcción teórica del concepto de monitorización puesto que desarrolla su conexión con la transparencia y presenta las principales formas en las que esta última se manifiesta en su aplicación práctica en el contexto digital cuando los ciudadanos asumen el protagonismo. De esta forma, se establecen los vínculos existentes entre monitorización y transparencia, situando la primera como un requisito para la activación de la segunda. Así, este trabajo contribuye a la ampliación de la teoría de la democracia monitorizada planteada por Keane (2009).

Mediante diferentes formatos, las plataformas digitales ciudadanas permiten el acceso a la información pública activando diversos mecanismos asociados a la transparencia. Se trata de la consecución de datos de gobierno abierto, de noticias de interés público, de ideas y puntos de vista variados, de respuestas de actores políticos o procedimientos vinculados a la toma de decisiones políticas. Con ello, contribuyen, potencialmente, a reducir la desafección política que separa a los representantes y los representados, a combatir los abusos, las malas prácticas y los casos de corrupción y, en suma, a mejorar la 
calidad de la democracia. Son ejemplos del ejercicio de contrapoder ciudadano en el entorno digital.

El contexto digital ofrece interesantes dosis de innovación en el campo de transparencia como las que aquí se han analizado que contribuyen a la transformación del campo de la comunicación política. Nuevas iniciativas que redefinen aspectos de la participación política de los ciudadanos. Proyecto que abren nuevas vías para la redefinición del funcionamiento de la democracia actual en las que la sociedad civil asume un nuevo protagonismo.

*Este trabajo forma parte del proyecto de investigación CSO2014-52283-C2-1-P financiado por el Ministerio de Economía y Competitividad del Gobierno de España.

\section{Bibliografía}

M Bunz (2014): The silent revolution: How digitalization transforms knowledge, work, journalism and politics without making too much noise. Nueva York: Palgrave Macmillan.

A Casero-Ripollés \& A López-Meri (2015): "Redes sociales, periodismo de datos y democracia monitorizada", en Las redes sociales digitales en el ecosistema mediático (Eds., F Campos-Freire \& J Rúas-Araújo). La Laguna: Sociedad Latina de Comunicación Social.

M Castells (2009): Comunicación y poder. Madrid: Alianza.

M Castells (2012): Redes de indignación y esperanza. Los movimientos sociales en la era de Internet. Madrid: Alianza.

C Cepeda (2006): "La calidad en los métodos de investigación cualitativa: principios de aplicación práctica para estudios de casos". Cuadernos de economía y dirección de empresas (ACEDE), $\mathrm{n}^{\circ} 29$, pp. 57-82.

VO Dabbagh-Rollán (2016): "La Ley de Transparencia y la corrupción. Aspectos generales y percepciones de la ciudadanía española". Aposta. Revista de Ciencias Sociales, nº 68, pp. 83-106.

KM Eisenhardt (1989): "Building Theories from Case Study

Research". Academy of Management Review, Vol. 14, n 4, pp. 532550. DOI: 10.5465/AMR.1989.4308385 
RA Feenstra (2012): Democracia monitorizada en la era de la nueva galaxia mediática. Barcelona: Icaria.

RA Feenstra, S Tormey, A Casero-Ripollés \& J Keane (2017): Refiguring democracy. The Spanish political laboratory. Nueva York: Routledge.

RA Feenstra \& A Casero-Ripollés (2014): "Democracy in the digital communication environment: A typology proposal of political monitoring processes". International Journal of Communication, $\mathrm{n}^{\circ} 8$, pp. 2448-2468.

C Fuchs (2014): Social media. A critical introduction. Thousand Oaks: Sage.

J Gray, L Bounegru \& L. Chambers (2012): Data Journalism Handbook. How journalists can use data to improve the news. Londres: Open Knowledge Foundation.

BC Han (2013): La sociedad de la transparencia. Barcelona: Herder Editorial.

H Jenkins (2006): Convergence culture: Where old and new media collide. Nueva York: New York University Press.

J Keane (2009): The Life and Death of Democracy. Londres: Simon y Schuster.

J Keane (2013): Democracy and media decadence. Cambridge: Cambridge University Press.

PC López-López, I Puentes-Rivera \& J Rúas-Araújo (2017): "Transparencia en televisiones públicas: desarrollo de indicadores y análisis de los casos de España y Chile". Revista Latina de Comunicación Social, Vol. 72, pp. 253- 272. DOI: 10.4185/RLCS2017-1164

V Mayer-Schönberger \& K Cukier (2013): Big data: la revolución de los datos masivos. Madrid: Turner.

JL Manfredi-Sánchez (2017): "Horizontes de la información pública". El Profesional de la Información, Vol. 26, nº 3, pp. 353-360. DOI: 10.3145/epi.2017.may.01

B McNair (2006): Cultural chaos. Journalism, news and power in a globalised world. Londres: Routledge.

A Moreno-Sardà, P Molina-Rodríguez-Navas \& N. Simelio-Solà (2017): "Impacto de la legislación sobre transparencia en la información publicada por las administraciones locales". El 
Profesional de la Información, Vol. 26, n 3, pp. 370-380.

DOI: 10.3145/epi.2017.may.03

M Rebolledo, R Zamora-Medina \& J Rodríguez-Virgili (2017):

"Transparency in citizen participation tools and public information: A comparative study of the Spanish city councils' websites". El Profesional de la Información, Vol. 26, n 3, pp. 361-369. DOI: 10.3145/epi.2017.may.02

M Rodríguez Pallares \& MJ Pérez Serrano (2017): “Decision-making and transparency of information and knowledge. The case study of listed media companies in Spain". Revista Latina de Comunicación Social, Vol. 72, pp. 719-736. DOI: 10.4185/RLCS-2017-1188

P Rosanvallon (2011): Democratic legitimacy: Impartiality, reflexivity, proximity. Princeton: Princeton University Press.

V Sampedro (2014): El cuarto poder en red. Barcelona: Icaria.

P Schiavi (2017): "Aportes para una nueva agenda en la lucha contra la corrupción: buena administración, control social, transparencia, capacitación y comunicación". Estudios de derecho administrativo, $\mathrm{n}^{\circ}$ 15, pp. 281-314.

H Simons (2011): El estudio de caso: teoría y práctica. Madrid: Morata. RK Yin (2013): Case study research: Design and methods. Thousand Oaks: Sage.

Cómo citar: L Alonso-Muñoz, A Casero-Ripollés (2017): “Transparencia y monitorización en el entorno digital. Hacia una tipología de las plataformas impulsadas por la ciudadanía". Revista Latina de Comunicación Social, 72, pp. 1.351 a 1.366.

http://www.revistalatinacs.org/072paper/1223/73es.html DOI: $10.4185 /$ RLCS-2017-1223 